\title{
Wyoming Landscape Conservation Initiative Science Workshop Proceedings, May 15-17,2007
}

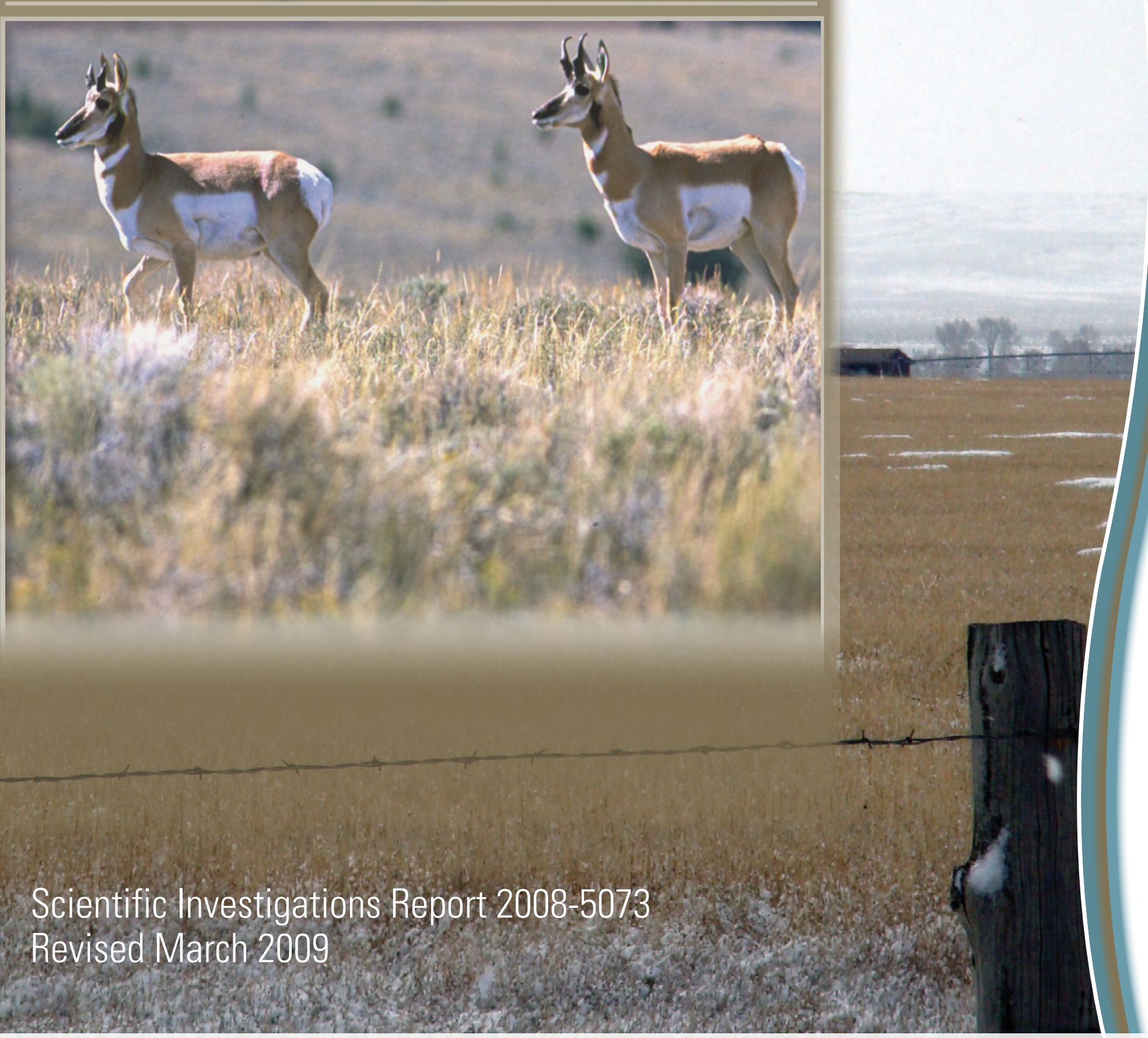

\section{U.S. Department of the Interior}

U.S. Geological Survey 



\section{Wyoming Landscape Conservation Initiative Science Workshop Proceedings, May 15-17, 2007}

Edited by Frank D'Erchia

With contributions by the Wyoming

Landscape Conservation Initiative Participants

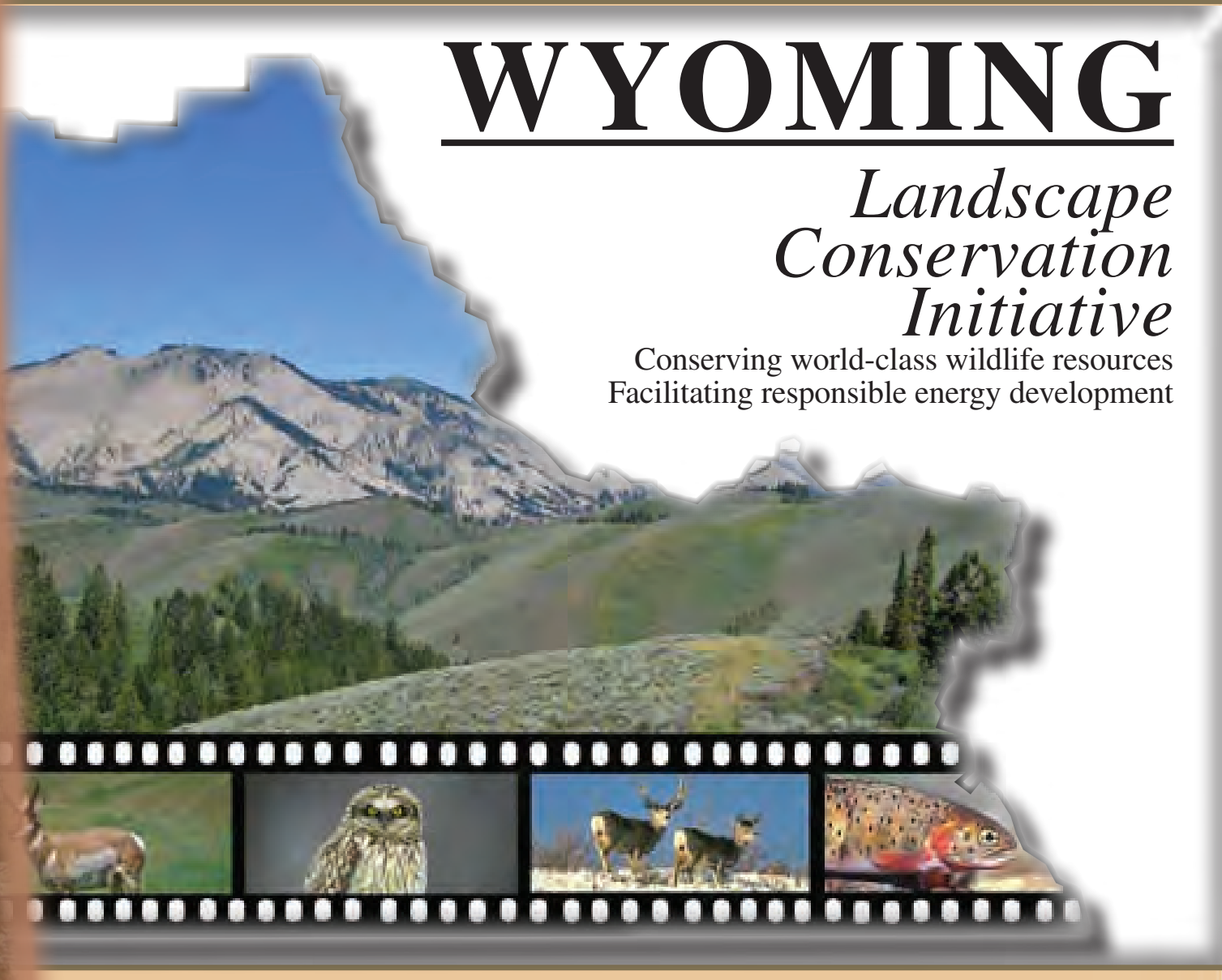

Scientific Investigations Report 2008-5073

Revised March 2009

U.S. Department of the Interior

U.S. Geological Survey 


\section{U.S. Department of the Interior}

KEN SALAZAR, Secretary

\section{U.S. Geological Survey \\ Suzette M. Kimball, Acting Director}

U.S. Geological Survey, Reston, Virginia: 2009

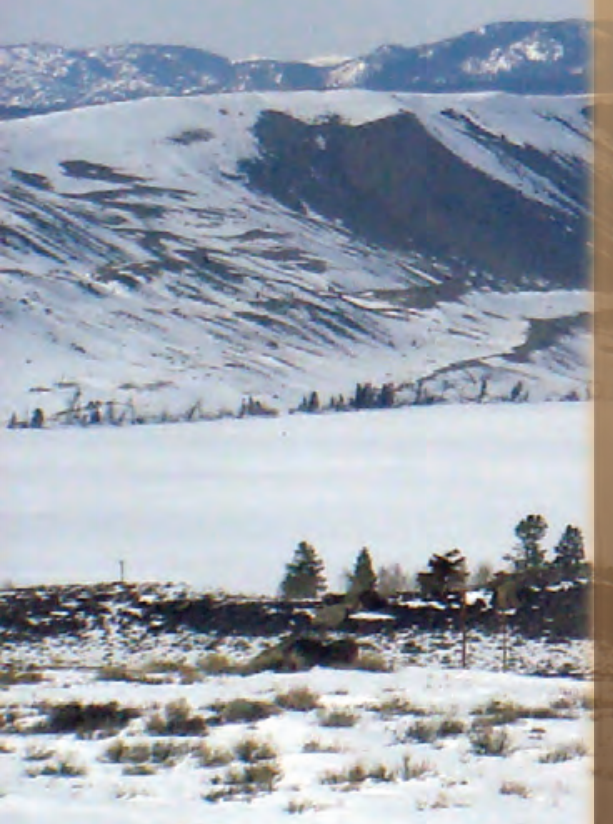

This and other USGS information products are available at http://store.usgs.gov/

U.S. Geological Survey

Box 25286, Denver Federal Center

Denver, C0 80225

To learn about the USGS and its information products visit http://www.usgs.gov/ 1-888-ASK-USGS

Any use of trade, product, or firm names is for descriptive purposes only and does not imply endorsement by the U.S. Government.

Although this report is in the public domain, permission must be secured from the individual copyright owners to reproduce any copyrighted materials contained within this report.

\section{Suggested Citation:}

D'Erchia, F., editor, 2008, Wyoming Landscape Conservation Initiative workshop proceedings, May 15-17, 2007:

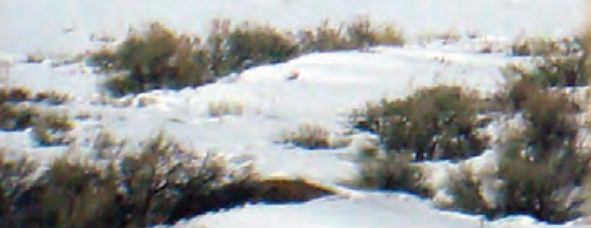

\section{U.S. Geological Survey Scientific Investigations Report 2008-5073, 96 p. (Revised March 2009)}
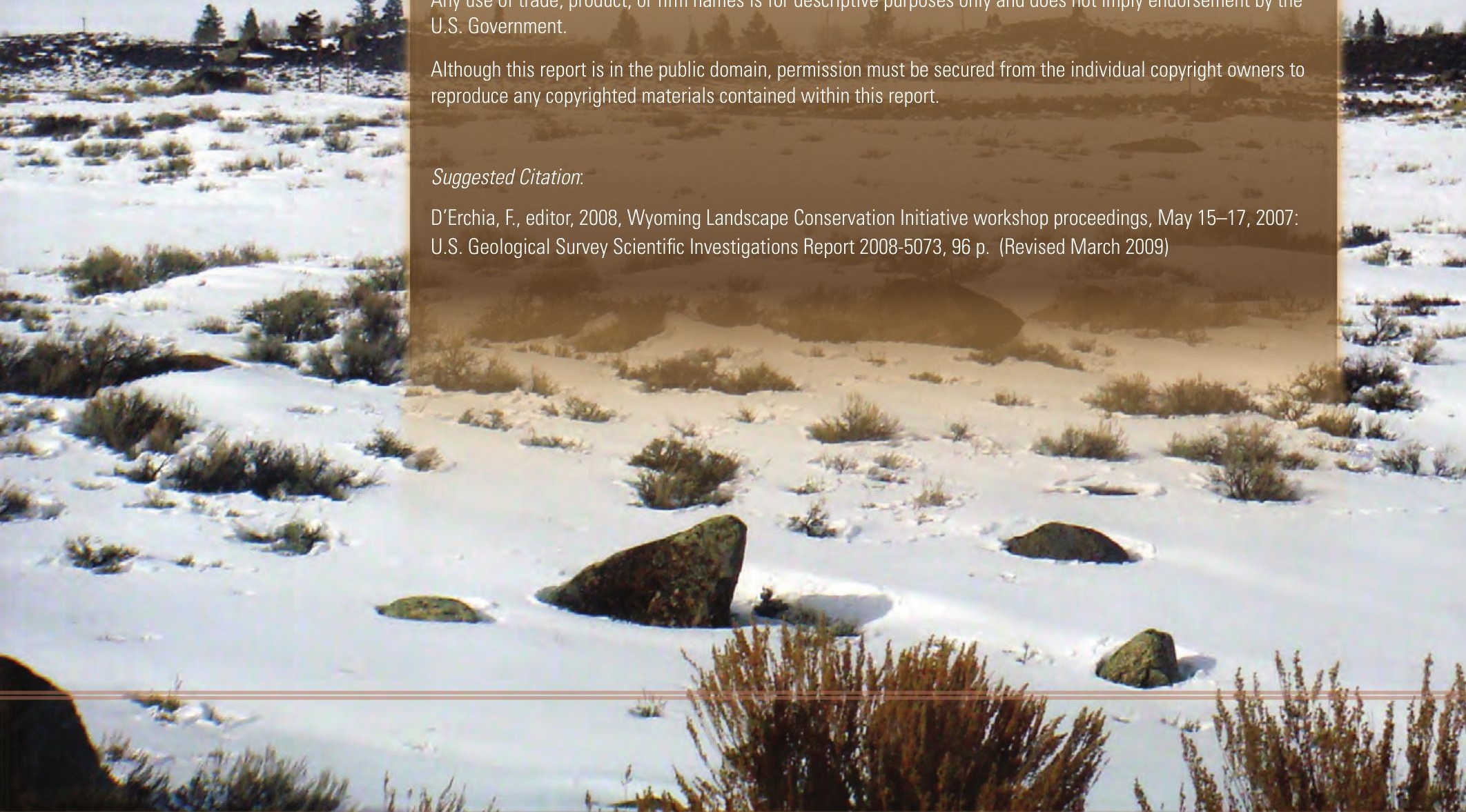


\section{Preface}

The Wyoming Landscape Conservation Initiative (WLCI) represents the U.S. Geological Survey partnership with other Department of the Interior bureaus, State and local agencies, industry, academia, and private landowners committed to maintaining healthy landscapes, sustaining wildlife, and preserving recreational and grazing uses while developing much-needed energy resources in the Green River Basin.

Since original publication of these proceedings, a number of accomplishments have brought the vision of the WLCl closer to reality.

The U.S. Geological Survey, along with WLCl partners and collaborators, has developed and published U.S. Geological Survey Science Strategy for the Wyoming Landscape Conservation Initiative (USGS SIR 2008-5195, http://pubs.usgs.gov/sir/2008/5195/). The Strategy was in large part based on the ideas and needs addressed at the 2007 workshop; it was written for a 5 -year research program and will be reviewed as the WLCI evolves.

Additionally, the USGS is developing models that depict past and current conditions and predict future scenarios related to energy development, climate change, and other changes. One such model is described in Multiscale Sagebrush Rangeland Habitat Modeling in Southwest Wyoming (http://pubs.usgs.gov/of/2008/1027/).

Currently, 32 projects under the auspices of $\mathrm{WLCl}$ are ranked and funded (https://my.usgs.gov/ Public/WLCl/ProjectsCritera/WLCl_2009_Final_Rankings090908.x/s). Plans in 2009 include a science and management workshop in Laramie, Wyoming, May 12-14 (see http://www.w/ci. gov). Continued collection and synthesis will be adding to the $\mathrm{WLCl}$ data clearinghouse, which continues to expand (http://my.usgs.gov/csc/w/ci/).

The WLCl continues to be a positive force in the effort to assess, monitor, and enhance aquatic and terrestrial habitats at a landscape scale in southwest Wyoming. Perhaps most importantly, this initiative will also serve as the foundation for future efforts in other landscapes as the models, protocols, and technologies developed will be transferrable to other areas where energy development is occurring or planned. 


\section{Participating Organizations}

\section{Principal Partners}

Bureau of Land Management, Wyoming

County Commissioners, representing Lincoln, Uinta, Sublette, Sweetwater, Carbon, and Fremont Counties

Conservation Districts, representing Lincoln, Little Snake River, Popo Agie, Saratoga-EncampmentRawlins, Star Valley, and Sublette

U.S. Fish and Wildlife Service, Mountain-Prairie Region U.S. Forest Service, Regions 2 and 4 Wyoming Game and Fish Commission Wyoming Department of Agriculture

\section{Additional Cooperators Include}

National Park Service, Intermountain Region

Natural Resources Conservation Service, Wyoming

U.S. Bureau of Reclamation, Upper Colorado Region Wyoming Department of Environmental Quality

Wyoming State Land Board

This report summarizes discussions at the Wyoming Landscape Conservation Initiative (WLCI) Science Workshop. This event was co-sponsored by the U.S. Geological Survey (USGS) and the WLCI Partners. Comments made by speakers not affiliated with the USGS do not necessarily reflect the positions of the USGS. 


\section{Contents}

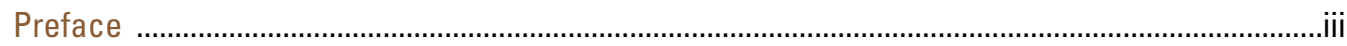

Acknowledgments ..........................................................................................................................

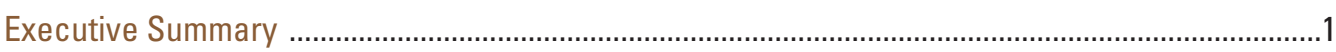

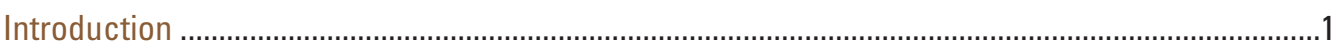

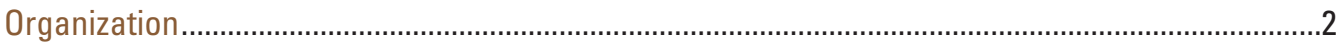

$\overline{\text { Session } 1}$ Cumulative Effects of Development Activities in Southwest Wyoming .............................

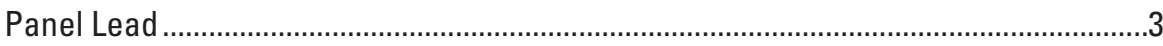

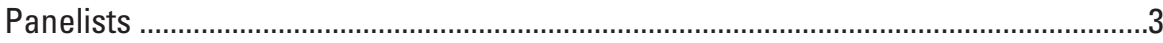

Panel Presentations ...................................................................................................

Audience Discussion .......................................................................................................

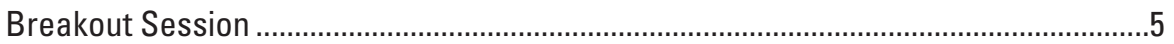

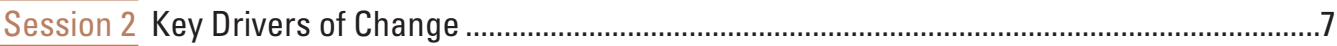

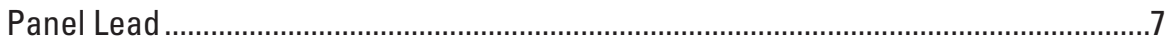

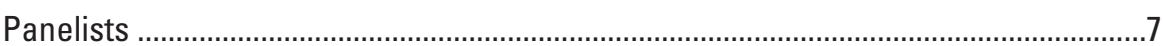

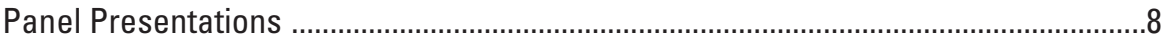

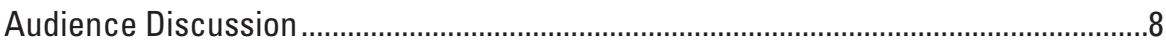

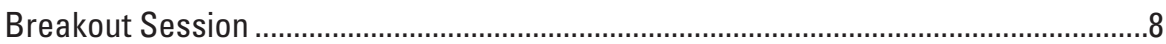

$\overline{\text { Session } 3}$ Conditions and Distribution of Key Wildlife Species, Habitat, and Species Habitat Requirements............................................................

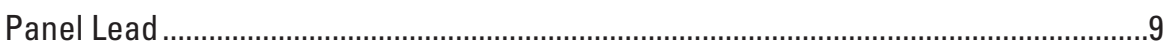

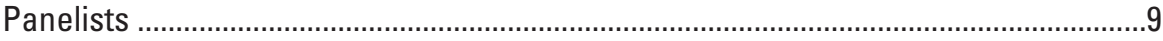

Panel Presentations .............................................................................................

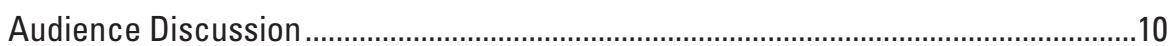

Breakout Session .............................................................................................10

Session 4 Wildlife and Livestock Responses to Development......................................................13

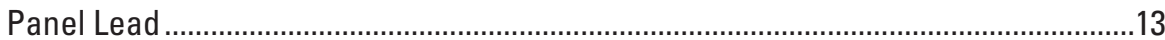

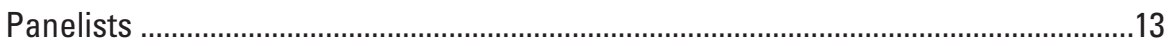

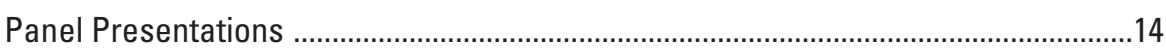

Audience Discussion ...........................................................................................14

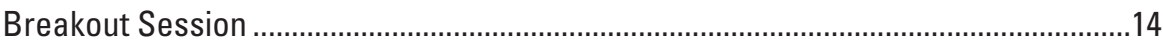

$\overline{\text { Session } 5}$ Inventory and Monitoring Strategy ………................................................................

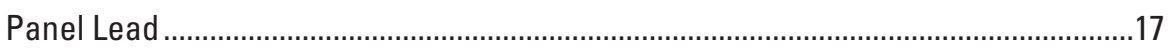

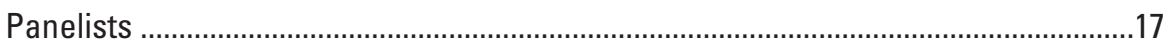

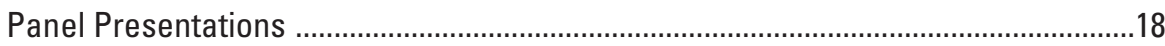

Audience Discussion ...........................................................................................18

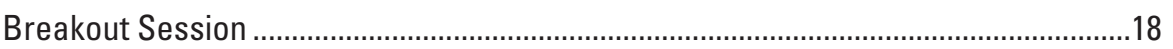

$\overline{\text { Session } 6}$ Data Clearinghouse and Information Management Framework ......................................21

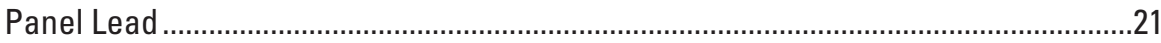

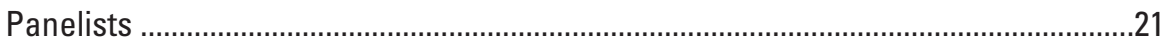

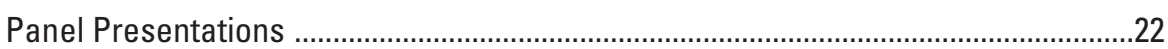

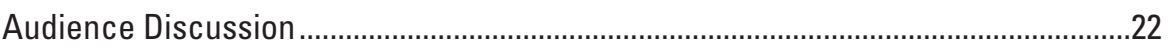

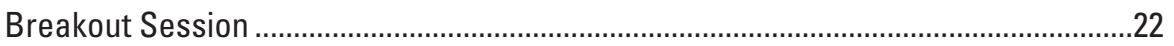


Appendixes

1: Compilation of workshop notes

2: Evaluating cumulative environmental effects of development activities in southwest Wyoming: State Trust Wildlife Resources

3: Existing major studies/data resources

4: Identify conditions and distribution of key wildlife species, habitat, and species habitat requirements .

5: High priority short-term and long-term science needs and ongoing science needs

6: Evaluating wildlife and livestock responses to development....

7: Development of an integrated inventory and monitoring strategy ......................................89

8: Workshop agenda

9: Plant and animal species discussed at the Wyoming Landscape Conservation Initiative Science Workshop, May 15-17, 1997
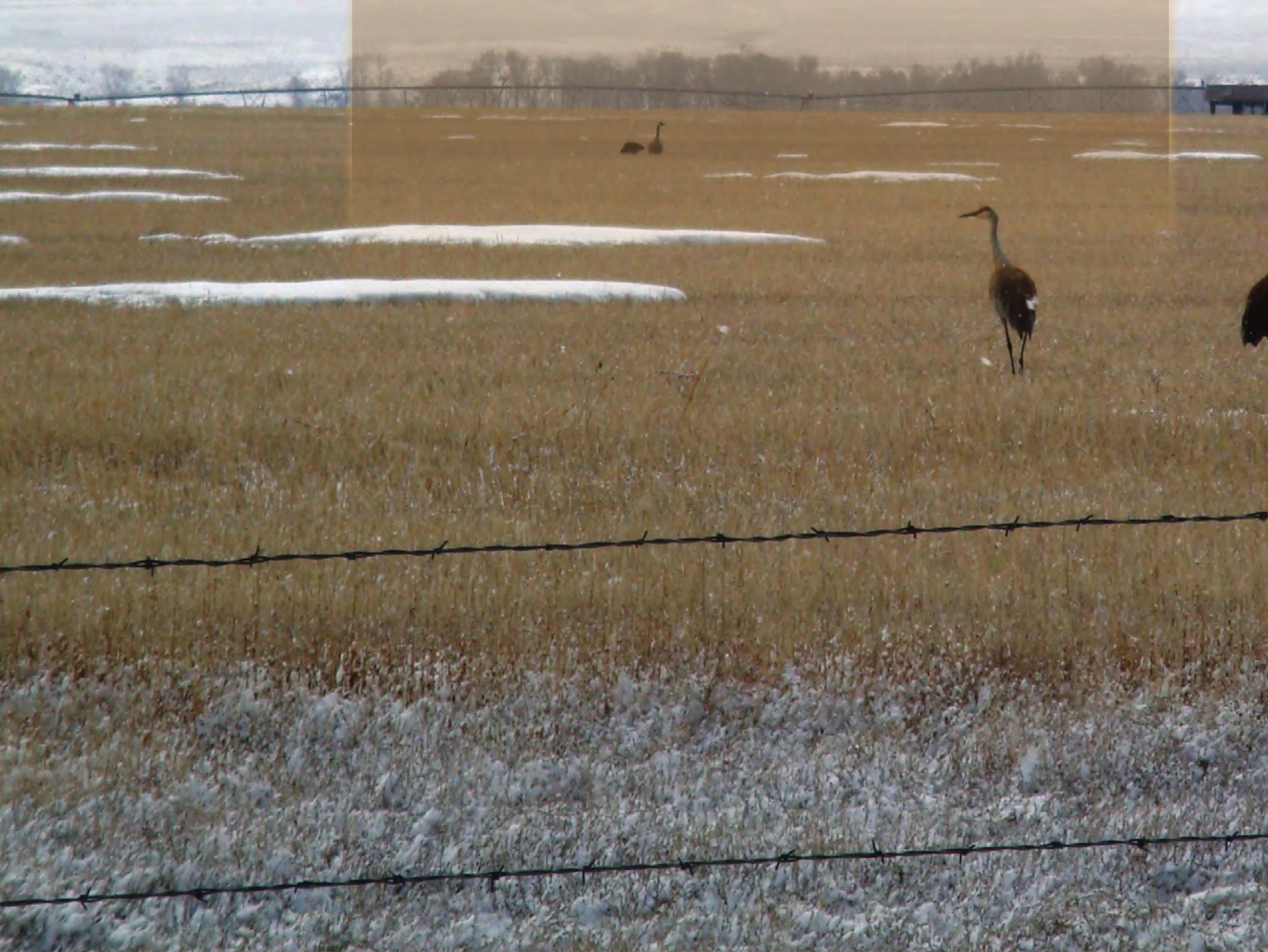


\section{Acknowledgments}

Many thanks to all the partners who attended the WLCI Science Workshop and actively participated throughout the sessions. Special appreciation is due those who helped organize this critical stakeholder forum, facilitating the panels and breakout groups and assisting in writing sections of this report. Panel and breakout facilitators included Zack Bowen, Sky Bristol, Warren Day, Tom DiNardo, Matt Kauffman, Vito Nuccio, and Mark Shasby.

Thanks also to staff at the Ruckelshaus Institute of Environment and Natural Resources at the University of Wyoming, Laramie, and to the Meridian Institute staff members who helped facilitate and record the discussions at the workshop and prepared the draft summary workshop report.

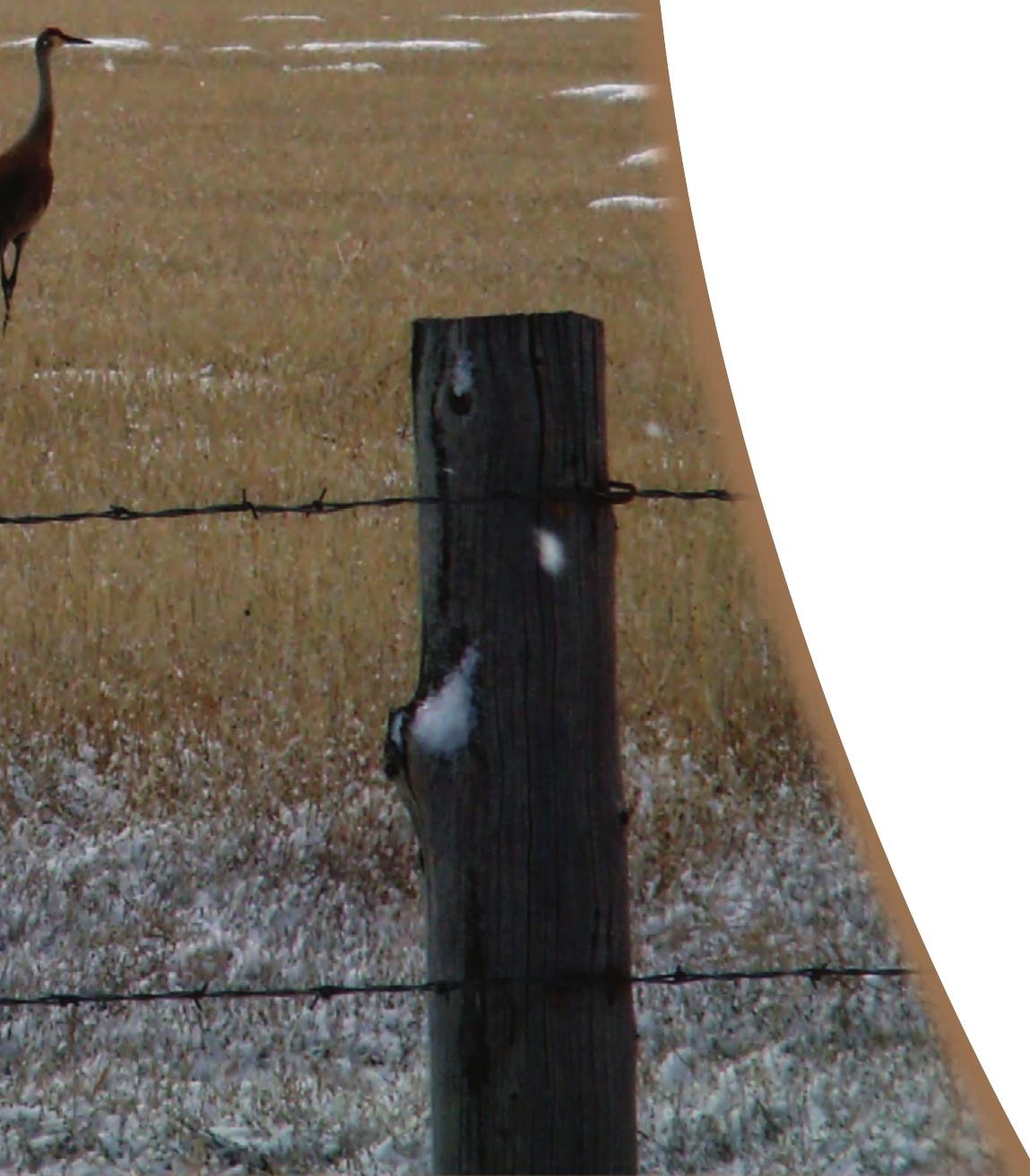




\title{
Wyoming Landscape Conservation Initiative Science Workshop Report
}

\author{
Edited by Frank D'Erchia \\ with contributions by the Wyoming Landscape Conservation Initiative Participants
}

\section{Executive Summary}

The U.S. Geological Survey (USGS) hosted a Wyoming Landscape Conservation Initiative (WLCI) Science Workshop at the University of Wyoming on May 15, 16, and 17, 2007. The goal of the workshop was to gather information from stakeholders about research needs and existing data resources to help develop the USGS WLCI science plan.

The workshop focused on six research and management needs identified by WLCI partners prior to the workshop:

- $\quad$ Evaluate the cumulative effects of development activities;

- Identify key drivers of change;

- Identify condition and distribution of key wildlife species, habitat, and species habitat requirements;

- Evaluate wildlife and livestock responses to development;

- Develop an integrated inventory and monitoring strategy; and

- Develop a data clearinghouse and an informationmanagement framework.

These topics correlated to six plenary panels and discussions and six breakout sessions. Several collective needs were identified:

- Create a long-term, accessible information database;

- Identify key habitats, indicator species;

- Collect and research missing critical baseline data;

- Begin on-the-ground projects as soon as possible; and

- Implement a monitoring program to assist with adaptive management techniques.

Several concerns were expressed repeatedly:

- $\quad$ Secure adequate and long-term funding;

- Meet the WLCI workload with agencies that are already understaffed;

- Assess cumulative effects as an analysis approach;

- Perform offsite mitigation in a way that is valuable and effective;

- Focus all research on providing practical applications; and

- Involve the public in WLCI proceedings.
The following document is a summary of the conference proceedings.

\section{Introduction}

The WLCI was

developed by a coalition of Federal and State government agencies in response to increased demands on southwest Wyoming's natural resources. The WLCI is a long-term, sciencebased initiative with the ultimate goal of assessing

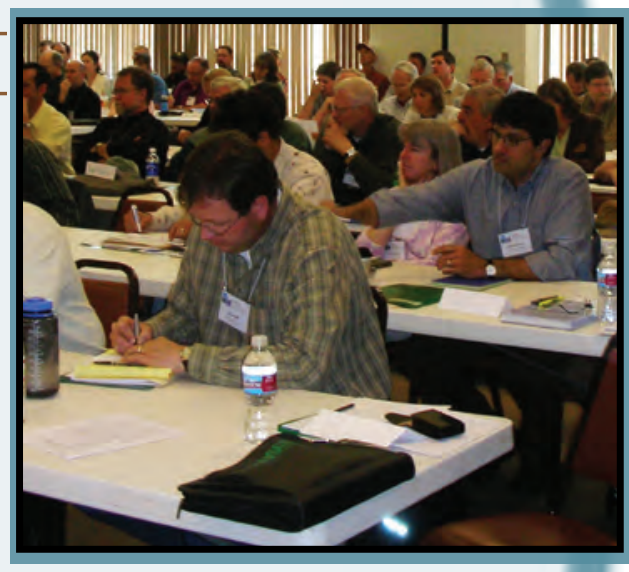
and enhancing the aquatic and terrestrial habitats of southwest Wyoming on a landscape scale while facilitating responsible energy development and other anthropogenic drivers of change.

Within the broader partnership of the WLCI, several working groups have formed to address specific needs. These groups include an Implementation Team that is overseeing the organizational aspects of the WLCI, a Science Planning Team that is drafting a science plan and establishing short-term and long-term science data and research needs, and a Data Information Management Working Group, which is working to address the data and information needs of WLCI partners.

To aid the working groups with their mandates, WLCI partners hosted 140 participants representing State and Federal agencies, the University of Wyoming, and nongovernmental organizations at a workshop in Laramie, Wyoming. The workshop was facilitated by personnel from the Meridian Institute and the University of Wyoming's Ruckelshaus Institute of Environment and Natural Resources, which also provided meeting support. Attendees worked under the direction of the panel leads and facilitators to identify primary research and management needs associated with increased demands on southwest Wyoming's natural resources and WLCI efforts. The results of the workshop have greatly aided the USGS in formulating their WLCI science plan. 


\section{Organization}

The 3-day conference was organized by the USGS and other WLCI partners. To begin, six primary topic areas were introduced through a series of opening plenary session presentations. Following the plenary presentations and discussions, participants chose to attend one or more of the six corresponding breakout discussions. The breakouts were based on the six original management needs. After the conclusion of the breakout sessions, attendees returned to a plenary session during which the breakout groups presented their conclusions and recommendations, and members of the USGS and the WLCI executive committee gave closing remarks.

The next section of this report is a summary of the plenary and breakout sessions for each of the management topics listed above. Appendix 1, which is located at the back of the report, is a compilation of the notes taken throughout the workshop.
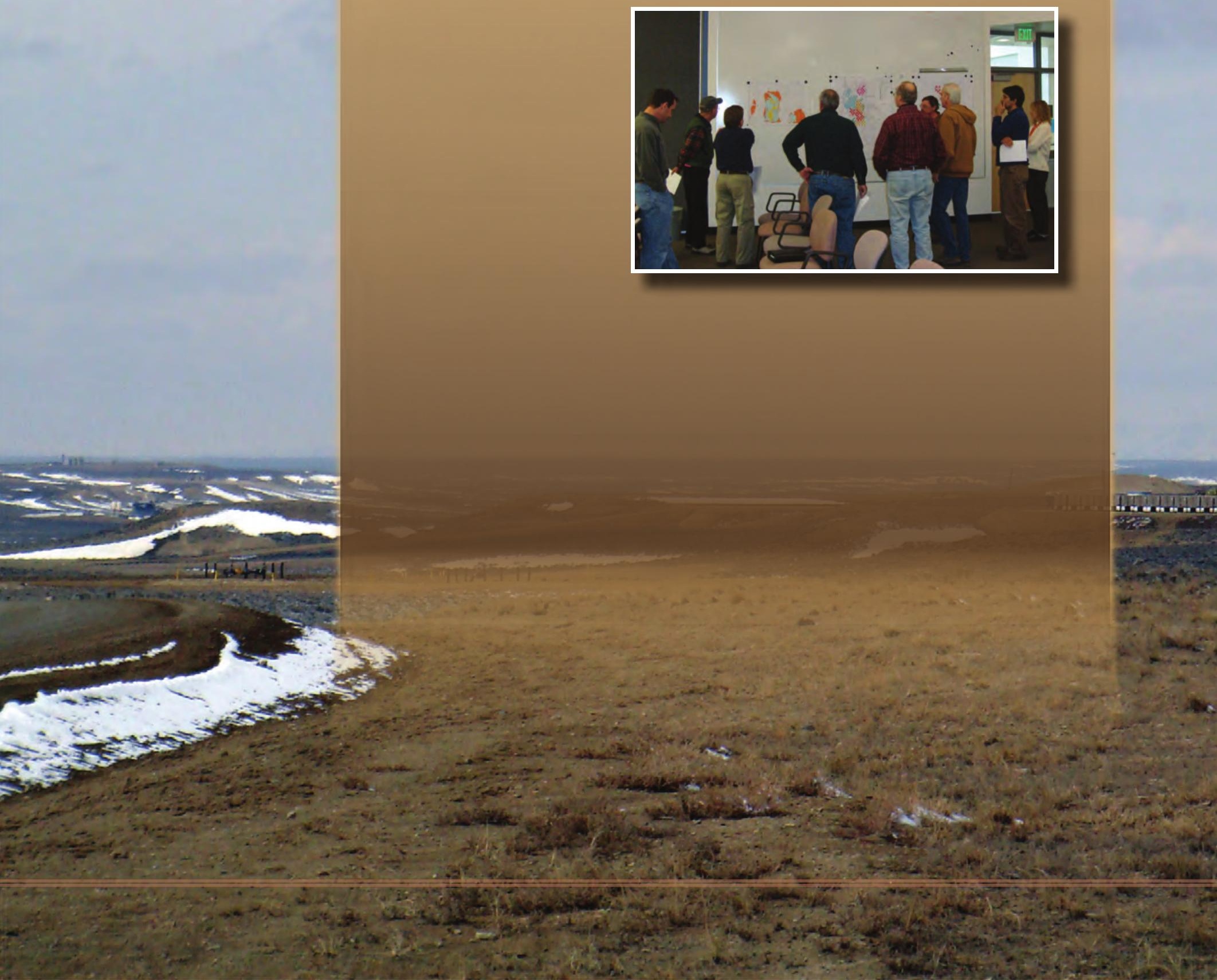


\section{Session 1}

\section{Cumulative Effects of Development Activities in Southwest Wyoming}

\section{Panel Lead}

Mark Shasby, U.S. Geological Survey (USGS)

\section{Panelists}

Patricia Deibert, U.S. Fish and Wildlife Service (USFWS)

Sharon Friedman, U.S. Forest Service (USFS)

Walt George, Bureau of Land Management (BLM)

Archie Reeve, Edge Environmental Steve Tessmann, Wyoming Game and Fish Department (WYGFD)

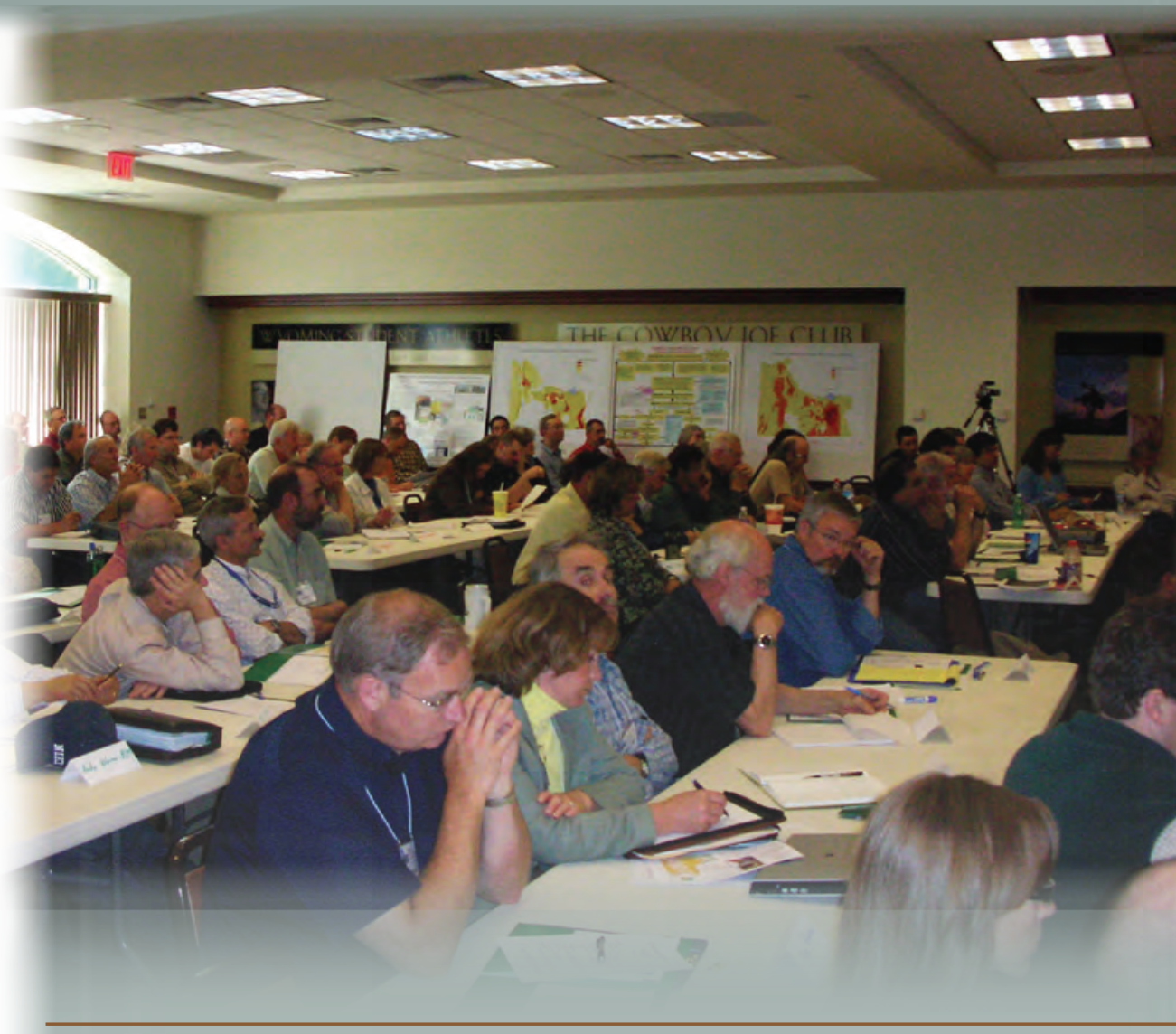

Research on the effects of energy exploration, development, and production in southwest Wyoming has occurred primarily within narrow disciplines or scopes. Session 1 panelists, presenters, and breakout participants considered a broader and deeper cumulative-effects approach to analyzing and assessing development activities in southwest Wyoming. Session 1 responses to the key workshop challenge are as follows:

- What are the highest priority needs and/or science contributions to be addressed in this management issue?

- Gather baseline empirical data;

- Identify a desired future condition;

- Agree on an analytical approach to cumulative effects; and

- Create a scope of analysis that is ecologically meaningful and appropriately scaled.

A number of conference participants questioned the ability of the WLCI to make accurate cumulative-effects analyses. The frequent expression of such doubts indicates that WLCI partners may wish to consider refining cumulative-analysis tactics or adopting another approach. 


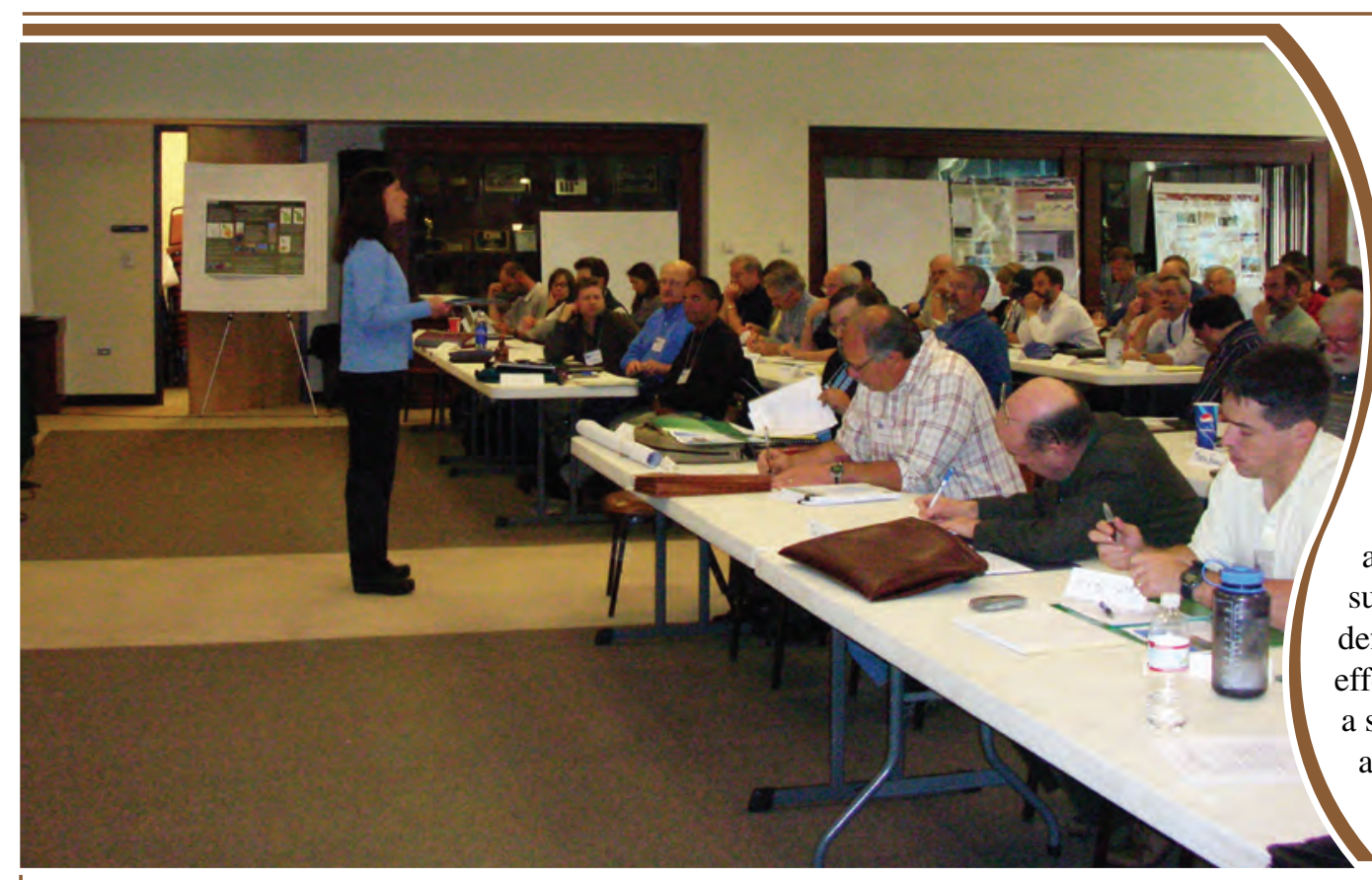

Despite the difficulties associated with cumulativeeffect assessments, the WYGFD representative stressed that the WLCI has the potential to address many of the issues. Requirements would have to be fulfilled by WLCI partners to successfully use a cumulative-analysis approach: obtaining sufficient baseline data; defining cumulativeeffects principles; creating a standardized analysis approach; and scaling the scope of analysis in a way that is ecologically meaningful. Strategies to

\section{Panel Presentations}

Cumulative-effects analyses evaluate changes to environmental systems by considering the cumulative significance of independent actions over time and in relation to the effects of other actions. Cumulative environmental assessment is an integral aspect of the National Environmental Policy Act (NEPA), and panelists discussed how cumulative analysis is handled and viewed as a NEPA requirement by various agencies.

The Council on Environmental Quality (CEQ) has published findings that show existing methods and resources are inadequate or incapable of supporting cumulative-effects analyses. This inadequacy is a result of a lack of resources and empirical data; agency mandates that do not emphasize cumulative-effects analysis; time limitations; narrow mandates and projects; and other limiting factors, such as politically expedited permitting. All panelists stressed that State and Federal agencies lack the empirical data needed to conduct accurate cumulative-effects analyses and that the speed of permitting for development does not allow enough time to gather that data nor to conduct sound analyses.

The BLM representative emphasized that in the context of the WLCI, coordinating diverse agency approaches to cumulative analysis is challenging. He noted the BLM has expanded its area of concern relative to cumulative effects and now considers not only the project area but also areas outside the project area that are within the same resource area. include gathering baseline data, creating a central repository of data, and using the collected data to inform specific on-theground management actions. These strategies also apply to the five other topics that were discussed during the workshop proceedings. Finally, the WYGFD believes the most effective way to mitigate effects is by reducing incremental disturbances as they occur in prioritized habitats.

The USFWS representative expressed several concerns about analyzing effects on a cumulative scale. The Endangered Species Act (ESA) requires the USFWS to consider effects on individuals, whereas cumulative-effects analyses consider effects on species as a whole. Also, the USFWS has the authority to enter into agreements with private landowners to ensure protection of endangered species, and the agency is concerned that the cumulativeeffects approach could jeopardize those agreements.

\section{Audience Discussion}

Audience comments during the plenary discussion revealed that many workshop participants share the concerns of the panelists. Participants discussed the inadequacy of available data, the difficulty of successful agency collaboration, the need to define cumulative effects in a way the public will understand and support, and the historically low success rates of cumulative-effects analyses.

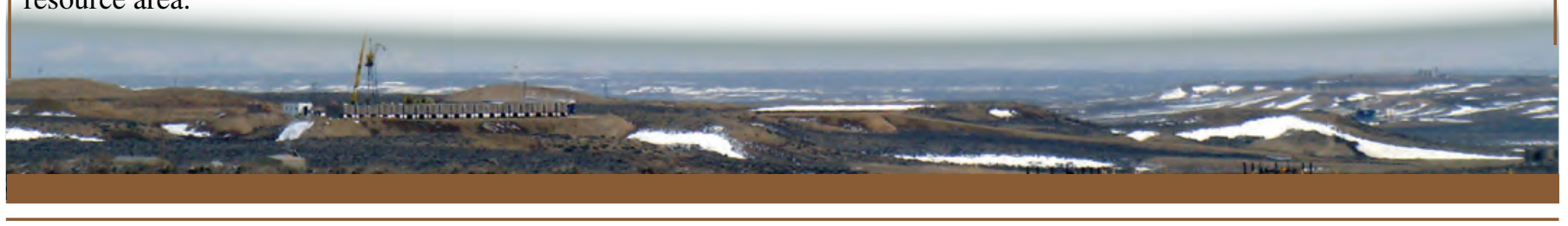




\section{Breakout Session}

The breakout group began by broadly discussing how to define cumulative effects and appropriate expectations for the WLCI. Various definitions of cumulative effects exist, including a legal definition outlined in Federal Statutes. Rather than deciding on a particular definition, the group instead focused on the need for conceptual models and potential approaches for creating a set of "nested" models ranging from general and qualitative to more specific and quantifiable (see Appendix 2).

Potential modeling approaches dominated much of the conversation. A set of four, hierarchically ordered models was proposed within an adaptive management framework. The structure of the proposed nested models is listed below:

- $\quad$ Level 1: Broad conceptual model (improving understanding of broad habitat and ecosystem components):

- Descriptive, including components and stressors; and

- System models (for example, for aquatics, plants, livestock, and soils).

- Level 2: Ecotypes (to prioritize and focus on specific components of concern):

- Specific models;

- High priority species (for example, mule deer); and

- At-risk or degraded components could be a focus.
- Level 3: Causal network and management approach (on-the-ground action):

- Decisions and actions as vector drivers; and

- More specific modeling at the places where management can affect change.

- Level 4: Refine treatments/adaptive management:

- Use treatment outcomes to refine treatments and models.

Throughout the discussion, participants expressed concern that the cumulative-effects approach has not been used successfully in the past. The approach was viewed as difficult to implement because of the differences between agency management approaches and regulatory requirements.

The group also briefly outlined major concerns, data needs, and other needs necessary for modeling cumulative effects. Participants identified a primary science need for baseline data (participants in all of the breakout groups identified this need). They emphasized, however, that WLCI efforts need to exclude collecting data that do not influence work on the ground.

Other priorities include developing a set of desired future conditions and management priorities, defining a threshold to help determine if desired conditions have been reached, and continuous monitoring to determine the effectiveness of treatments and to identify changing baselines.

The discussion concluded with the group outlining a series of goals and general timelines.

Identify polygons on a map

Identify existing work and data

Define desired future states

Develop and review of broad conceptual models

Identify nested models

Start treatments

Refine high priority models

Update lower priority models

Update cumulative-effects approach (reflects development)

Update and refine models

Continue to update the approach

Assess whether WLCI is working to achieve desired future states
SHORT-TERM

SHORT-TERM

LONG-TERM

SHORT-TERM

MIDTERM

MIDTERM

LONG-TERM

LONG-TERM

LONG-TERM

LONG-TERM

LONG-TERM

LONG-TERM 


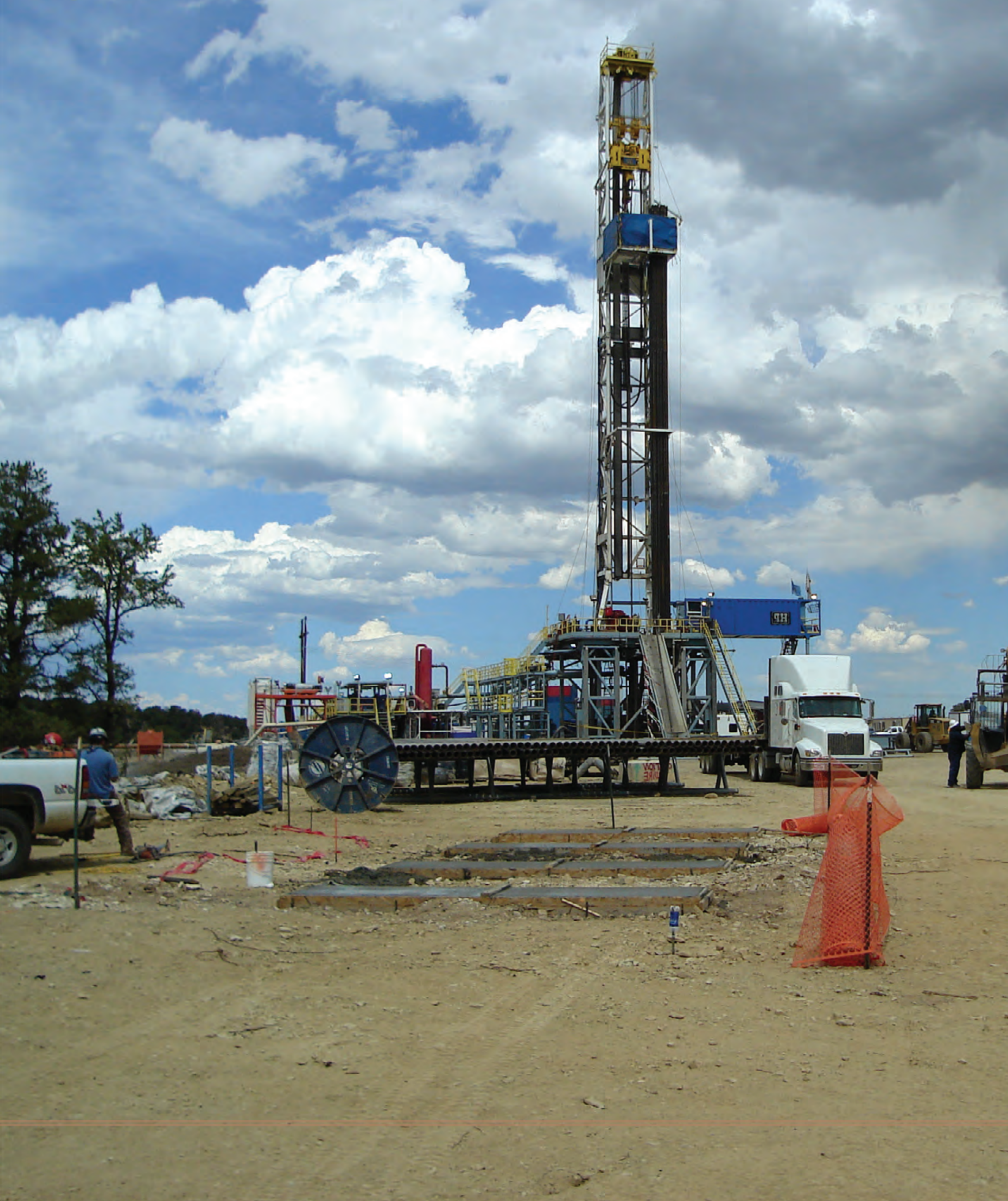




\section{Session 2}

\section{Key Drivers of Change}

\section{Panel Leads}

Vito Nuccio (Chair), U.S. Geological Survey (USGS)

Warren Day (Co-Chair), USGS

\section{Panelists}

Jason Begger, Petroleum

Association of Wyoming

Mark Hogan, U.S. Fish and

Wildlife Service (USFWS)

Sarah Shafer, USGS

Vern Stelter, Wyoming Game and Fish Department (WYGFD)

Dean Stillwell, Bureau of Land Management (BLM)

Ron Surdam, Wyoming Geological Survey (WYGS)

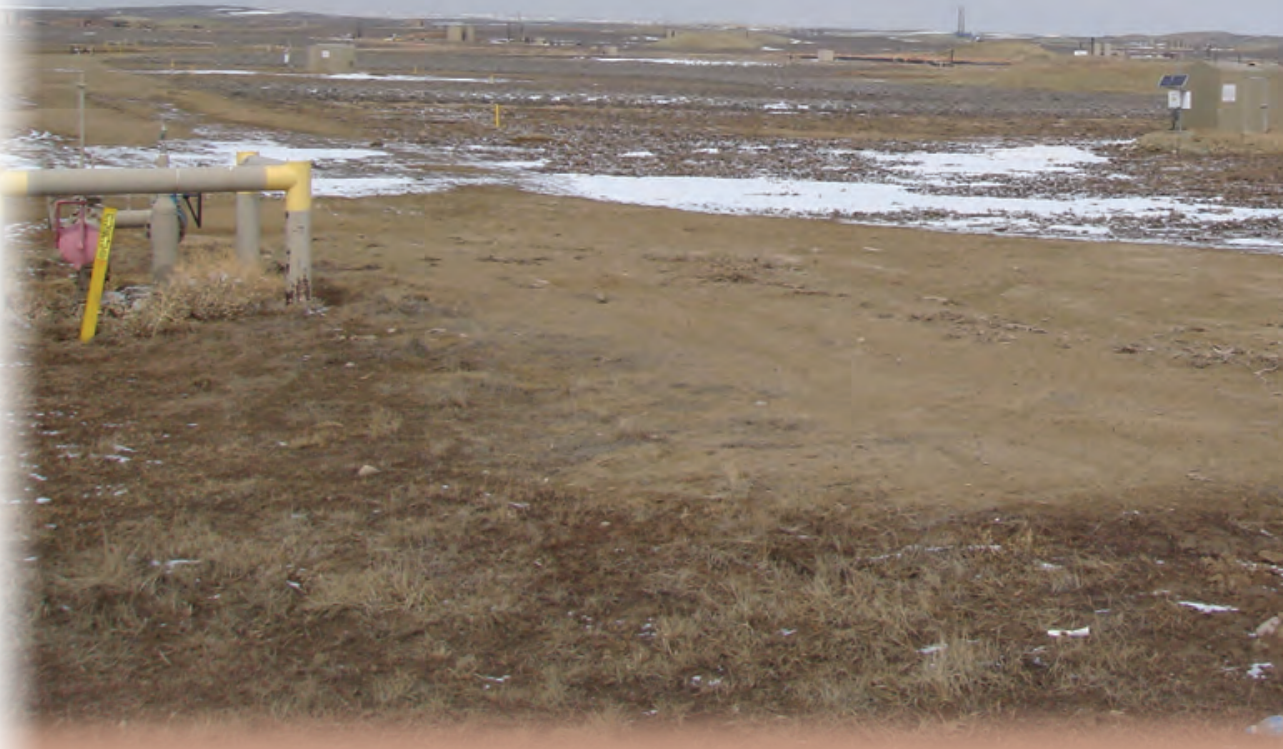

To create a vision of southwest Wyoming's future landscape, key drivers of change in the region need to be identified and evaluated in the context of quantifiable changes and estimated effects. Session 2 panelists, presenters, and breakout participants made a preliminary evaluation of drivers of change in southwest Wyoming that identified primary drivers, separate components of those drivers, and subsequent stressors. Session 2 responses to the key workshop challenge are as follows:

- What are the highest priority needs and/or science contributions to be addressed in this management issue?

- Gathering baseline data concerning air, water, and geochemistry;

- Completing resource assessments and ecological studies;

- Mapping development locations; and

- Developing mitigation strategies. 


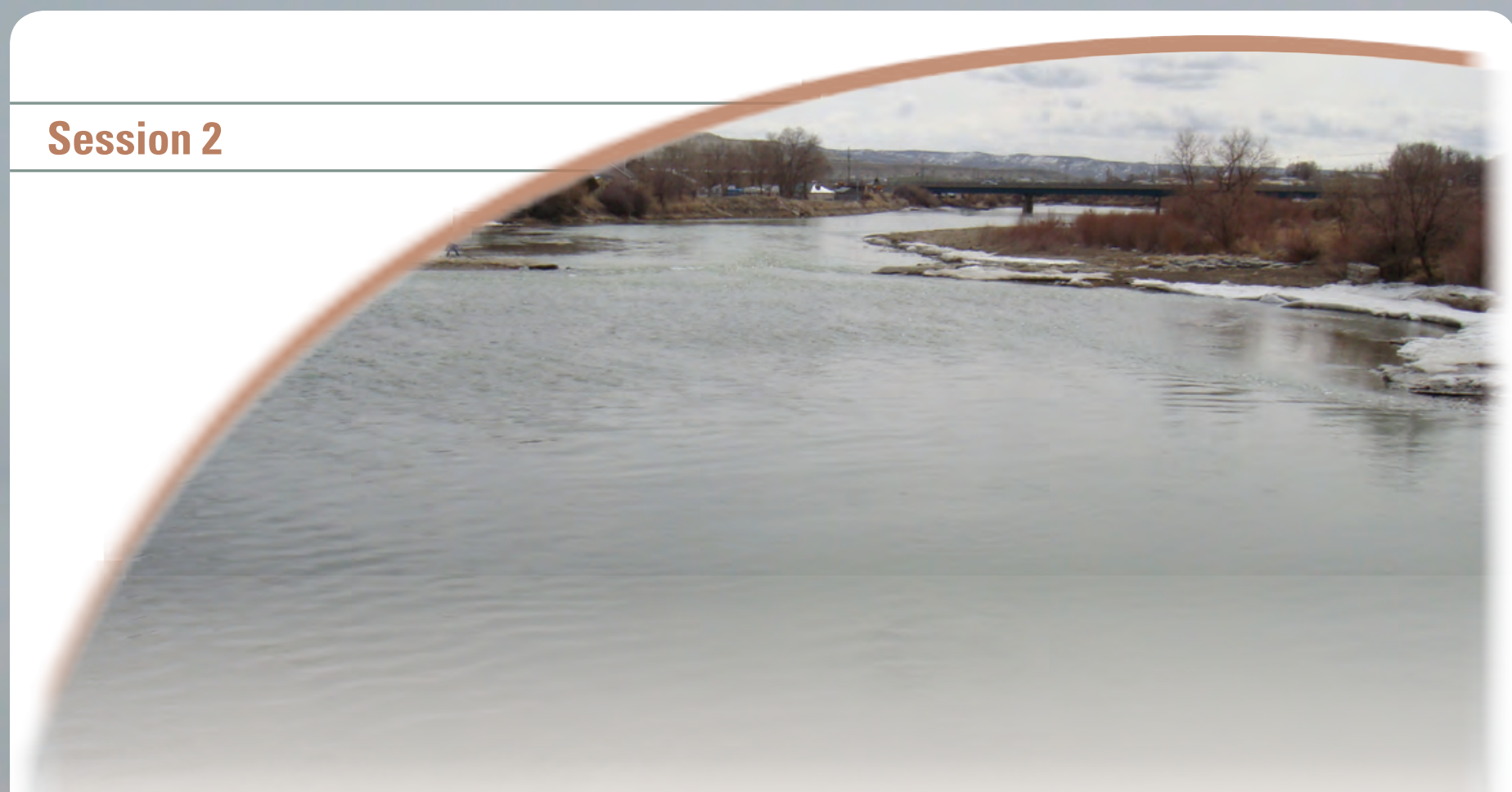

\section{Panel Presentations}

Panelists consistently identified energy development and climate change (especially as it relates to drought) as the primary drivers of change in southwest Wyoming. Several panelists emphasized that the current (2007) development and the current drought are occurring at an unprecedented rate and scale. The rate of development is not expected to slow substantially, nor is the availability of water expected to increase.

One panelist reminded the group, however, that although energy development is a key driver of change in Wyoming, it is not the only driver, and leasing does not necessarily mean development. The audience was urged to remember that housing and economic development are also important drivers.

\section{Audience Discussion}

Audience members noted that panelists did not focus on specific components of energy development and neglected to discuss energy-related issues such as invasive species and contaminants. Participants asserted that to address energy development adequately, a commitment needs to be made to evaluate changes at every level through every stage of development.

\section{Breakout Session}

The breakout group began the session by identifying key drivers of change. Participants agreed that energy development and climate change are the primary drivers of change in southwest Wyoming. However, a lot of attention was given to the different components of energy development. Politics, money, industry, population growth, and economic growth also were identified as primary drivers.

The discussion turned to concerns related to those drivers. Air quality, water quantity and quality, and habitat and population fragmentation were mentioned frequently. Concerns were voiced about climate-change effects, such as altered frequency of drought and extreme weather events, decreased water resources, and general stress to species. Finally, the consequences of population and economic growth, including increased water demand, stress on wildlife populations, and rural housing development were identified.

The group set priorities and emphasized the need for baseline data, especially for data about air, water, and geochemistry. Additionally, the group identified conducting resource assessments and ecological studies, mapping and understanding the leasing and location of development areas, and developing mitigation strategies as important long-term goals. Finally, the group outlined existing data resources that can aid the WLCI process (see Appendix 3). 


\section{Session 3}

\section{Conditions and Distribution of Key Wildlife Species, Habitat, and Species Habitat Requirements}

\section{Panel Lead}

Zack Bowen, U.S. Geological Survey (USGS)

\section{Panelists}

Gary Beauvais, Wyoming Natural Diversity Database (WYNDD)

Jack Butler, U.S. Forest Service (USFS)

Doug Keinath, WYNDD

Robb Keith, Wyoming Game and Fish Department (WYGFD)

Joe Kiesecker, The Nature Conservancy (TNC)

Bob Oakleaf, WYGFD

Dave Roberts, Bureau of Land Management (BLM)

Mark Rumble, USFS

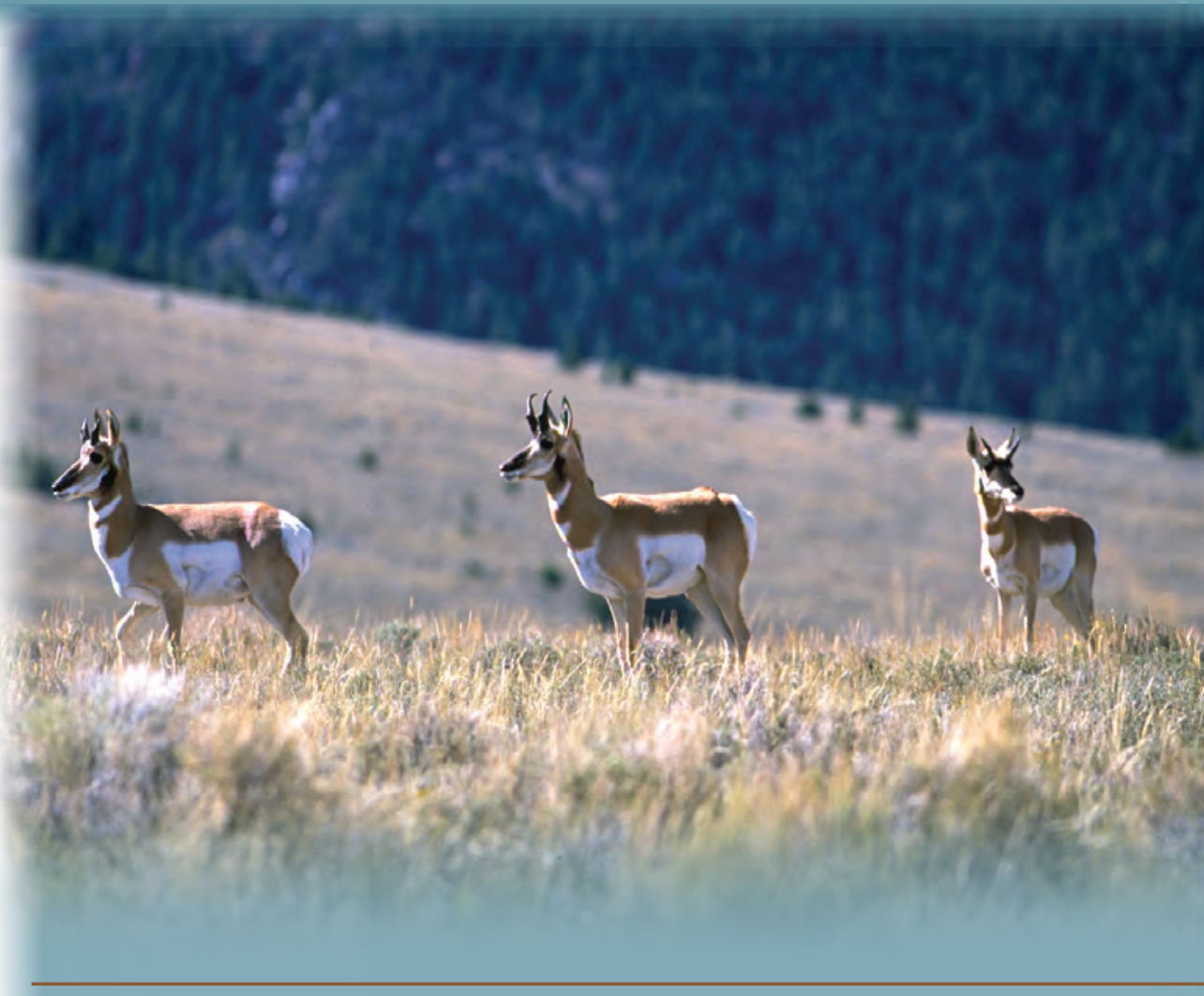

Although several wildlife and habitat assessments have been made in southwest Wyoming, landscape-scale knowledge of wildlife species, habitat, and species habitat requirements is limited. Session 3 panelists, presenters, and breakout participants discussed existing knowledge, data gaps, and next steps concerning conditions and distribution of key wildlife species, habitat, and species habitat requirements. Session 3 responses to the key workshop challenge are as follows:

- What are the highest priority needs and/or science contributions to be addressed in this management issue?

- Compiling existing data;

- Gathering baseline data;

- Mapping areas of concern; and

- Identifying key umbrella or indicator species. 


\section{Panel Presentations}

The panel presentations regarding conditions and distribution of key wildlife species, habitat, and species habitat requirements focused on general procedural and science needs, existing knowledge, and data gaps. The WYGFD provided an overview of catalogued aquatic, herpetological (reptiles and amphibians), and terrestrial wildlife distributions and needs (see Appendix 4).

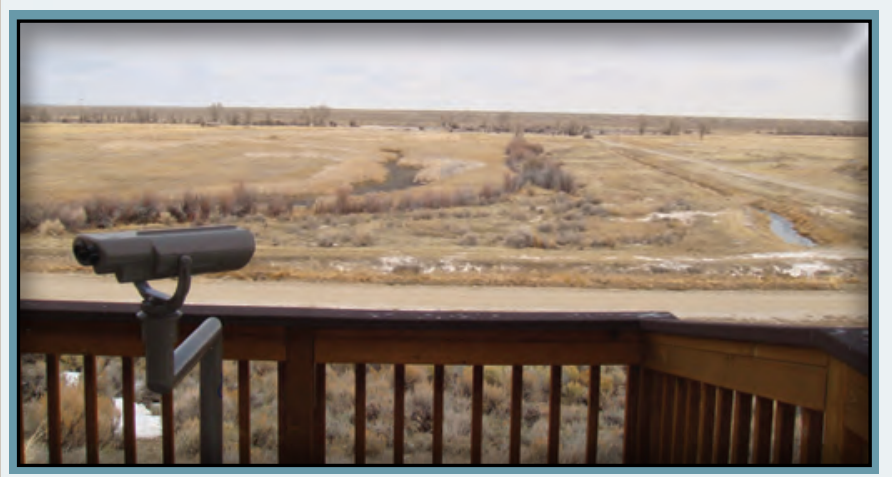

Panelists understood that all of the agencies and their managers have a different mandate and perspective regarding how to deal with habitat and wildlife issues. Because of these differences, panelists saw defining WLCI management objectives and refining a universal terminology as important first steps to help avoid communication issues. The next crucial step is to identify a baseline for species and a baseline for physical resources; agencies then can identify coordinated priorities, which will evolve through the use of management feedback loops.

The presenters also emphasized setting priorities. Ideally, priorities would be based on a spatially explicit species-range model, but such models are not available for all species, and priorities need to be based on existing data. However, WLCI partners need to be aware that species of concern vary, depending on the interests of the group creating the list, and that species often have competing interests. Science-based prioritization needs to be emphasized as much as possible.

\section{Audience Discussion}

During discussion, members of the audience mentioned several ideas not discussed by presenters. Many attendees commented that an obvious method of prioritization is identifying indicator and umbrella species and then focusing mitigation efforts on those species. Several other participants were surprised that presenters focused on individual species rather than on ecosystem or habitat management.

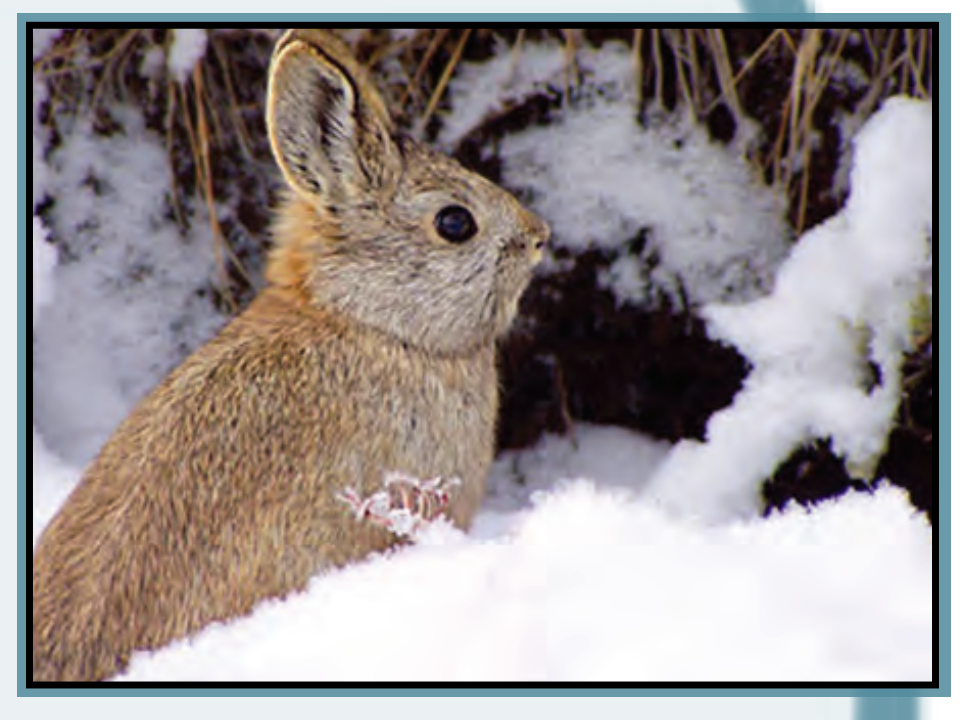

Audience members were concerned that the presenters focused on science. Panelists responded that managers and the public need to engage in and drive the debate because there is no time to ensure that the science is perfect.

There was emphatic agreement that terminology and methods need to be standardized for any type of monitoring or inventory effort to be successful.

\section{Breakout Session}

The breakout session began with a general introductory period when participants expressed their thoughts on panel presentations, their concerns, and what they were hoping to address in the session and throughout the WLCI process. During this period, several critical needs emerged, including the necessity of focusing on immediate needs and placing longer term research in a position of secondary importance; compiling existing data and defining baseline conditions; standardizing methods; assessing current management strategies; and finally, identifying key indicator and umbrella species.

As the discussion progressed, the group began considering the questions posed by their panel.

Short- and long-term science needs, current activities that relate to the WLCI, and the highest priority science contribution that could be made by the WLCI were identified. The short- and long-term needs that were identified overlapped with those identified within the other management topics (see Appendix 5). In addition to discussing these needs, panel participants identified the most important science 
contributions that the WLCI could make to benefit on-the-ground management. The contributions identified were assimilating data; identifying specific data gaps and need overlaps, including the need for habitat maps, surveys, information on rural housing development, and more; and finally, providing science to inform adaptive management decisions. The group was fairly specific about data gaps and needs, identifying the need for more smallmammal species surveys; avian surveys; and information about in-stream, riparian, ephemeral, and perennial systems, with an emphasis on surface disturbance, erosion, runoff, salt loading, high organic soils, and the eutrophication of the Flaming Gorge. The group placed an emphasis on managing and collecting data about herpetological species because little is known about these species.

To conclude, the group recommended the next steps the WLCI needs to take toward identifying the condition and distribution of key wildlife species, habitat, and species habitat requirements. The participants recommended the WLCI host a meeting in Rock Springs with people who work in the field. After this meeting, WLCI efforts can shift to identifying key wildlife, key habitat, and knowledge gaps. An overall consensus was reached on the need to prioritize, the need to address immediately funding and staffing, the need to transform research into practical applications, and the need for post-operational monitoring to assist an adaptive management process.
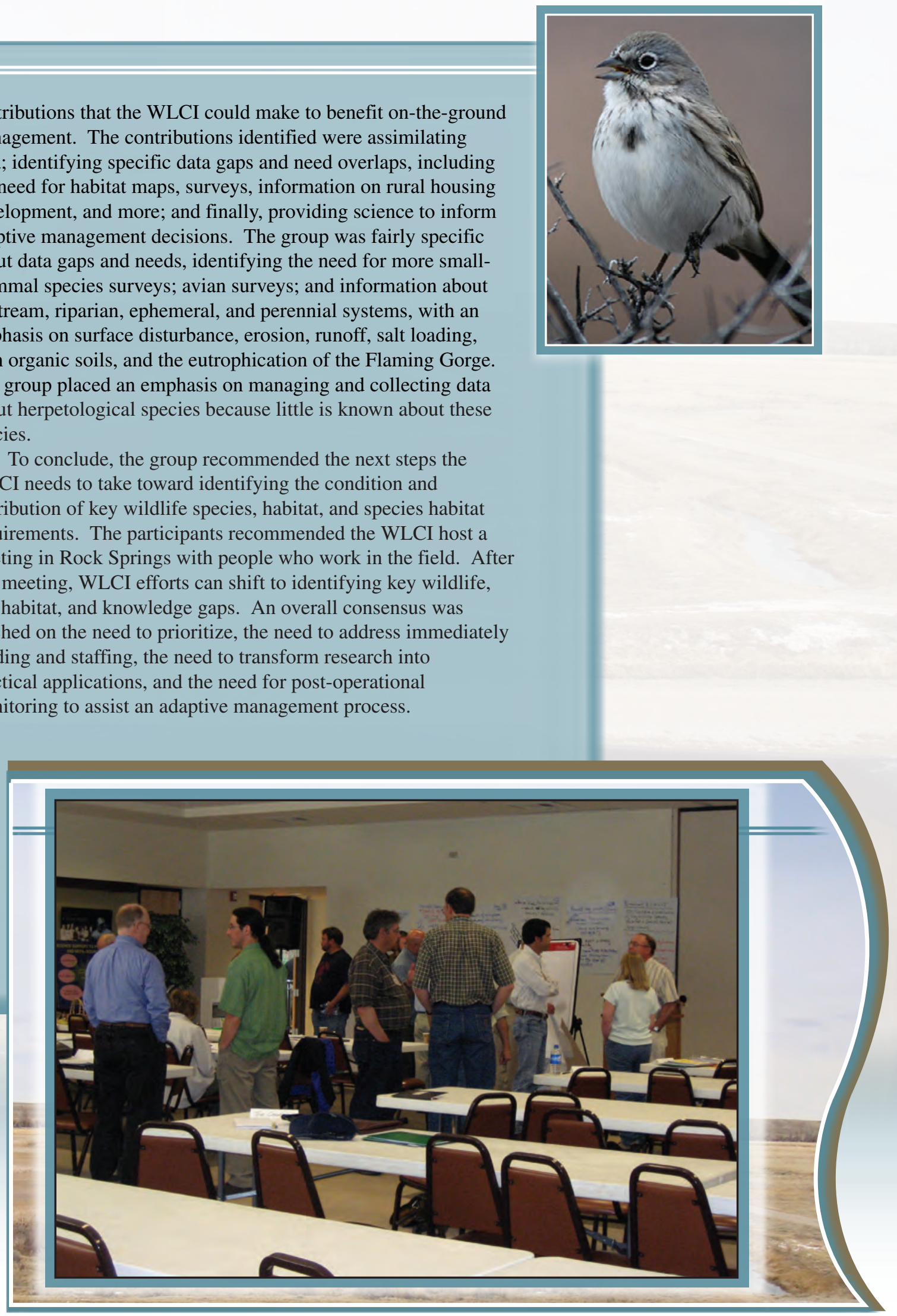


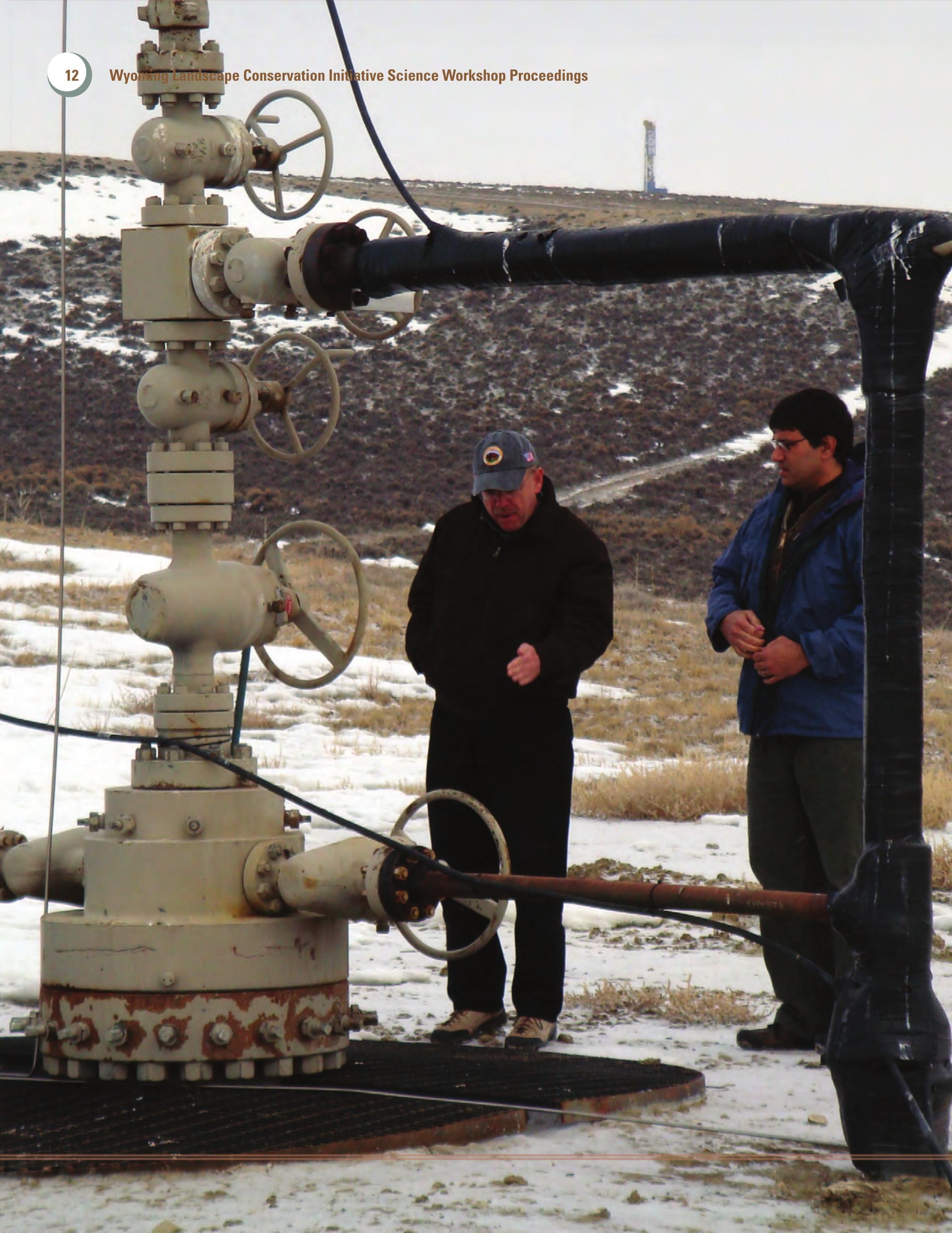




\section{Session 4}

\section{Wildlife and Livestock Responses to Development}

\section{Panel Lead}

Matt Kauffman, U.S. Geological Survey (USGS)

\section{Panelists}

\section{Zack Bowen, USGS}

Dean Clause, Wyoming Game and Fish Department (WYGFD)

Pat Deibert, U.S. Fish and Wildlife Service (USFWS)

Niels Hansen, Wyoming State Grazing Board

Mark Shasby, USGS

Rollie Sparrow, Theodore

Roosevelt Conservation

Partnership

Kevin Spence, WYGFD

Andy Warren, Bureau of Land Management (BLM)

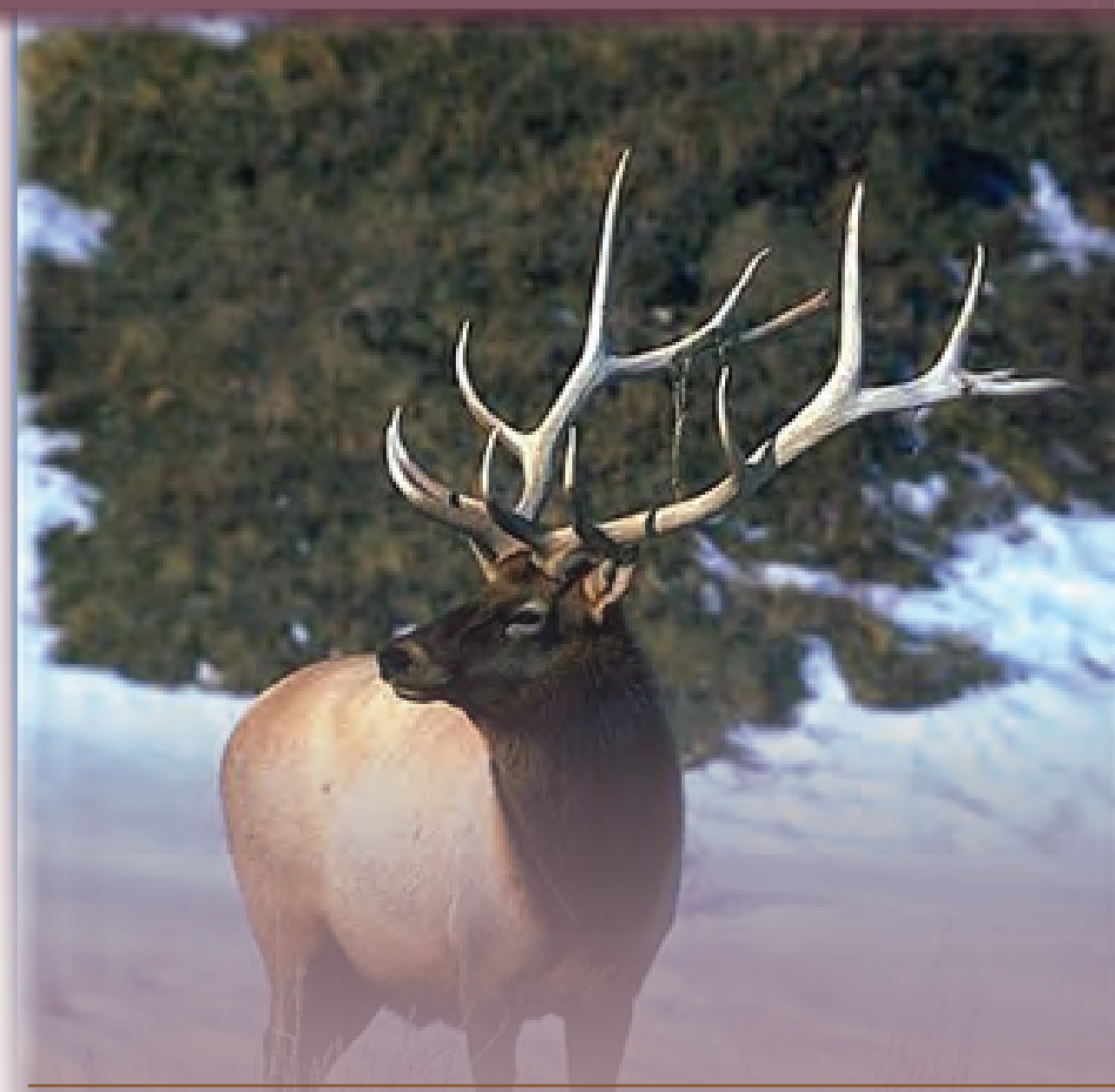

Knowledge of cumulative changes from energy development on wildlife and livestock is limited in southwest Wyoming. Little is known about the extent of future development, about potential indirect effects, or about the effects of development as they are specific to the region and to the responses of the region's wildlife and livestock herds. Session 4 panelists, presenters, and breakout participants analyzed wildlife and livestock responses to development and how those responses relate. Session 4 responses to the key workshop challenge are as follows:

- What are the highest priority needs and/or science contributions to be addressed in this management issue?

- Engaging local and public stakeholders;

- Developing a dataset documenting all development activities;

- Identifying umbrella and keystone species; and

- Determining which grazing practices enhance or improve habitat. 


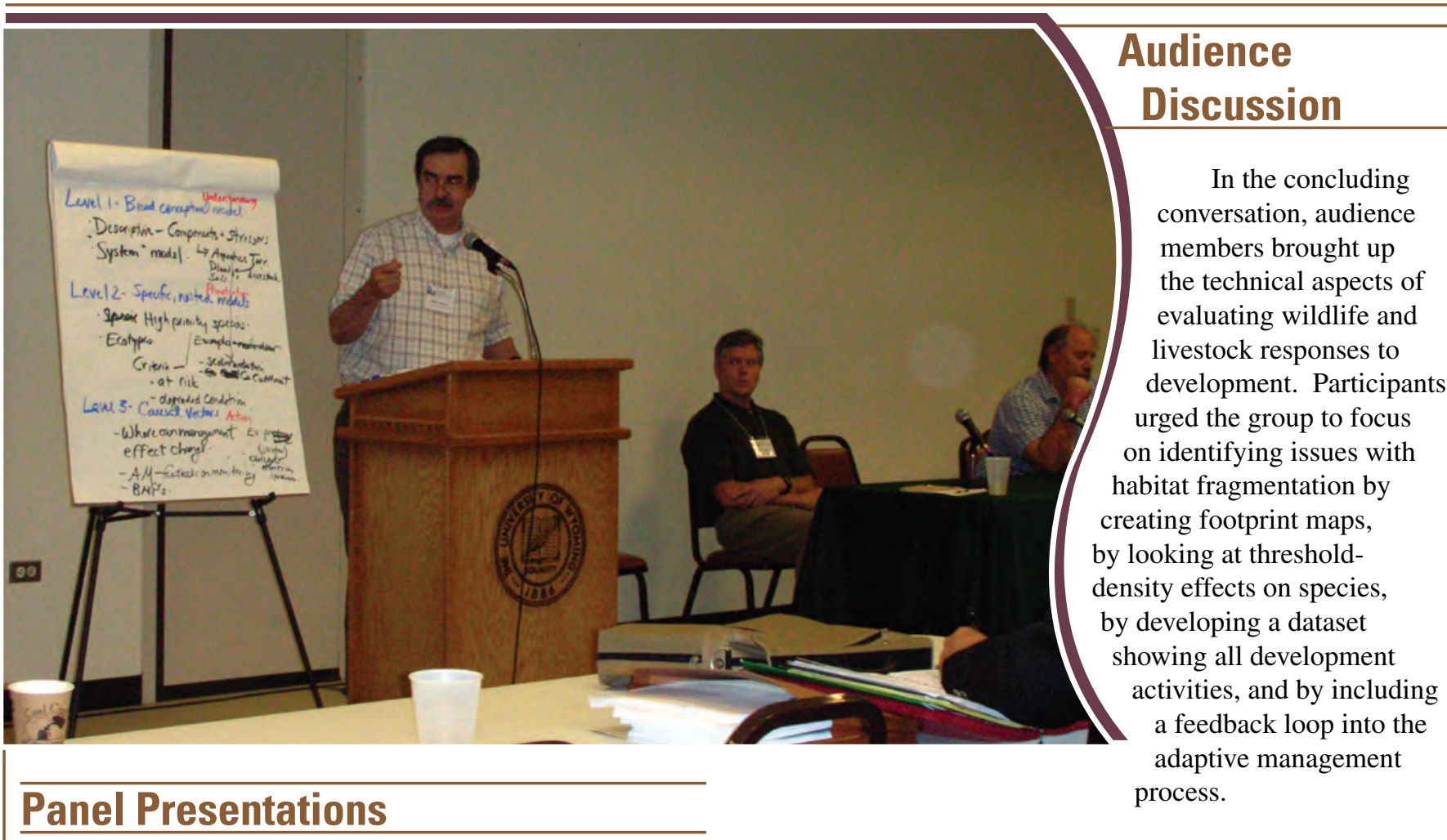

The panel stressed that the effects of development on wildlife and the effects of development on livestock cannot be separated from one another and noted that differences exist only in relation to economic effects. Panelists also discussed mapping needs, the urgent need for more geographic information science (GIS), and the need to quantify changes across all levels of development.

Several presenters were also concerned with the importance of engaging local stakeholders and with some of the difficulties associated with doing so. The public needs to be able to see the relation between landscape-scale mitigation efforts and livestock and wildlife herds. The audience was very receptive of this idea and expressed that the WLCI has a duty to ensure the public is involved with the process.

The WYGFD identified several issues affecting terrestrial and aquatic wildlife and their habitats, including planning and land-management decisions; habitat protection, reclamation, restoration, and enhancement; habitat condition, fragmentation, and competition; wildlife data; wildlife mortality (illegal and incidental); water quality, watershed function, and contamination; and air quality. The agency also determined some direct and indirect effects on wildlife because of development. These identifications and corresponding explanations can be seen in Appendix 6.

\section{Breakout Session}

Participants in the breakout session were asked to consider research priorities that evaluate the responses of wildlife and livestock to development. To begin, the group spent time discussing data gaps in livestock monitoring that could be researched to support using livestock as an indicator species for some big game populations. Actions to address data gaps include identifying core areas of wildlife populations and opportunities to connect those areas; determining the threshold level at which development affects wildlife and wildlife habitat; predicting patterns of predation as a result of energy development; and identifying species that are thriving in the disturbed environment.

The group established several high priority needs, many of which are related to species identification. Needs to be addressed immediately are identifying how wildlife, livestock, and feral horses respond to the different types, stages, and features of development over time; determining what grazing practices can enhance or improve habitat; identifying umbrella or keystone species; and researching different patch-size needs and edge effects that influence the behavior, the demography, and the population growth of various wildlife and livestock species. 
After establishing priority needs, the group established criteria for determining specific priority projects. Priority projects need to do one or more of the following: keep in touch with public views and administrator needs; have strong and diverse project partners and matching funds; protect and enhance ecosystems; emphasize management on the ground; build on existing data and information; consider landowner interests; fill identified data gaps; address species urgency and habitat levels; provide common benefits to all interested partners; prioritize actions that benefit multiple species; and finally, continue coordinating and sharing information.

The group also began determining direct and indirect effects of development on habitat and wildlife. Direct effects identified include vegetation and habitat loss; traffic, noise, and increased activity levels as related to animal stress; fragmentation of migration corridors and species dispersal; population performance; water quality, quantity, and flow regimes; light; dust; and changes in overland hydrology. Initial identification of indirect effects produced a list that included disturbance avoidance, a reduction in herd size or animal unit months (AUMs), animal stress, rural development, water demand, water development, population performance, and roads and wells.

From this list, the group identified research needs, including some general cross-cutting needs. The session concluded as the group discussed increasing public involvement in the WLCI process. Private landowners and ranchers especially are viewed as an untapped resource of information in determining development effects on livestock and wildlife.

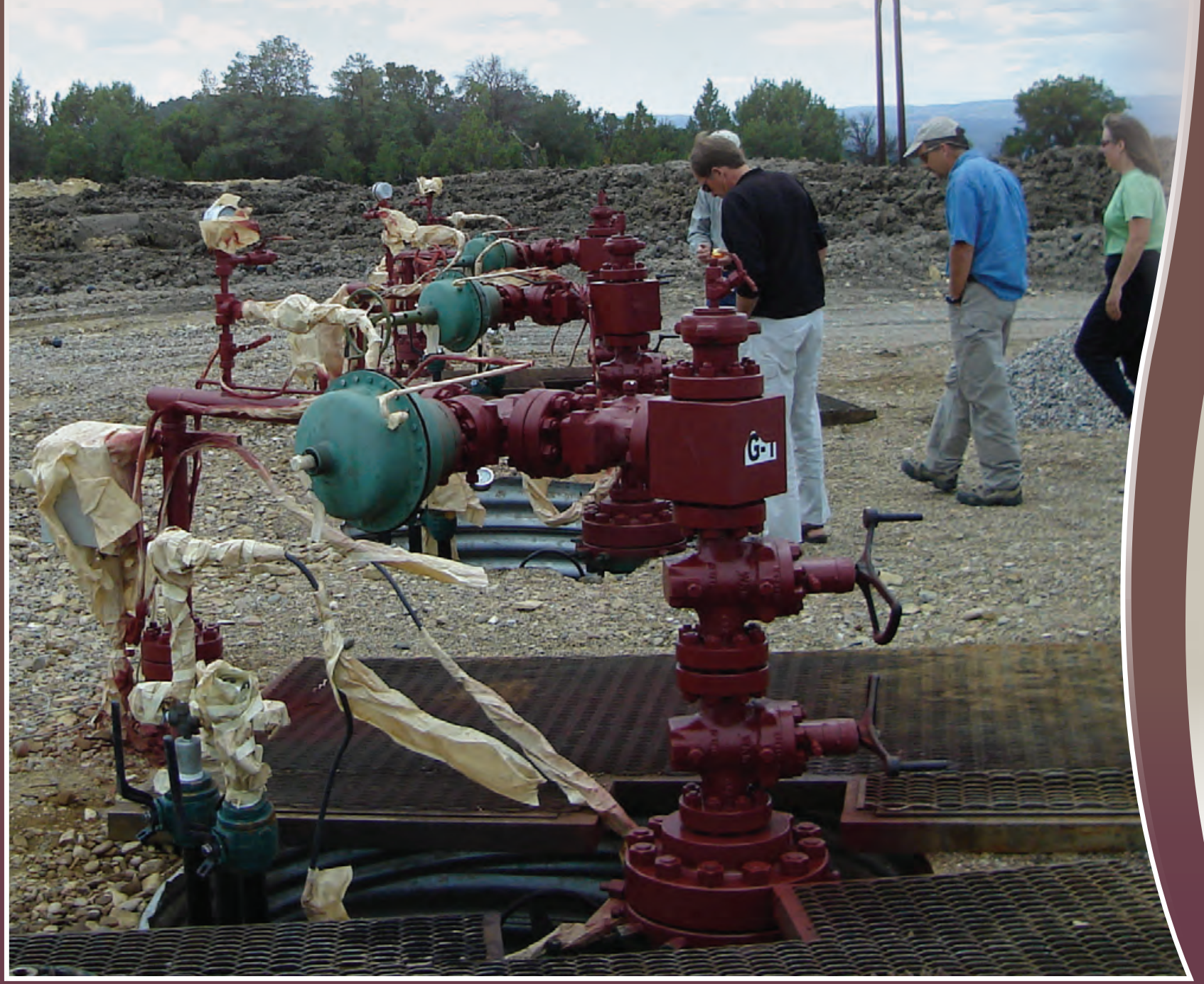




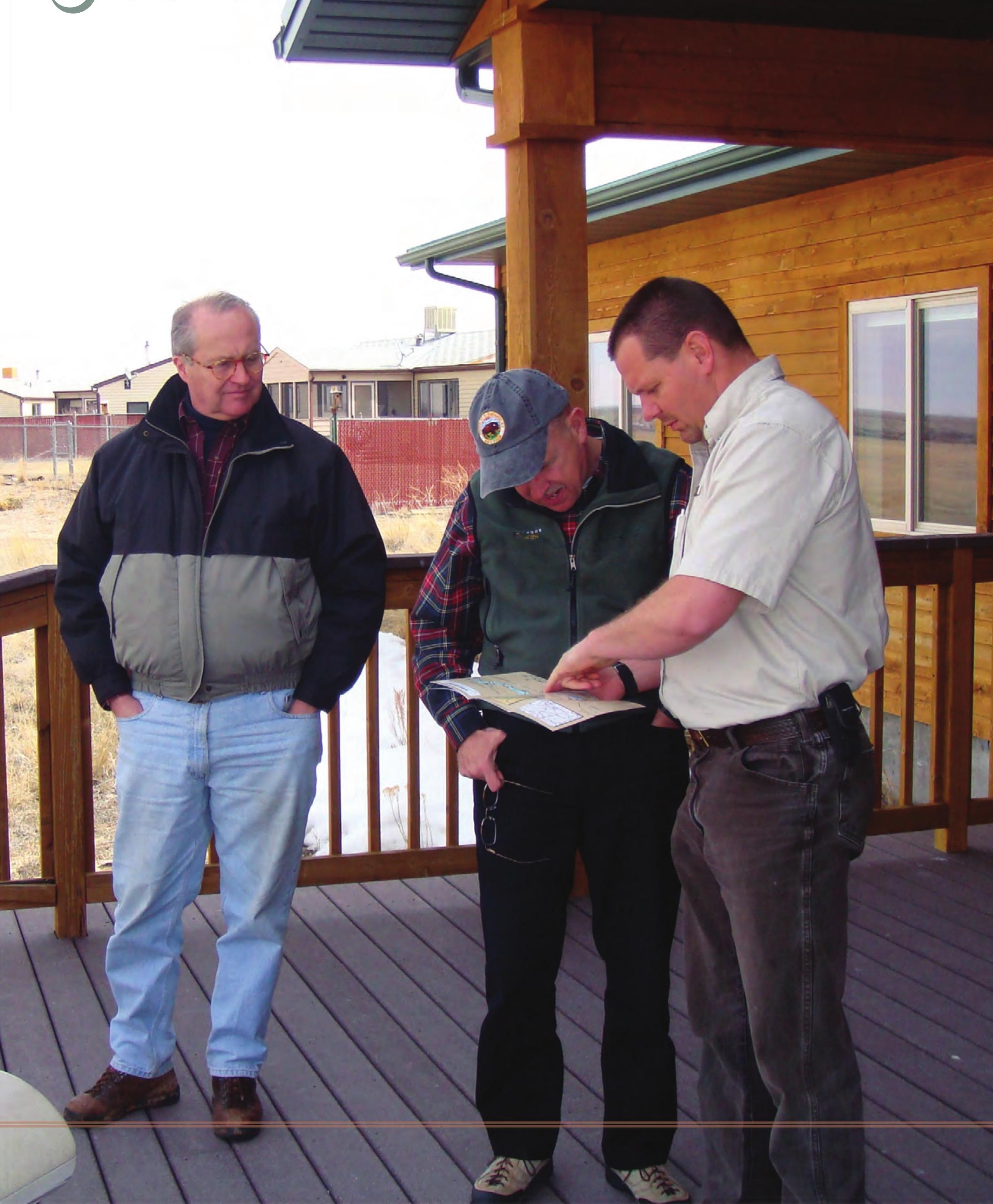




\section{Session 5}

\section{Inventory and Monitoring Strategy}

\section{Panel Lead}

Tom DiNardo, U.S. Geological Survey (USGS)

\section{Panelists}

Pat Anderson, USGS

Myron Brooks, USGS

Jim Cagney, Bureau of Land

Management (BLM)

Greg Hayward, U.S. Forest

Service (USFS)

Dustin Perkins, National Park

Service (NPS)

Kathy Purves, Trout Unlimited (TU)

Lisa Reinhart, Wyoming

Department of Agriculture

(WYDA)

Dan Stroud, Wyoming Game and Fish Department (WYGFD)

Alma Winward, WYGFD

Dave Zafft, WYGFD
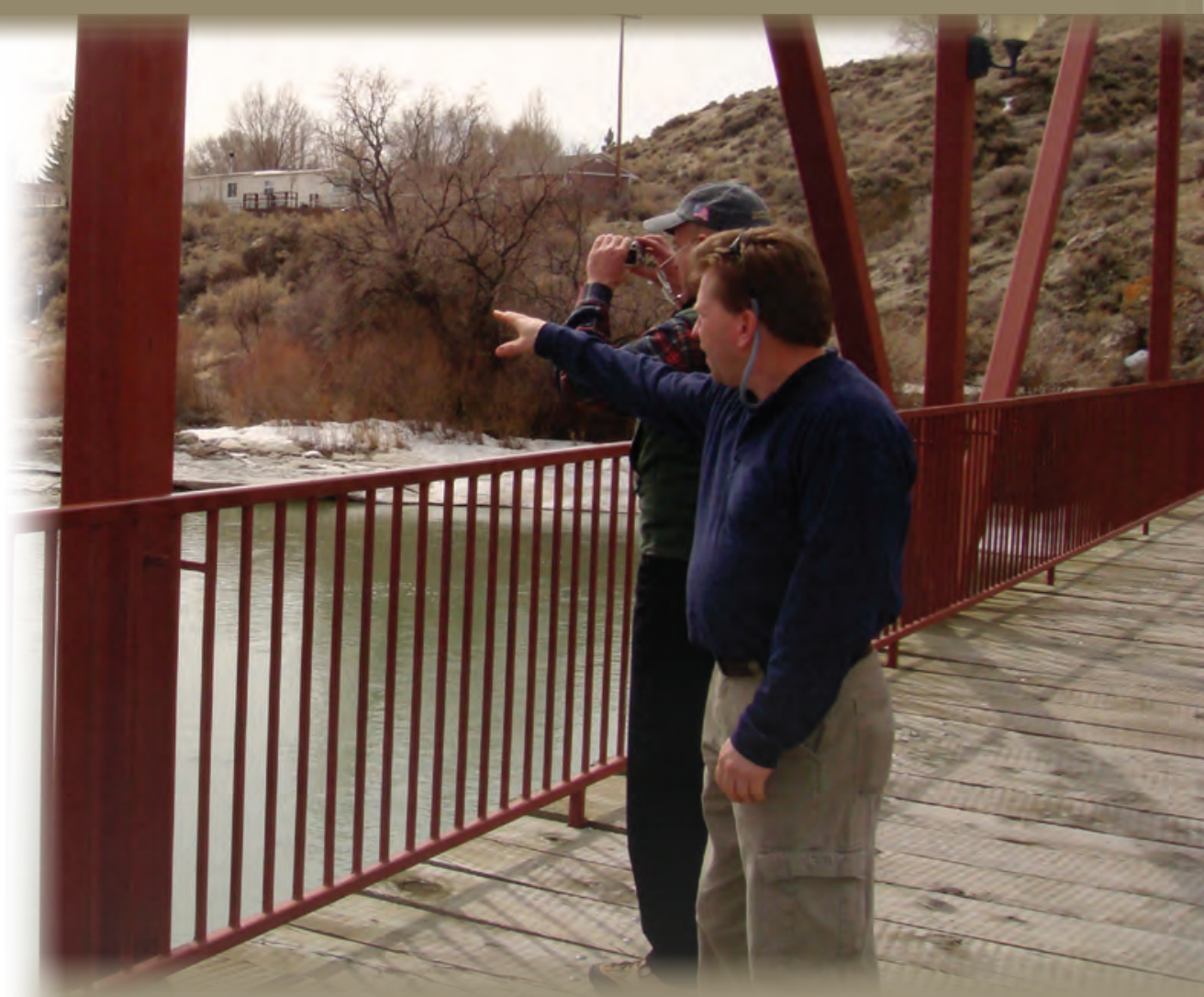

Inventory and monitoring efforts are being implemented throughout southwest Wyoming through various venues. However, for these efforts to be useful on a comprehensive landscape scale, they need to be integrated and coordinated. Session 5 panelists, presenters, and breakout participants began developing a strategy for this scale of inventory and monitoring effort. Session 5 responses to the key workshop challenge are as follows:

- What are the highest priority needs and/or science contributions to be addressed in this management issue?

- Securing long-term funding for monitoring;

- Standardizing monitoring protocols;

- Using preliminary information to prioritize needs; and

- Linking strategies to on-the-ground action. 


\section{Panel Presentations}

Presenters emphasized developing a strategy for inventory and monitoring and the capabilities necessary to implement that strategy. They recommended prototypes for monitoring protocols and strategies, established starting points and focus areas, and identified technical and administrative needs.

Adaptive management, feedback from managers in the field, funding, and review of existing monitoring programs were tools seen as necessary to create a successful monitoring program. To maximize efficiency and funding, it is necessary to learn from monitoring programs that already exist and to minimize repetition of mistakes. Based on past lessons, it is especially important to maintain communication in the early years of monitoring, to understand the value of concise information summaries, to use the correct indicators, and to remember the importance of stakeholder support.

Technical state of knowledge summaries and data needs for aquatic wildlife, reptiles and amphibians, nongame wildlife, and vegetation and habitat were outlined by the WYGFD (see Appendix 7). Within the broader technical needs identified by the panel, the WYGFD representative noted a special need to remember aquatic concerns, and commented that reptiles and amphibians need to be included in data collection and field management efforts.

In terms of protocol, the nongovernmental contributor stressed the need for better communication venues, a longterm landscape vision, better collaboration with industry, and the support of the public and decisionmakers. It was noted that the Wyoming public addresses issues at a political level.

Finally, the Jonah Interagency Mitigation and Reclamation Office (JIO) explained its role in providing adaptive management recommendations to the BLM, and stressed that the office has a lot of information to share but needs an information system.

\section{Audience Discussion}

Audience members cautioned that monitoring will be irrelevant if on-the-ground mitigation projects are not funded. Several participants also noted the importance of pretreatment monitoring and that monitoring can take on different dimensions depending on the type of mitigation strategy being used.

It was suggested that WLCI partners begin habitat enhancement and other offsite mitigation efforts immediately, followed by monitoring to determine if concerns about offsite mitigation are relevant.

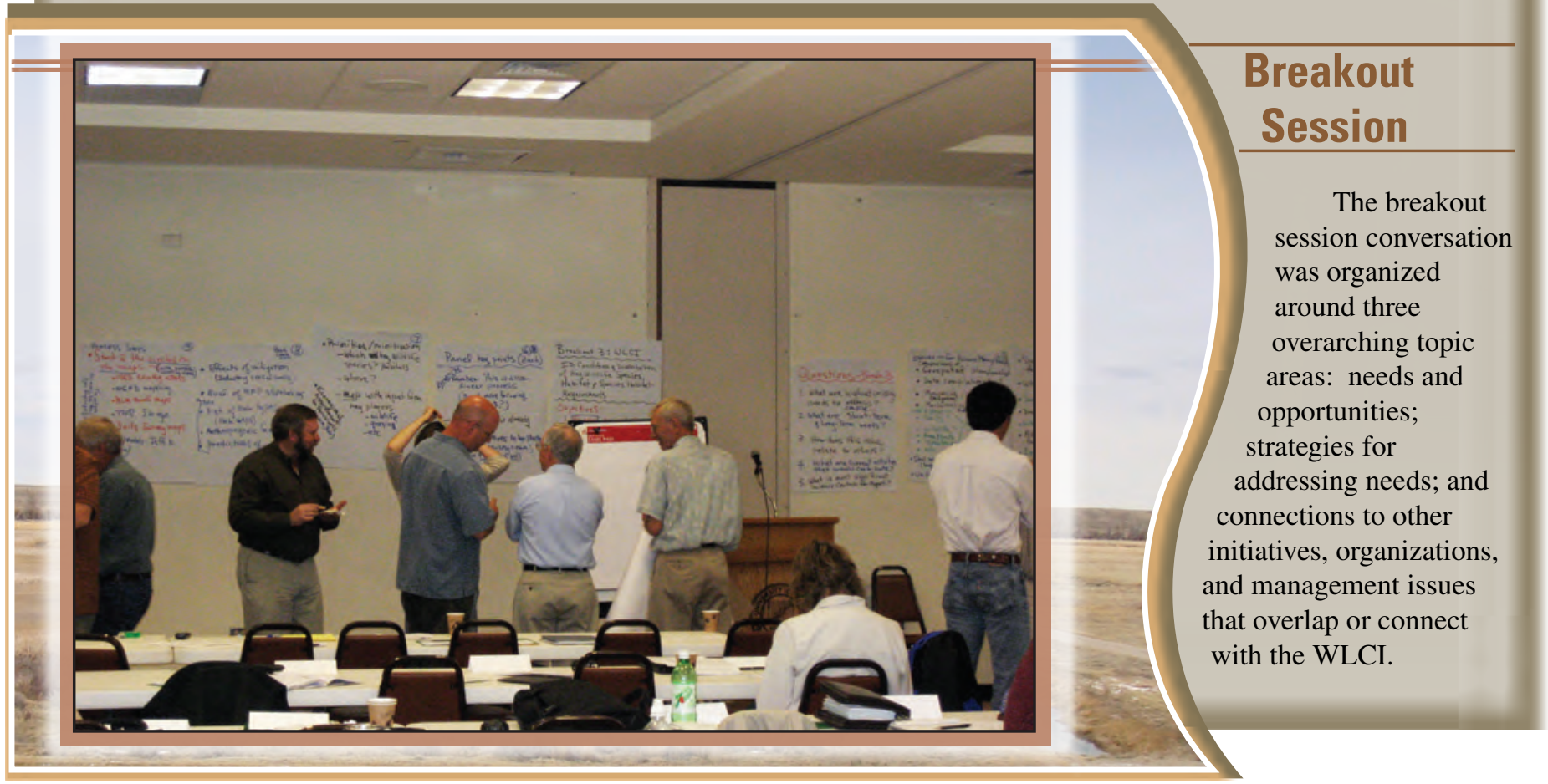




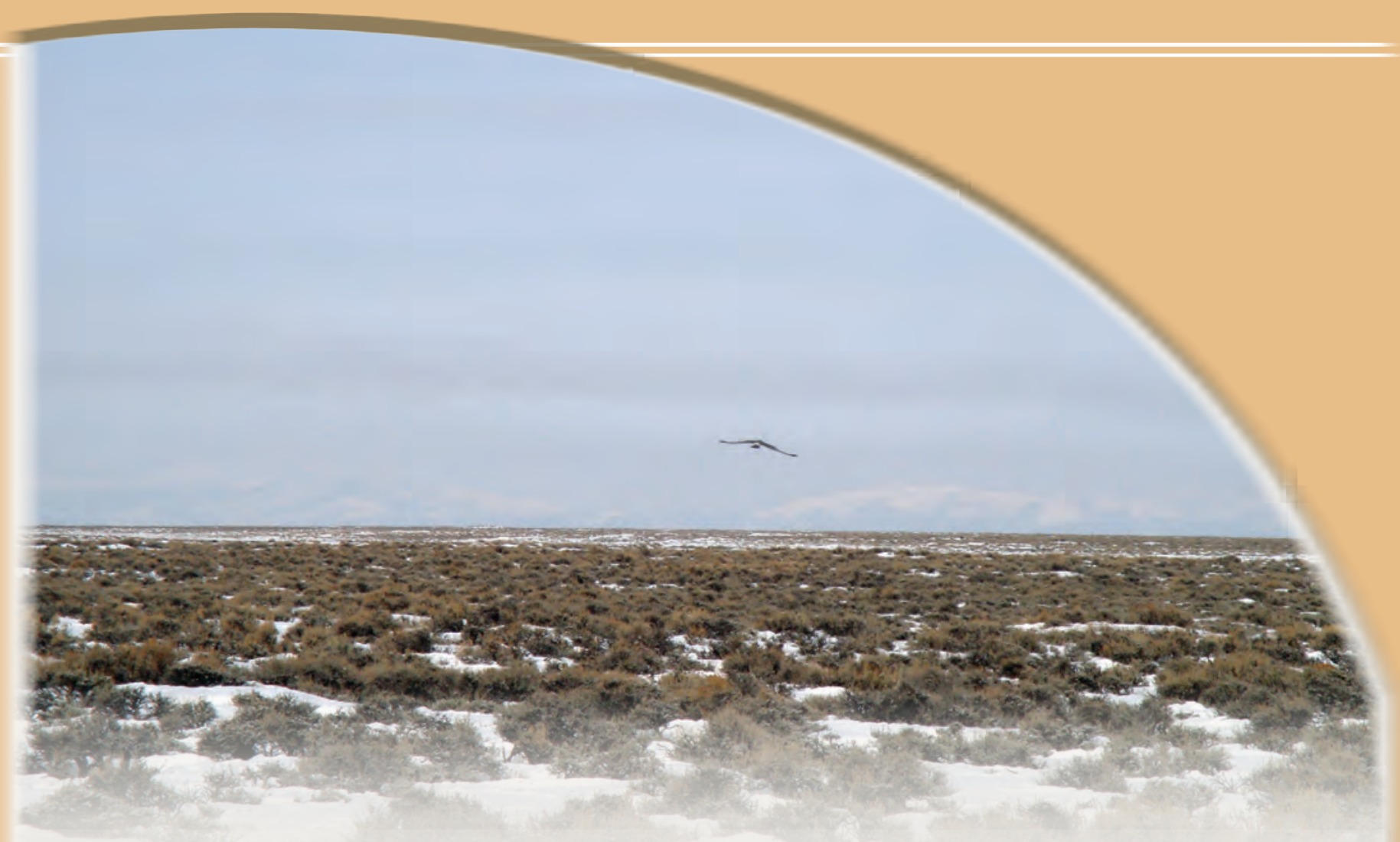

Discussion began with the identification of the obvious needs of the WLCI. As group participants began to discuss needs specific to inventory and monitoring, they emphasized the need to secure long-term funding for monitoring purposes. Terminology was an important subject, and the group identified the need to clarify and define cumulative effects and to develop a better framework for the issue by understanding regulations, legal issues, and limiting factors that are specific to this region. Science-based needs include ambient water-quality monitoring for surface water; air-quality monitoring; inventory and monitoring for aquatic habitats, indicator species, vegetation and habitat conditions; and developing sampling sites to yield statistical information about the effects of development on these resources. Social aspects of the strategy include considering conditions and changes of human dimension, ensuring there is a joint vision of monitoring success, and considering general social system factors. Finally, the group determined a need to document responses, actions, and damages to habitat from energy development.

Next, the group determined strategies to meet these needs. Recommendations include linking monitoring needs to the clarified objectives and standardizing monitoring to increase success rates. Existing monitoring efforts need to update critical data fields into their repository. Data need to be managed on a daily basis, and the data management team needs to be determined and funded quickly.
Although monitoring needs to be selective and standardized, it also needs to be customized to each agency's regulatory abilities and the local situation. The group recommended a fundamental strategy of (1) using preliminary information to make decisions about high-level priorities; (2) focusing on monitoring and coordinating data collection strategically among partners; and (3) focusing on avoidance, reclamation, mitigation and enhancement with an emphasis on linking to on-the-ground actions. To conclude the strategies discussion, the group recommended the creation of a "lessons learned" clearinghouse.

Finally, the group discussed linkages to other data sources, projects, and agencies:

- The Wildlife Chapter is developing aids for cumulative-effects assessment of oil and gas development.

- The Rocky Mountain Leadership Forum has created reasonably foreseeable development scenarios and cumulative-effects analyses.

- TU uses a spatial analysis plan to work with energy companies, State and Federal agencies.

- The JIO comprises the BLM, the Department of Environmental Quality, the WYGFD, and the WYDA. It provides adaptive management recommendations to the BLM. 


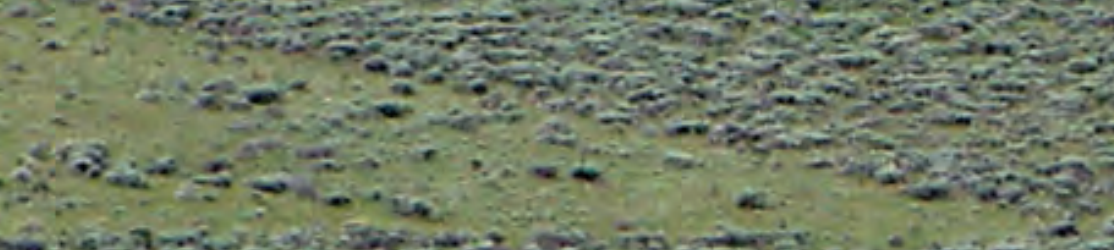

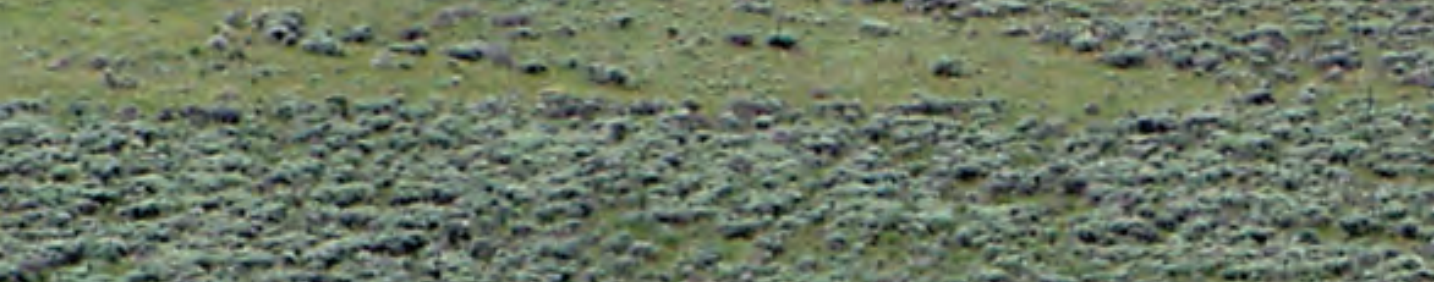




\section{Session 6}

\section{Data Clearinghouse and Information Management Framework}

\section{Panel Lead}

Sky Bristol, U.S. Geological Survey (USGS)

\section{Panelists}

Gary Beauvais, Wyoming Natural Diversity Database (WYNDD)

Dan Blake, U.S. Fish and Wildlife Service (USFWS)

Tom DiNardo, USGS

Jeff Hamerlinck, Wyoming

Geographic Information Science Center (WYGISC)

Larry Neasloney, Bureau of Land Management (BLM)

Kirk Nordyke, Wyoming Game and Fish Department (WYGFD)

Barb Ray, USGS

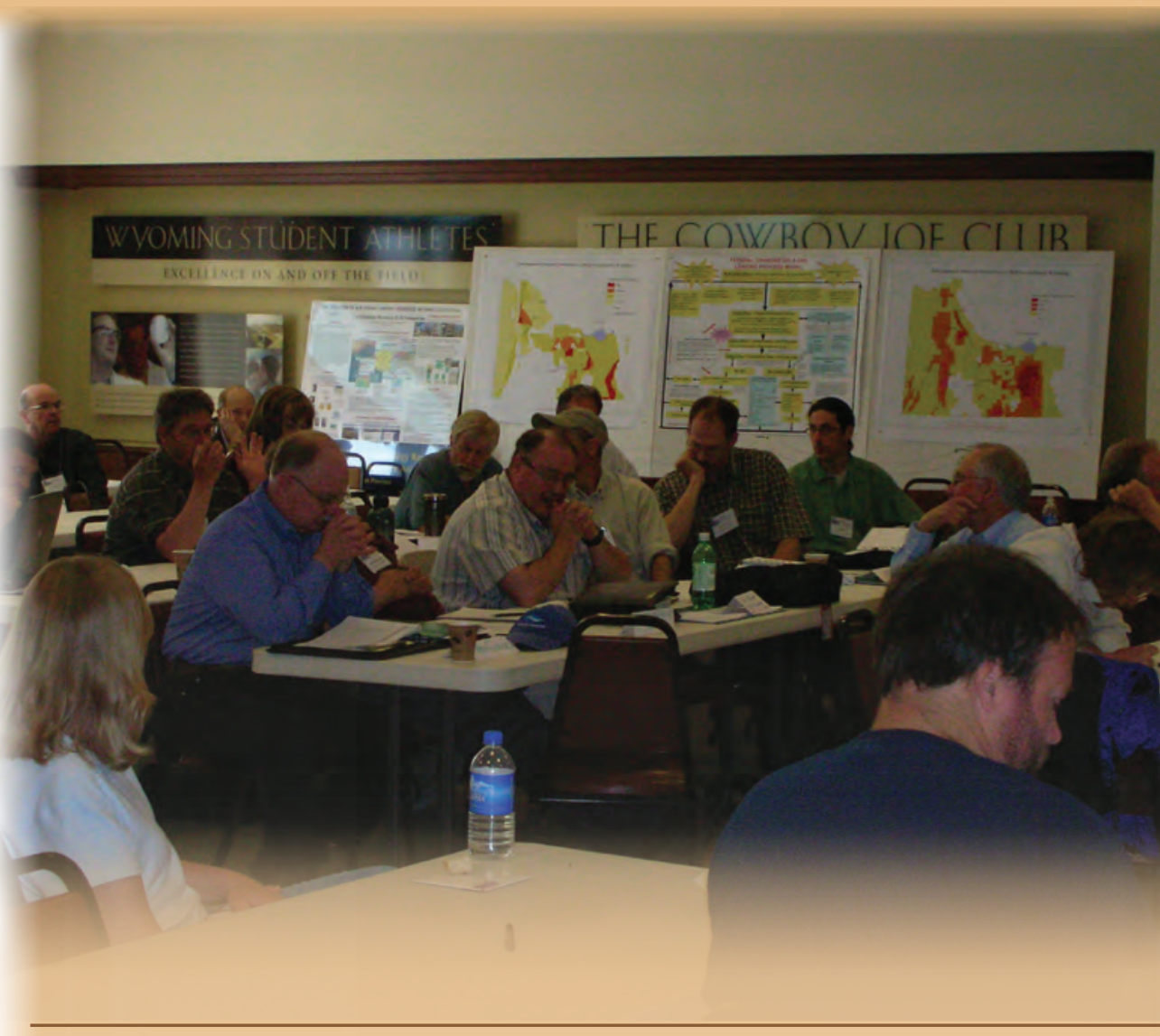

Similar to inventory and monitoring efforts, data repositories for southwest Wyoming are isolated and disjointed from other data resources. Existing databases often are inaccessible, incomplete, and not maintained. WYGISC has spearheaded the creation of an effective and comprehensive state-wide geospatial data clearinghouse, and the WLCI intends to follow their lead when developing an information-management system. Session 6 panelists, presenters, and breakout participants began developing a strategy for the creation of this type of data clearinghouse and informationmanagement prototype. Session 6 responses to the key workshop challenge are as follows:

- What are the highest priority needs and/or science contributions to be addressed in this management issue?

- Identifying primary data resources;

- Collecting missing baseline data; and

- Focusing on public outreach by creating an accessible and durable database. 


\section{Panel Presentations}

Presenters emphasized the services WYGISC and WYNDD can offer the WLCI relative to creating a data clearinghouse and information-management framework. The panelists also focused on the importance of creating a sustainable and accessible database. The database needs to be simple, durable, and unique-all the agencies stressed that creating another database but not investing in its maintenance would be a waste of resources.

WYGSIC's database, the Wyoming Energy Resources Information Clearinghouse (WERIC) is a geospatial model that can be used as an example by WLCI partners. WERIC includes statewide spatial data from agency sources and is a good model for multiple agency collaboration. WYNDD is a natural resource data infrastructure and has the potential to be either a component of a WLCI database or a contributing member. The existing WYNDD database provides data on rare animals, plants, and certain land-cover types in Wyoming.

\section{Audience Discussion}

Following the presentations, audience members voiced and repeated several concerns. The first issue was to determine for whom the database is being created-it was decided that the audience will be broad, and the data need to be as accessible and simple as possible to aid decisionmakers and to help to engage the public. The database will have multiple audiences and it is important to serve all of them, but serving the public was seen as especially important.

Some participants were also concerned with protecting data that should not be available to all audiences. Panelists assured those who were concerned that clear guidelines exist about what information can be protected or withheld, and that data security would be implemented as appropriate.

\section{Breakout Session}

The breakout group began by recognizing a clear theme from the plenary discussions that the public is a major component of the audience, and that the proposed data resource needs to focus on public outreach and accessibility for nontechnical persons. The group considered several proposals for the data resource's framework and sources. One proposal was to develop two types of databases, a clearinghouse open to the public, and a managerial interface that would enable managers to upload information and access secured data. Two other options considered for the database framework were creating a new database or creating a system that draws from existing databases. An approach was not agreed upon clearly, but it was determined that WERIC needs to serve as a foundational model. At the end of the conversation about frameworks and data sources, concern arose over the use of private land information in the database. Ranchers and other private landowners have valuable data, but those data are sensitive. Whatever type of framework is adopted, the clearinghouse needs to be designed so it does not require a major change in the way data are currently collected. The development of data-management protocols could help mitigate these types of issues.

Regardless of setup and data sources, the database or clearinghouse needs to provide baseline information over spatial, topical, and temporal data ranges; provide status and compliance monitoring; track changes in resources; track project status; and keep metadata records. The group agreed that primary data holdings need to be identified. Concrete next steps need to be developed and implemented quickly so information can be provided to key groups. Professional services are needed, and a technical representative from each of the partners to help develop the strategy. Developing a budget for a database is an issue; group members suggested the USGS support this maintenance effort.

To conclude, group participants outlined the critical components of creating an information database for the WLCI. They suggested the proposed data-strategy team be composed of State and Federal agencies and university clearinghouses such as WYGISC and WYNDD. The data-strategy team needs to facilitate data strategy, models, and architecture and new database efforts and an information management plan. Data architecture includes spatial, temporal, and topical datasets; information; and tools. An ongoing inventory and management-issues evaluation also will be directed by the data-strategy team. The group suggested actions be taken quickly to get the database operational. The timeline includes the creation of an information-management work plan by Labor Day (September 3, 2007), a functioning dataexplorer Web site by December 2007, managementissues evaluation by fiscal year 2008 , and an ongoing inventory effort. 


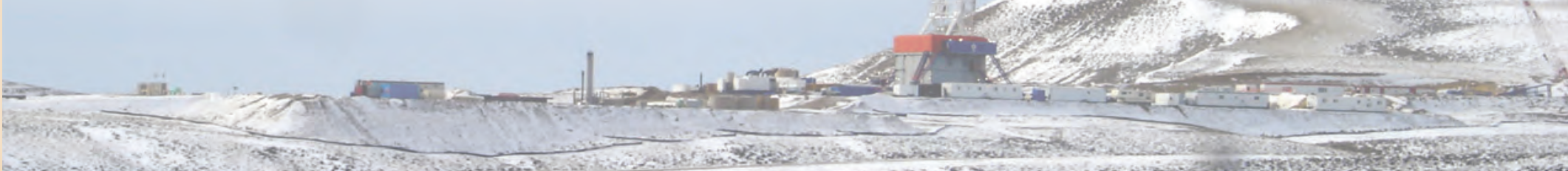

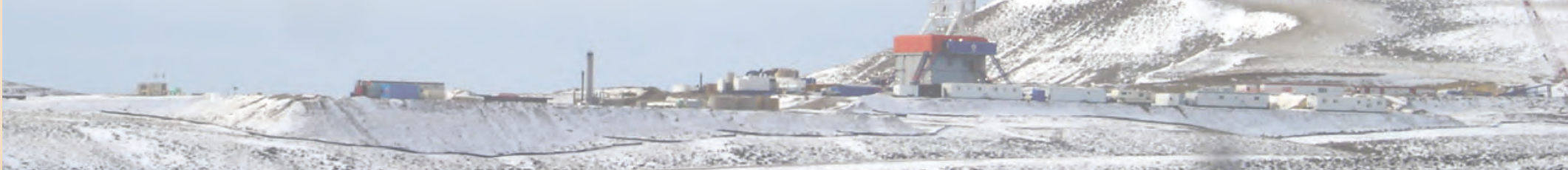

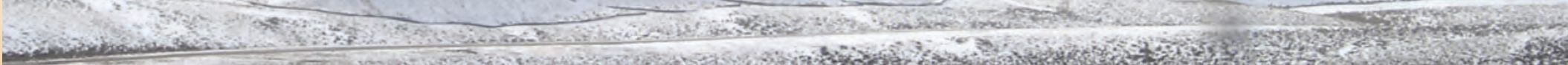

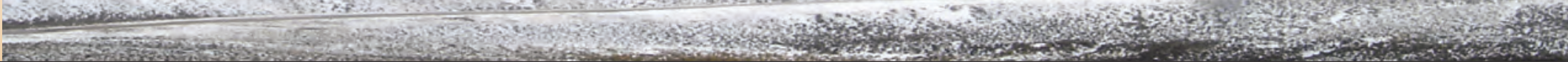

\section{Appendixes.}




\section{Appendix 1. Compilation of Workshop Notes}

\section{Wyoming Landscape Conservation Initiative Science Workshop}

\section{U.S. Geological Survey}

University of Wyoming, Laramie, Wyoming

May 15-17, 2007

\section{Background}

The Wyoming Landscape Conservation Initiative (WLCI) was developed by a coalition of government and nongovernment organizations in response to the increased demands on southwest Wyoming's natural resources. The WLCI is a long-term, science-based initiative with the ultimate goal of assessing and enhancing the aquatic and terrestrial habitats of southwest Wyoming on a landscape scale while facilitating responsible energy development.

Within the broader partnership of the WLCI, several working groups have formed to address specific needs. These groups include an Implementation Team that is overseeing the organizational aspects of the Initiative; a Science Planning Team that is drafting a WLCI science plan and establishing short-term and long-term science data and research needs; and a Data Information Management Working Group, which is working to address the data and information needs of the WLCI partners.

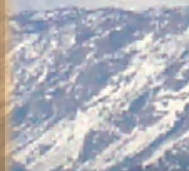

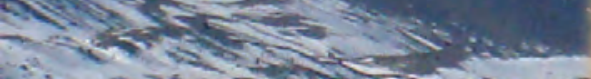

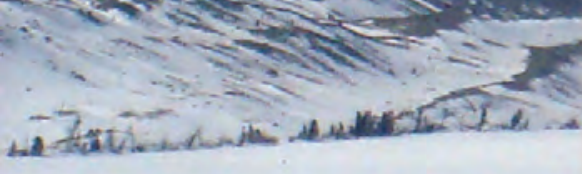

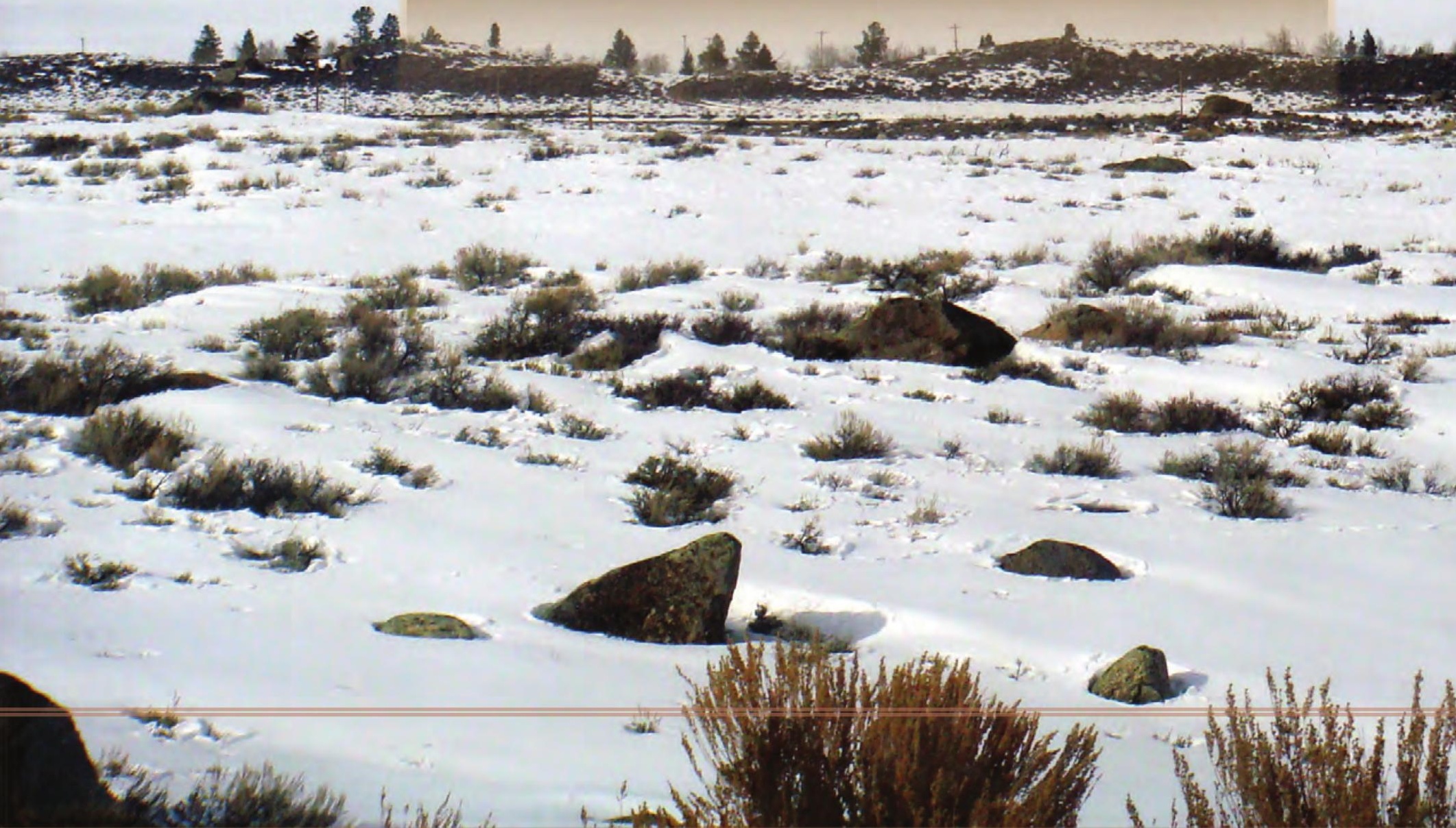




\section{Introduction}

To help the working groups identify the immediate needs and long-term goals of WLCI partners, the U.S. Geological Survey (USGS) hosted a WLCI Science Workshop at the University of Wyoming from May 15-17, 2007. The workshop focused on six areas:

- Evaluating cumulative effects of development activities in southwest Wyoming;

- Identifying the key drivers of change;

- Identifying condition and distribution of key wildlife species, habitat, and species habitat requirements;

- Evaluating wildlife and livestock responses to development;

- Developing an integrated inventory and monitoring strategy; and

- Developing a data clearinghouse and information-management framework.

These six topics correlated with six plenary panels and discussions and six breakout sessions, which were facilitated by personnel from the Meridian Institute, the Ruckelshaus Institute of Environment and Natural Resources, and the USGS.

Several overlapping findings of the six plenary and breakout sessions included the following needs:

- To create a long-term, accessible information database;

- To identify key habitats, indicator species, and umbrella species; and

- To implement a monitoring program to assist with adaptivemanagement techniques.

Several overlapping concerns also were expressed, including:

- Securing adequate and long-term funding;

- Meeting the WLCI workload with understaffed agencies;

- Using the approaches of cumulative effects assessment and offsite mitigation successfully;

- Transitioning to on-the-ground adaptive management; and

- Placing too great of an emphasis on research.

Representatives from most agencies also clearly expressed the need to begin on-the-ground projects immediately.

The following is a compilation notes from the conference proceedings, including panel presentations, plenary discussions, and breakout sessions. 


\section{Opening Plenary Presentations}

\section{Frank D'Erchia, Regional Chief Scientist U.S Geological Survey (USGS)}

- Welcome and thanks for participating in the WLCI Science Workshop.

\section{Molly Mayo, Meridian Institute}

- Introduction to the flow of the workshop.

- The workshop is intended to be as interactive as possible.

- Introduction of Harold Bergman and the Ruckelshaus Institute and Haub School, University of Wyoming, Laramie.

\section{Tom Casadevall, Director of the USGS Central Region}

- Over 140 participants registered for this workshop.

- Introduction to the work of the USGS and the Healthy Lands Initiative. Concern for disruption of sage habitat and energy development led to the creation of a budget initiative for the Healthy Lands Initiative.

- President Bush's budget for 2008 had three top priorities for the U.S. Department of the Interior, one of which was the Healthy Lands Initiative.

- The USGS is within the U.S. Department of the Interior, but USGS does not manage lands, does not regulate, and does not enforce laws. The bureau comprises four primary divisions: Water Resources, Biological Resources, Geology, and Geography. A fifth discipline deals with geospatial information and data management. Representatives from all of those science disciplines, and key representatives from all the funded agencies, are involved with this WLCI conference.

- The hope is that this workshop will give WLCI committee members a sense of the interest and passion that participants have for the issues.

- There are acute issues in Wyoming, specifically the Green River Basin, which will be addressed through the WLCI.

\section{John Emmerich, Deputy Director of the Wyoming Game and Fish Department (WYGFD), WLCI Introduction}

- How do we focus resources to enhance habitat? WLCI was conceived when this question was addressed for Wyoming and for the Nation. WLCI is a long-term, science-based effort to assess and enhance aquatic and terrestrial wildlife habitats at a landscape scale, while facilitating responsible development.

- An interdisciplinary, interagency partner approach to address these issues is needed. There has always been agency coordination, but this initiative will make that cooperation more effective and more wide ranging. WLCI will serve as a partnership model, especially at a local level.

- WLCI will be focused at a landscape level. To successfully support wildlife populations, recreational opportunities, and livestock use, habitats need to be maintained at the landscape level. But how do we achieve this goal? Is there sufficient support on a national and State level? All agency partners, from those that compose the steering committee to the National Park Service (NPS), the Natural Resources Conservation Service (NRCS), the Bureau of Land Management (BLM), the Wyoming Department of Environment Quality (WDEQ), the Wyoming State Land Board, the Jonah Interagency Mitigation and Reclamation Office, the University of Wyoming, local governments, nongovernmental organizations (NGOs) and others felt this was the right approach to address the landscape challenges southwest Wyoming is facing.

- The structure of the WLCI is organized around a Steering Committee, the Science and Technology Advisory Group, and the Coordination Team.

- WLCI has been developed in southwest Wyoming because, despite large changes in the region, many natural systems are still intact. Wyoming still has the same vertebrate species that were here 200 years ago. The area has grazing habitat and world-class wildlife that includes large populations of ungulates with long migrations between summer and winter ranges, it supports 1,400 agricultural operations, and it has important energy resources. 
- Large changes in the region come not only from energy development but are also driven by climate change, invasive species, drought, and urban development (especially in wildlife-crucial habitat).

- All that has been done so far is the development of a framework. The actual science plan is scheduled to be completed by early 2008 calendar year.

- By early 2008 calendar year, WLCI hopes to get the coordinating teams established; engage local partners to shape the specific objectives; and determine the final objectives. We need to decide what we want to see on the landscape. For example, what are the vegetation requirements needed to maintain wildlife habitat and grazing lands? What do we need to keep livestock operations viable?

- Finally, WLCI is a partnership, and it is the goal of the WLCI to reach the level of partnership that occurs when your partner represents your interests when you are not there.

\section{Frank D'Erchia, USGS, Workshop Goals}

- To acquire information and perspectives on the six management issues.

- Evaluate the cumulative effects of development activities in southwest Wyoming.

- Identify the key drivers of change.

- Identify condition and distribution of key wildlife species, habitat, and species habitat requirements.

- Evaluate wildlife and livestock responses to development.

- Develop an integrated inventory and monitoring strategy.

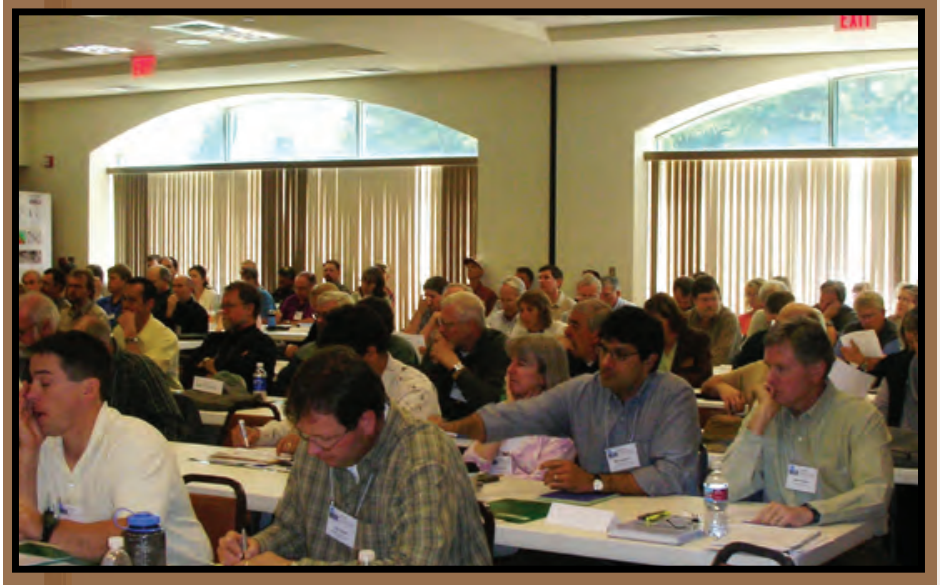

- Develop a data clearinghouse and informationmanagement framework.

- The next step is identifying the effects of these changes across the landscape. Changes and effects include benefits to local economies, meeting national energy needs, and effects to wildlife habitat.

- Then, the following task is to discuss the management issues in depth. The breakout sessions will allow identification of overlaps and details.

- Panel sessions will inform participants of the current (2007) state of knowledge, needs, and gaps and include audience ideas on how to address each of these six main issues.

- Breakout groups will allow for detailed discussion.

- The Science Plan will be written by the USGS science team and will be based on information provided at this workshop. Workshop participants will also be asked to review the resulting scienceplan document.

- The level of work that results will be a function of the budget, and that is unknown at the time of this meeting.

\section{Audience Questions and Comments}

- What about partnerships that involve public stakeholders beyond agencies? Not all of the stakeholders are represented here. How much public involvement will there be, and what is the plan for reporting to ensure accountability?

- At this point, the goal is to identify what science and research is needed, but we will identify next steps. A future workshop will be held to review what has been accomplished based on the plans.

- The advisory group has been formed. There is landowner representation on the advisory group, and it is planned that group will develop a model for including local groups. There is also a representative from each of the partners on the committee. 


\section{WLCI, Panel 1: Plenary and Breakout Sessions}

Plenary Session: Evaluate Cumulative Environmental Effects of Development Activities in Southwest Wyoming

\section{Panel Lead}

Mark Shasby, U.S. Geological Survey (USGS)

\section{Panelists}

Patricia Deibert, U.S. Fish and Wildlife Service (USFWS) Sharon Friedman, U.S. Forest Service (USFS)

Walt George, Bureau of Land Management (BLM), National

Project Manager in Cheyenne

Archie Reeve, Edge Environmental Consulting

Steve Tessmann, Wyoming Game and Fish Department

(WYGFD)

\section{Panel Presentations}

\section{Mark Shasby}

- Several years ago, the National Academy of Sciences conducted a 2-year cumulative-effects study of energy development on the North Slope of Alaska. The conclusion of the study was that there was not enough baseline data going back to the onset of development, nor an adequate, scientifically based inventory/monitoring and research program following development that would allow them to be able to make any statements regarding effects and change in the natural systems, or enable them to identify and quantify the drivers of change. Based on these conclusions, the USGS began a process of developing a strong collaborative science-based effort to try and understand the effects and interactions of development and a rapidly changing set of environmental conditions.

- With the WLCI, the USGS is again engaging in that type of process, and today (2007) is an opportunity to determine where we are in the process. We have assembled here a cross-section of panel members from Federal and State agencies and a private consultant to share their perspectives on cumulative effects as they relate to the WLCI. Then, during discussions following this presentation today and in Thursday's Breakout sessions, we hope to facilitate your inputs on what cumulative effects means to you and what needs to be considered in the design of a WLCI science plan that studies at cumulative effects. We are at the grassroots level of the science plan. We have brought five people together who are experts at working on cumulative effects. However, the format for this workshop was not to have it dominated by what we know; we want to hear what you know.

- Cumulative effects are the accumulation over time of the independent decisions and the development actions and their effects, positive and negative, on the physical, biotic, and human environments of the geographic region of interests.

- This is an organizing and integrating principle and a systems-oriented approach. It is designed to accumulate knowledge, and it is important to work together to envision a desired future state. Then, we can define metrics that enable us to adaptively manage to meet goals.

\section{Walt George}

- Regulations and guidance

- The Wildlife Chapter is planning aids for cumulative-effects assessment of oil and gas development.

- The Rocky Mountain Leadership Forum has created development scenarios and cumulativeeffects analyses.

- Evolution of cumulative analysis in the BLM

- Originally, BLM only studied the project area. Then a buffer surrounding the project area was also studied. Now, the BLM considers areas outside the project area but within the same resource (for example, watersheds, mule deer herd unit).

- Analysis is done by using the county's database. For wildlife effects, the BLM uses the herd units established by the WGFD. For water, soils, and other related resources, the topographic limit of the applicable watershed is used.

- Challenges of cumulative analysis

- Complex and confounding information leads to loss of focus regarding what is affected.

- Diverse agency objectives make collaboration difficult. 
- Effects often happen before there is time to collect and analyze data.

- The potential outcomes of future issues are complex, and the variety of projections about the future makes it difficult to determine project accuracy.

- Two broad paths

- There is a comprehensive and academic approach, geared toward amassing information.

- There is also a problem-solving approach using adaptive management.

\section{Patricia Deibert}

- Endangered Species Act (ESA)/WLCI discrepancy

- The ESA requires the USFWS to consider effects on individuals, but cumulative-effects analysis considers effects on whole species.

- Migratory Bird Treaty Act of 1917

- Requires consideration of whole species across political boundaries.

\section{- USFWS/WLCI}

- USFWS has the ability to enter into agreements with private landowners, and it is a USFWS focus to ensure they are protected. Cumulative effects need not jeopardize those agreements, but cumulative effects also must not interfere with landowners.

- Consultation effects

- Consideration needs to be given to how consultations affect species and regional populations. Consider cumulative effects of activities and the cumulative temporal effects: What happens when you remove a species for a while? When species move somewhere else, what effect does that have on the species in the new area?

- The effect of projects on fish and wildlife movement, population distribution, resource use, habitat quality, habitat quantity, and habitat availability all must be considered.

\section{Archie Reeve}

- Cumulative effect may be seen as a tyranny of small decisions.

- Many small decisions have been made without accountability or analysis and have accumulated over time, combined, and resulted in large effects.
These small decisions create direct effects (caused by the action and occurring at the same time) and indirect effects (caused by the action and are later in time or farther removed in distance but are still reasonably foreseeable). Indirect effects often affect habitat.

- Large decisions have been made and also have had effects.

- Is the cumulative effect to wildlife additive, synergistic, or antagonistic?

- Basically, it is starting with a resource level that is sufficient. Then slowly the effects occur until the resource decreases below some significant threshold.

- How are thresholds of effect set? Is the threshold biological, social, cultural, or all of these?

- Mitigation is an attempt to get the population back up to the threshold value, whatever that may be.

\section{Steve Tessmann}

- The Council on Environmental Quality (CEQ) has found that existing data methods are incapable of determining cumulative effects.

- The speed of permit issuance for mineral development does not allow sufficient time for data analysis.

- There are three requirements to address knowledge and data gaps and create a good analysis.

- The scope of analysis needs to be defined. The CEQ regulations and U.S. Environmental Protection Agency (USEPA) offer guidelines for this. The scope needs to be ecologically meaningful; be scaled to the resources of concern; determine what ecological components are of concern; define appropriate landscape boundaries; and consider the breadth of analysis, including if previous activities will be considered, to what degree future actions will be considered, and how the analysis will be used to address on-theground actions.

- Sufficient baseline data are necessary, including a centralized and thorough data repository and baseline sampling.

- Wildlife population levels need to be determined. What is the right amount of development, and how much degradation can occur without adverse effects? 


\section{Mark Shasby}

- The current quality, accessibility, and extent of data are inadequate.

- Our science objectives are to identify gaps in knowledge that hinder the identification of cumulative effects and to develop a comprehensive inventory, monitoring, and research plan.

\section{Audience Questions and Comments}

\section{Comments and concerns about the cumulative effects approach}

- This is a modeling effort-numeric or a nonparametric model. All assumptions would have error bars. When bringing together errors, they are multiplicative. How does the precautionary principle play into this initiative?

- The principle of "do no harm" cannot be strictly applied here. Rather, we are seeking to minimize effects. Development is much denser than it used to be. The management practices used by the BLM 10 years ago are not adequate for today's challenges. The BLM's approach is to try to make reasoned decisions that can be adapted to make corrections if necessary.

- The WGFD tries to apply a spectrum of Best Management Practices (BMPs) to the extent possible. Also, mitigation occurs as we go when effects are unavoidable, rather than worrying about theoretical thresholds before being allowed to mitigate.

- Cumulative effects are a series of pluses and minuses. There will be offsets in this location because there is world-class wildlife and world-class energy. We need a measure of what is happening out there as a result of the initiative. In order to do that, a big-picture look at the landscape needs to be available.

- Cumulative effects are not a primary objective here, and these effects will be understood by doing these other areas of research. Effective monitoring and inventory will lead to identification and understanding of trends. Causes and effects then can be determined. This is a background concept, but the immediate focus needs to be on baseline information and trends to ensure viability of wildlife resources.
- The definition of cumulative effects needs to include the positive and beneficial effects of our work in southwest Wyoming. Measures are needed to describe why a proposed project on the ground would be worthwhile in a cumulative-effects perspective. Enthusiasm for a cumulative-effects approach has not often been expressed.

- To know where you are going, you need to look backwards. Consider the evolution of an oilfield. Oil companies were key players early on, but then they sold to small independents. Concurrently, there was a decline in resources to do adequate operation and maintenance and a decline in environmental compliance. That change needs to be considered for cumulative effects. What happens when the bigger companies are no longer in the Upper Green? How will smaller companies deal with restoration and mitigation?

- As an approach, why have cumulative-effects analyses not worked? We need to look at the full body of knowledge, and instead of reinventing what we already do, we need to focus on what has worked in the past (when, where, and why) to determine how we can make this research credible, relevant, and durable. Consideration needs to be given to the deeper issue of sustainability — capacity of the land, capabilities to even identify cumulative effects, and communication to ensure long-term success (changing public values through education and leadership).

\section{Differences between agencies}

- Understanding cumulative effects is important, but getting there is difficult. Different agencies have different jurisdictions and mandates. Has anyone considered how to deal with cross-jurisdictional boundaries?

- There will be stumbling blocks with individual agencies and agency plans. Agency personnel need to think about how cumulative-effects analysis can be done differently in their own agencies.

- There is dichotomy among agencies (visible on this panel), and there is a need for clarification of "the question." Is analysis comprehensive or focused? Do we need a landscape or ecosystem focus? Is the question "what is the effect on sage-grouse or ranchers?" 
- There is tension between practical and the longer term strategic research. If the components of the system are unknown, only a partially correct tactical answer can be provided. Some longer term research may be needed before answering more applied questions.

- Given the limited resources available, narrow kinds of questions need to be focused on to inform management.

\section{Transition to on-the-ground, adaptive management}

- What population threshold for mule deer is acceptable? How do we select threshold values, and what do we do as we approach thresholds? From an adaptive management perspective, this is the kind of information needed.

- Basically, "what is the value of wildlife?" and "at what level?" The threshold may be established by Population Viability Analysis (PVA) and a vote. Is mitigation possible once avoidance of effect is impossible? Establishing the value of the wildlife resource, especially in juxtaposition with other demands on the lands, needs to happen first.

- Do not collect data that do not influence onsite work. Products need to be simple, durable, and understandable by managers and stakeholders.

\section{Data needs}

- Baseline information is lacking. Population status information for some game species exists, but there are major data gaps.

- A key data need is a historic range of variability.

\section{Public involvement/human population}

- Most of the concepts presented were ecological and that was not satisfying. Will people want to live and work on these landscapes? How are we going to get that kind of input into our measures?

- We need to consider human values. However, as the WLCI is evolving, the size of the focus needs to be managed. It is a real issue, but it is an addition to the list.

- Cumulative effects need to be defined in a way that the public can understand. Public buy-in will be very important. For example, with regard to mule deer, how do we relate that to wolves, haystacks, or hunting pressure?

- Cumulative effects are not the ends themselves. First, landscapes need to be defined, and that definition needs to be something that scientists and the public can understand. Numerical and modeling outputs are exciting to scientists but maybe we need to communicate a more qualitative perspective to citizens.

\section{Additional comments}

- What about ecological services? Will their role and their interaction with cumulative effects be evaluated?

- Evaluation is part of a more theoretical modeling approach. Finding a balance between on-theground research and a theoretical approach is necessary.

- Ecosystem Services are more important than just a model spin. In Europe, they are adopting the Millennium Assessment. "Ecological services" provides a positive spin.

- Dealing with energy development, we came up with criteria or a filter of funding, accountability, coordination and science. This same filter needs to be used here.

- What kind of effect do you hope a given project will have? Cumulatively, what are you trying to domove a migration corridor?

- What are the odds that funding will be in place for 10 years? We need ranchers, NGOs, and county commissioners to understand this and buy-in.

- If a project is informing decisionmaking agencies, then the project is appropriate, but if not, it belongs to academia.

- What are the research and monitoring projects that would address some of the questions discussed here?

- Specific research projects would be what is studied by other panels; this panel is focused on the conceptual stage. 


\section{WLCI, Panel 1: Plenary and Breakout Sessions}

\section{Breakout Session: Evaluate Cumulative Effects of Development Activities in Southwest Wyoming}

The group began with a general discussion of how to define cumulative effects and appropriate expectations for WLCI. There are several definitions for cumulative effects, including a legal definition outlined in Federal Statutes. Rather than deciding on a particular definition, the group instead focused on the need for conceptual models and potential approaches for creating a set of nested models ranging from general and qualitative to more specific and quantifiable. A set of four, hierarchically ordered models was proposed within an adaptive management framework. The group also briefly outlined major data and other needs that are required for modeling cumulative effects.

\section{Importance of managing expectations}

- Mark Shasby outlined the administrative and funding structure of the WLCI. The USGS will aim for a subset of the budget for scientific assessments. There is uncertainty about what this science workshop represents. The organization is set up with an executive committee that is supported directly by the Science and Technical Advisory Committee (STAC). The core is underneath these two bodies. Scientific needs are identified by STAC. The WLCI and USGS science strategies will overlap, but the issues that will be outside of WLCI funding per se are the longer term, hard-core scientific goals of the USGS.

- Because of funding uncertainties and the various levels of administration, it is unclear how and where money will be available within WLCI.

\section{General discussion on the importance of cumulative effects}

- When considering cumulative effects, we have to think about "cumulative effects to what?" What can we possibly measure on the ground? Then what can we mitigate? What is the research on the ground to date (2007) showing? There are known responses by sage-grouse, mule deer, pronghorn, migratory birds, grassland and sagebrush obligates. This leads to considering population effects and the importance of considering life cycles. Limiting factors are an essential aspect. Setting thresholds may be problematic. A management rather than an academic approach is important.
- The measurement of population is very difficult. What is the context?

- Other important factors include considering the distribution of habitat.

- This means an inventory is important. Some inventory approaches are already done, for instance, critical winter range in western Wyoming.

- Understanding cumulative effects is important for applied and academic needs. It is important to understand systems and their components. What is the appropriate scope and breadth of conceptual models?

- The first step is to identify a management approach and a desired end product for the landscape. A desired state needs to be identified first.

- Desired states need to be identified for one issue at a time-for instance, sage-grouse. What are the effects of activities and management approaches compared to the effects from protected raptors? To evaluate cumulative effects requires that we know where we are going.

- It is impossible to model the system completely, so first we need to identify biomes, then critical species, and then determine the trends that we wish to change.

- Conceptual models need to identify (1) effects, (2) aspects of concern on the landscape, and (3) management plans or desired states.

- Energy development is the most important driver to be considered.

- On-the-ground results are needed quickly. What is the importance of 3 years of baseline data? Collecting baseline data needs to be balanced with some actual results.

\section{Potential modeling approaches}

- Hierarchical or nested models could be used to begin the study with a broad perspective and then focus on more specific issues and effects. Thus the models are initially general and become more specific in particular issues of concern. Start with a general perspective and then analyze the effects. 
- This would be a good approach for land management. It gives a good view that can also be used to identify issues that continue into the future. This is adaptive management through time.

- It is better to be fast and simple. Complexity leads to being bogged down. Instant gratification may be important. There is a need for actions on the ground.

- Two broad-spectrum model types could be considered, for instance, (1) populations within a specific ecotype, and (2) wildlife that occupies seasonal ranges that may or may not be limiting.

- Model 1 needs a habitat approach, and model 2 needs a components approach.

- There is a need for a baseline. This requires a catalogue of the factors that produce the effects, including human and natural issues. The former may be wide ranging.

- What are the ecotypes and critical species? It is not just wildlife because there are also agricultural interests. Agriculture is not represented in the group. This exemplifies the difficulty of multiple stressors that overlap, which does not allow for specific management options. If traffic is an issue, then it is possible to set management options. But this option needs to be related to objectives.

- Information needs include (1) basic information, including resources and uses, and (2) understanding how effective current (2007) management is, and what is the potential for changing management objectives.

- The possibility of obtaining models from other sources would save time. For example, the USGS sage model is very useful. It will be important to include a timeline of actions and management goals. The sage model has taken 2 years to develop, and at the fine level, it describes important drivers and allows for real actions that have management goals. For example, actions could include water extraction, land treatments, and fire suppression. They are working with existing data and use specific submodels.

- Regarding a timeline, WLCI work needs to be conducted concurrently rather than consecutively. Data collection can help drive model development. Monitoring and follow-up will be important.

- This type of approach is already used by agencies that deal with the National Environmental Policy Act (NEPA) and energy development.

- Cumulative-effects modeling as proposed here is not necessarily the same as would be used in a NEPA or
ESA approach. It is important to state that from the start this is not a NEPA assessment-it is a regional analysis. They are very different. Efforts need to be directed and have a goal.

- Although there are data needs, we need to avoid repetition of work already done. WLCI needs to build from these reports:

- Southwest Wyoming Resource Assessment

- CITF: Cumulative Impacts Task Force. This floundered, then became Green River Basin Advisory Group, and then became a Federal Advisory Committee Act (FACA) report with recommendations.

- The BLM range-program allotment assessments

- Wyoming Game and Fish herd assessments

- Natural history data

- Natural Resources Conservation Service soil inventory

- Within cumulative effects, should we consider economic or social factors?

- Social factors could be considered as drivers rather than components. It is important that effects are linked to the values that are related to natural resource issues.

\section{Specific data and other needs}

- The primary data need for cumulative-effects modeling is a set of desired future conditions and priorities for management

- There is a two-step proposal for doing this: (1) look at existing documentation, such as landmanagement plans that outline desired future conditions, and then (2) refine this information with stakeholder input.

- With this approach, it might be necessary to define a breakpoint or threshold for assessing whether desired future conditions are being achieved.

- The actual desired future condition needs to be broad rather than specific; numbers may be too problematic and lead to debates that cannot reach agreement.

- Baseline condition data/inventories.

- Availability, quantity, and quality of habitat and linkages.

- Continuous monitoring to test for effectiveness of treatments and changing baselines. 


\section{Milestones and timeline}

The group then identified a series of goals within cumulative-effects analysis. These goals then were grouped generally into short- and long-term objectives.

The discussion concluded with the group outlining a series of goals and general timelines.

Identify polygons on a map

Identify existing work and data

Define desired future states

Develop and review of broad conceptual models

Identify nested models

Start treatments

Refine high priority models

Update lower priority models

Update cumulative-effects approach (reflects development)

Update and refine models

Continue to update cumulative effects approach

Assess whether WLCI is working to achieve desired future states
SHORT-TERM

SHORT-TERM

LONG-TERM

SHORT-TERM

MIDTERM

MIDTERM

LONG-TERM

LONG-TERM

LONG-TERM

LONG-TERM

LONG-TERM

LONG-TERM

\section{Structure of the proposed nested model}

- Level 1: Broad conceptual model (improving understanding of broad habitat and ecosystem components)

- Descriptive, including components and stressors

- System models (for example, for aquatics, plants, livestock, and soils)

- Level 2: Ecotypes (to prioritize and focus on specific components of concern)

- Specific models

- High priority species (for example, mule deer)

- Criteria could focus on at-risk or degraded components

- Level 3: Causal network and management approach (on-the-ground action)

- Decisions and actions as vector drivers

- More specific modeling at the places where management can effect change

- Level 4: Refine treatments/adaptive management

- Use treatment outcomes to refine treatments and models. 


\section{WLCI, Panel 2: Plenary and Breakout Sessions}

\section{Plenary Session: Identify Key Drivers of Change}

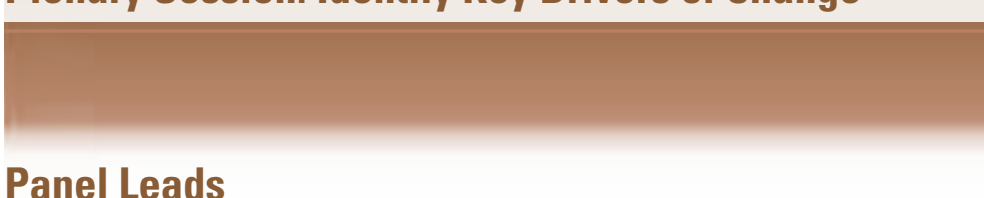

\section{Panel Leads}

Vito Nuccio (Chair), U.S. Geological Survey (USGS)

Warren Day (Co-Chair), USGS

\section{Panelists}

Jason Begger, Petroleum Association of Wyoming

Mark Hogan, Private Lands Coordinator, U.S. Fish and

Wildlife Service (USFWS)

Sarah Shafer, USGS

Vern Stelter, Wyoming Game and Fish Department (WYGFD)

Dean Stillwell, Bureau of Land Management (BLM)

Ron Surdam, Wyoming Geological Survey (WYGS)

\section{Panel Presentations}

\section{Vito Nuccio}

- Major drivers of change are energy development, population growth, and climate change.

- Energy development includes well pads, roads, pipelines, and other infrastructure.

- Population growth results in changes from roads, water supplies, building materials, waste facilities, and recreation.

- Climate change encompasses changes in current environments and the introduction of invasive species.

\section{Mark Hogan}

- Consider southwest Wyoming's trust resources. We need to work with threatened and endangered species, species of concern and other species within wetland and upland areas, and aquatic systems.

- Priority areas of concern are the occurrence of trust species/species of concern, private and public ownership patterns, habitat/land cover, partnership opportunities, tribal trust responsibilities, and refuge or unique lands.
- The WLCI partnership is important for agencies because it pools financial resources. The partnership is important for energy development because it creates a solid restoration plan up front. We need to ensure that when a field is designed, restoration is possible at the end (for instance, use the right hydrology, design better culverts).

- We need more information sharing and openness between industry and agencies.

- Consideration needs to be given to where we can do work to restore habitat that will not be developed down the line.

\section{Dean Stilwell}

- Oil and gas development tends to have the largest current (2007) and future effect on wildlife.

- Activity projections need to include where wells are likely to be drilled, what density of activity may occur, how many wells could be drilled, and what associated surface disturbance is expected.

- Management uses to be considered include questioning whether a management plan needs updating or revising; analyzing direct, indirect, and cumulative effects of activity; making leasing decisions balanced with management of other resources; and monitoring the effects of activity.

- A consideration of whether a management plan needs to be updated or revised then can occur.

\section{Vern Stelter}

- Two of the most important drivers are energy development and drought.

- Energy development today (2007) is unprecedented in history. The current energy developments in Wyoming encompass about 25 percent of the State's surface area. Substantial effects just from the development phase will occur for at least 2 or 3 decades. The pace of development is getting a lot of attention, but because of worldwide energy demands, the scale of development will continue regardless. 
- The drought is 6 years old and is causing substantial vegetation change in the State. By 2012, 85 percent of all conifer trees will be dead as a result of pine beetle kill if the drought continues as it has. Shrubland and grassland productivity is considerably reduced.

- Look to WLCI and similar initiatives to respond appropriately to these and other drivers.

\section{Sarah Shafer}

- There is a range of climate-change scenarios. Models are all simulating increases in temperature in the Western United States. The scenarios vary in the pattern of change that is predicted, but there is agreement among the models for the direction of change-warmer.

- This increase in temperature can be expected to affect the distribution of species, disturbance regimes, water resources, and land uses. There are various change models of climate relative to sagegrouse range. Variation occurs among the models, but all models show contraction of sage-grouse range. There is a similar situation with sagebrushall models show contraction of available sagebrush range given future climate change.

- These maps represent statistical modeling, so they do not include other factors like reproductive behavior and disturbance regimes. However, they do give some idea of the potential effects of climate change in the region.

- Needs

- Identify and constrain the uncertainties associated with future climate change. Given disagreements among models, how can we constrain uncertainties? Can we develop information at the right spatial and temporal scales for land management?

- Develop information on future climate changes at the temporal and spatial scales relevant for land management.

- We need additional monitoring and additional research to identify where and how quickly climate changes are occurring.

- Additional research on the sensitivities of ecosystems to climate change.

\section{Ron Surdam}

- Energy is the greatest driver in southwest Wyoming.
- We will have increasing pressure for developing oil and gas in the Rocky Mountains in the future.

- Wyoming oil production has leveled out recently because of Enhanced Oil Recovery (EOR) projects taken on by Anadarko and development in the Pinedale Anticline and Jonah.

- For coal, continued growth is expected.

- Gas wells will be drilled in the future. The number of wells drilled depends on completion of pipelines to get natural gas out of Wyoming and to the East.

- Wyoming is now the number one State for exporting energy; the State exports about 10 percent of the Nation's BTUs. Wyoming exports enough energy to fuel California's entire economy.

- Over half of State revenue generated by oil and gas comes from the Green River Basin. The State total is $\$ 1.2$ billion.

- The quest for more resource is resulting in closely spaced wells. (Jonah infill drilling could be as small as 5-acre spacing.) Although habitat would be grossly fragmented with this type of spacing, the development would be confined to 35,000 acres. Operators at the Jonah Infill project are willing to consider offsite mitigation.

- The very first carbon dioxide sequestration experiments may take place in the Greater Green River Basin.

\section{Jason Begger}

- Energy is a key driver of change in this State, but it is not the only driver.

- Drought is a huge driver of change. It is harder than energy on reclamation efforts and wildlife.

- Housing and economic development are important too. A housing site is about the same size as a well pad.

- The dense development in Jonah is the exceptiondevelopment is not that big a driver in most of Wyoming.

- Perspective is important. The developments are big but this is a big State.

- Leasing does not necessarily mean development.

- The conflict is not either energy development or wildlife. Energy companies are funding a lot of research. There will be no silver bullet. It will be a thousand little actions that add up to get us to where we want to go. The employees of the oil and gas industry are Wyoming 
citizens as well, and they are some of the biggest outdoorsman out there. They do not want to see irreversible changes to the landscape either.

\section{Questions for the Audience}

Identify the historical anthropogenic drivers of change in the basin. How will drivers increase or change in the future? What are the most important key drivers to study for restoration, conservation, and land management decisions?
- If we do nothing out there with the WLCI, invasive species will likely be one of the main agents of change. If maintenance of sagebrush habitat is the goal, we need to consider that.

- Think of conceptual models when considering drivers, and keep in mind inherent uncertainty, especially with regard to wildlife populations. It is easy to ignore high background variability in populations. If this is a short-lived process, the benefit will be an increased understanding of how to better manage human effects.

\section{Approaches to development, mitigation, and leasing}

\section{Identifying and considering drivers}

- The general economy of the State and the Nation is an important driver of the subdivision of ranches into ranchettes. Land is selling at 3 to 30 times production values, which will make it difficult to keep it in production, and agriculture is one of the best ways to protect habitat.

- The energy industry is the big driver of change in Wyoming.

- The pace of development is a driver. Are the agencies involved resigned to accepting the current (2007) pace of development? The BLM has the authority (and the obligation under adaptive management strategies) to consider pace. The Energy Policy Act does not supersede other environmental acts, such as the Endangered Species Act.

- Regarding the pace of development, it is difficult to control in a practical perspective. Right now, the ability of the BLM to turn out permits is determining the pace. Only so many rigs are available, and pipelines are at or near capacity, and both of these situations are controlling pace. But these are not logical, thought-out ways to control pace. Practical ways to better control pace need to be developed.

- There is a need to better recognize the external drivers that have an effect, for instance, Wasatch Range inputs to air quality and downstream energy user demands.

- There is also a need to consider other things within the broader topic of energy development, such as invasive species, contaminants, and other factors.

For instance, if roads are the issue, more than the whole road needs to be considered: other considerations include the edge of the road and movement of invasive species.
- Areas that have already been leased need not be excluded from consideration, because if leasing patterns are analyzed, the Upper Green River Valley is basically all leased. The public also is not going to agree with discounting leased areas.

- Areas that have the very highest wildlife values need to be protected. Full-field development can be modified to maintain wildlife, and phased development (only a percentage of landscape is allowed to go to full-field development at any given time) can also be considered.

- The U.S. Forest Service (USFS) offers a model for leasing, in how it leases forest resources. meets its management goals.

- A more active approach is needed rather than being subjected to geologic and economic phenomena.

- There is a temporal component and a spatial component. Energy development is not a temporary use of the land. What are examples of full reclamation of fullfield developments in the State? Habitat fragmentation associated with oil and gas development does not go away once the development is gone. The roads, traffic, and human activity may remain even after the wells are gone.

- There is a need for a change in perception effects. There needs to be an opportunity at the management level to look for change. Development is allowed by the USFS in a way that as to what can actually be done to mitigate 


\section{Information Needs}

- There is a need to know where we are headed beyond a decade or so.

- It is difficult to look beyond 2020. The oil and gas industry is pretty dynamic. Only 15 years ago, there was not much going on in southwest Wyoming. There is no good answer on how to project further out than 15 to 20 years.

- By 2020, hopefully the Nation will have an energy policy.

- We need a "Manhattan Project" to figure out what to do about energy in this Nation.

- The price of crude oil is linked to stabilization of the Middle East, and energy will continue to be very expensive.

- A plan that integrates renewables is needed.

- Oil-shale technology will not be available by 2020. Oil-shale development also requires powerplants and water allocations just for oilshale development.

- We need to use technologies that are currently (2007) available.

- New ideas are needed to determine how to offset the effects of energy development. These will probably involve offsite mitigation

- Some people here may believe that the USGS does not need to study these issues for 10 years. There is already experience in Pinedale at working with operators to reduce activity in the mule-deer winter range. Reductions in activity allow deer to use areas that they were not using previously. We could make a lot of strides for specific Best Management Practices (BMPs) without researching these things to death.

- The mule deer data you mention was a USGS project when it started. It is an example of how the USGS science can benefit the management. We cannot just look at what is on the ground right now.

- Both things have to go on at the same time. There are existing data to work with, but at the same time the gaps will have to be identified in the science plan.

- We need to create a spatial and temporal map (scenario-based map) of where energy development is likely to occur in the study area. Market forces and other factors influence this, but the temporal and spatial scale is critical to understanding the effects of disturbances to wildlife. A lot of the on-the-ground work is occurring without data-we may have been enhancing habitat that in 5 years will become an energy field. We need scenarios that project to the years 2050 and 2070. How close are we to getting this information, and what are the impediments to getting this information?

- In the last 5 years in southwest Wyoming, the assessment necessary to create this type of map has begun.

- It is difficult to speculate where different resources will be developed. The Environmental Impact Statement (EIS) for oil-shale leasing is being produced at warp speed. This is a whole new force in the Green River Basin.

- Also, a play or an assessment unit can be a fairly large area. The USGS does not make assessments at the prospect level, which would probably be most helpful for wildlife studies. The USGS does not have the resources or the mandate to access at that scale although the industry does spend a lot of money to get down to that scale. The USGS can produce information on where, in a general way, energy production might occur in the future. The USGS are projecting 20 to 30 years, and this does not consider future technology breakthroughs.

- We need to determine areas where reclamation is actually working and apply those techniques elsewhere in Wyoming.

- The knowledge base for conceptual models needs to be improved.

- A lot of information sharing is needed. The scale of development makes the variety of issues considerable, and there is a need for more people to work on this.

- Vegetative succession and its history need to be considered; these have been a concern for some time. There is a need to take into account successional changes.

\section{Additional Comments}

- The WLCI's goal is to assess, maintain, and enhance habitats. The science plan is to compile the known information so that it can be used to identify the research needs and the gaps to improve management in the future.

- More needs to be said about social values and the uses of the landscape surrounding wildlife viewing.

- We have a unique opportunity now to protect wildlife.

- We are not at the starting point for dealing with energy effects. A lot of work is already being done in reclamation and mitigation. We need a lot of approaches to mitigation and reclamation and avoidance of effects. 


\section{WLCI, Panel 2: Plenary and Breakout Sessions}

\section{Breakout Session: Identify Key Drivers of Change}

The group began the session by identifying key drivers of change. There was overall agreement that energy development and climate change are the primary drivers. However, a lot of attention was paid to the different components of energy development-politics, money, industry, population growth, and economic growth were all identified as primary drivers. After identifying these drivers, the discussion focused on the concerns that stem from those drivers. From there, priority needs were discussed. Finally, the group identified existing resources that will aid the WLCI process.

\section{Introduction}

- Energy development is the key driver.

- The full phase of energy development includes abandonment at the end of extraction of old oil fields, old coal mines, underground lines, and iron ore.

- Does wildlife move back in after abandonment?

- Every species has different sensitivity levels to development; species may adapt, but with stress, susceptibility to disease increases.

- Once sage-grouse leks (mating grounds) are gone, they are gone. The same holds true for migration routes, which is why reintroduction is not working.

- Stressors need to be distinguished from the primary drivers.

- Roads and stressors that come with other drivers need to be considered.

- Clearer identification of drivers between stressors: if you identify the drivers, the chances of identifying a stressor increase.

- Identifying drivers and stressors helps determine what is important and what is not.

\section{Discussion}

Drivers

- Energy development is the main driver.

- Wyoming is energy friendly: The State has more energy development than other states, as evidenced by oil shale, close-spacing oil and gas wells, and coal-bed methane production.

- This includes coal-fired power from the southern Green River Basin, but also clean wind-generated energy.

- Natural resources are being mined on top of each other.

- The core drivers are attitudes and money.

- There is economic benefit and incentive in southwest Wyoming for energy development.

- Politics is a driver.

- Wyoming provides huge resources for the West. The United States has extra regional influences and is driving energy development. Policies of other states are also a big issue, because other states have a stake in our resources.

- Industry is a driver.

- Social values, recreation, and speculation (there are no large land areas) are also drivers.

- Another driver is the large demand on water supply, which is focused on the Green River Basin-water is being exported from there to Colorado.

- Wind is also a driver. As soon as wind energy can be transmitted, wind farms will increase. There are already 1,200 units along the Interstate- 80 corridor. 
- The pace of development is a huge concern. The BLM is overwhelmed by permitting. The regulations exist, and are great, but the enforcement is impacted by lack of personnel.

- Climate change is another primary driver.

- Consider economic growth and population growth as drivers.

- The 2007 reauthorization of the Farm Bill and the revisions it is facing are going to be a big driver.

\section{Concerns}

- Air quality

- Water quality

- Water produced from coal-bed methane development in creeks is changing aquatic environments.

- Water quantity

- Fragmentation of habitats and populations

- Sociological effect on communities: communities cannot keep pace with the energy development, cannot handle the amount of people, and cannot compete with the energy companies for employment.

- Wind farming has an effect on the landscape view, and indirectly on tourism.

- Wind also creates a habitat fragmentation issue - and the turbines require a lot of upkeep.

- Consider combining wind development with oil and gas fields that have already been developed for oil and gas.

- Climate change creates many stressors.

- Climate change can create drought.

- It changes habitat, disturbance regions, and the magnitude of fires.

Needs

- It alters the frequency of extreme events: freezing, droughts, and huge storms.

- Climate change affects agriculture.

- It changes water resources-the timing of snowmelt.

- It exacerbates water wars.

- It affects species.
- It affects recreation.

- The injection of carbon dioxide might make the lives of fields longer through enhanced recovery.

- It has a cultural effect: tribal resources, sense of place through attachment to the landscape.

- It creates a greater migratory need for birds and other wildlife in response to climate changeanimals used to go North-South, but now humans have crossed those routes.

- It can result in an increase in endangered species.

- Directly and indirectly (through drought) it results in an increase in disease-for wildlife and timber.

- Results in an increase in invasive species.

- Energy development itself contributes to climate change. What about addressing these concerns?

- Population increases and economic growth:

- They increase water demand.

- Trends and attitudes change over time.

- Population growth is not necessarily happening in cities but rather in rural areas.

- All Terrain Vehicles (ATVs) are part of this change - people become accustomed to the road, and it is hard to remove.

- Also, man camps. The need for temporary housing is clear, but in the middle of nowhere, temporary housing is affecting the landscape.

- Medical facilities and school systems are taxed and affected by growth.

- Growth creates roads, which can be dangerous because of the use of heavy equipment from energy development.
- Current activities and needs need to be identified.

- There is a lack of baseline studies.

- Example: Coal-bed methane-there is little knowledge concerning how much water is being produced.

- There is a lack of baseline studies concerning water. 
- Biological information is also lacking.

- WLCI and its partners need to identify indicator species and study them, and then use those studies to implement on-the-ground management.

- WLCI and partners need to consider selected species, such as sage-grouse and mule deer. If the sage-grouse become endangered, then there will be no energy development.

- Abiotic indicators, such as erosion, also are important.

- Baseline air data are also needed, not just dust, but also diesel fumes, ozone, and carbon dioxide emissions.

- Geochemistry baselines are missing.

- Land cover and land use historic baseline data are missing.

- What about getting baseline monitoring for climate change?

- Baselines for attitudes and values need to be considered.

- Strategic science needs to be considered.

- An example of strategic science is the annual hyperspectral imaging maps (high resolution).

- There is a need to set long-term goals.

- Resource assessments (oil and shale, for example).

- Ecological studies

- Setting priority questions:

- Where is oil and gas development going to be located?

- Does leasing of the whole basin mean development of the whole basin?

- Mitigation strategies need to be developed-must mitigation occur offsite?

- Completing many, many different kinds of assessments is necessary for success.

\section{Existing Resources}

- A lot of these studies are being done right now-what about data sharing? Accessing existing baselines is important.
- E-maps have been implemented to national coverage (EPA).

- Energy effect CD exists.

- Geologic maps and ground-water maps are available.

- The BLM has maps, land-use plans, and oil-andgas potential plans. Also, the BLM can provide Environmental Impact Statements.

- USFWS can offer wildlife surveys, habitat maps, and restoration techniques, but the scale is very small because it is covering mainly only refuge lands.

- WYGFD has many resources.

- Wyoming Oil and Gas Conservation has the best information on oil and gas in the State.

- The DEQ, WYGISC, WYNDD, TNC, and the Wyoming State Engineer's Office are also resources for information.

\section{Additional Comments}

- Another concern is agriculture and ethanol production. For every 1 gallon of ethanol generated in plants, 5 gallons of fuels are used.

- What about reclamation needs? What does it take in money and time? We need to ensure adequate funds are available for reclamation-inflation is a factor and it needs to be considered during funding appropriations.

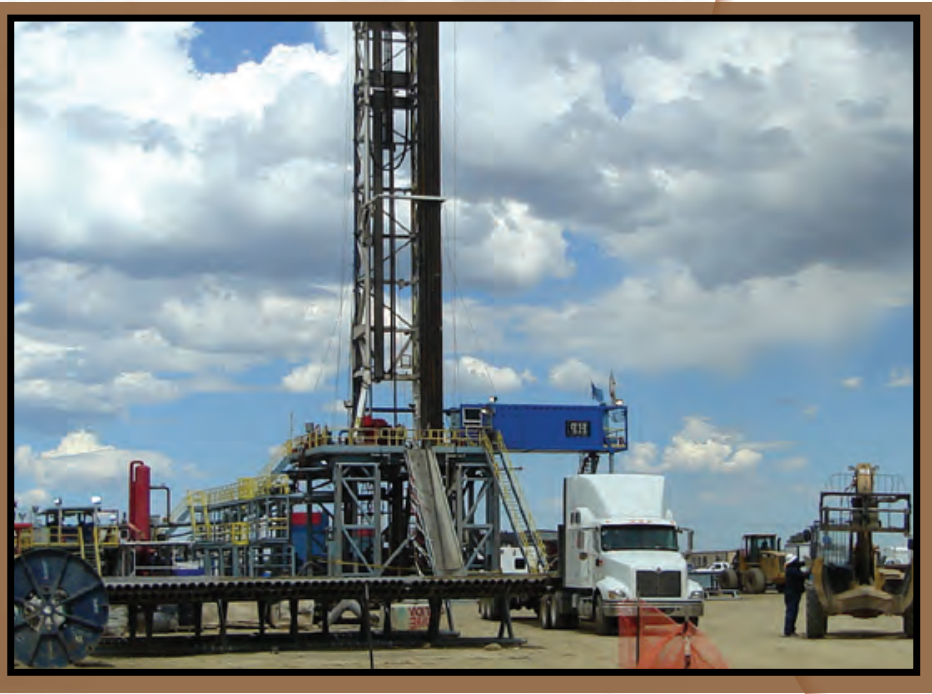




\section{WLCI, Panel 3: Plenary and Breakout Sessions}

\section{Plenary Session: Identify Condition and Distribution of Key Wildlife Species, Habitat, and Species Habitat Requirements}

\section{Panel Lead}

Zack Bowen, U.S Geological Survey (USGS)

\section{Panelists}

Gary Beauvais, Wyoming National Diversity Database (WYNDD)

Jack Butler, U.S. Forest Service (USFS)

Pat Deibert, U.S. Fish and Wildlife Service (USFWS)

Doug Keinath, WYNDD

Robb Keith, Wyoming Game and Fish Department (WYGFD)

Joe Kiesecker, The Nature Conservancy (TNC)

Bob Oakleaf, WYGFD

Brian Rutledge, Audubon Society

Dave Roberts, U.S. Bureau of Land Management (BLM)

Mark Rumble, USFS

Greg Watson, USFWS

\section{Panel Presentations}

\section{Objectives}

- To discuss the topic and learn from panel and meeting participants.

- To identify and begin to prioritize information needs, emphasizing the integration of existing work guiding potential research and technical assistance.

- To establish a list of points of contact for postworkshop coordination.

- This work will continue regardless of what comes out of this conference. However, it is important to get good information out of this conference.

\section{Three-Question Approach}

- What information do land managers need?

- What can science do?

- What information is the most important?
Dave Roberts

- What information do land managers need?

- To determine information needs, we need to identify perspectives of various users/functionaries. They all have different mandates and perspectives. These stakeholders include individual parties and individual landowners; non- or quasi-governmental organizations such as environmental organizations and land and resource trusts; and local, State, and Federal government agencies.

- The two basic information themes that are needed for effective wildlife-resource management are to clearly articulate management objectives and to create a common and universal terminology.

- Baseline wildlife-species information (terrestrial and aquatic)

- What species are going to be used for a baseline?

- Species distribution

- Species condition

- Species response to management

- Basic physical resource and habitat information (terrestrial and aquatic)

- What habitats are going to be used for a baseline?

- Habitat distribution and capability

- Habitat condition (effects and concerns)

- Habitat relations

- Habitat models

- We need to coordinate priorities of effort in the following areas (although coordinated efforts do not mean the same efforts):

- Topical

- Spatial

- Temporal 
- Environmental indicators

- Threats and risks

- Managerial experiments

- Need to develop and use models where appropriate, but refine them as the process continues.

- Information needs to be meaningful, usable, and accessible.

- Information storage and retrievable systems.

- Management feedback loops are important: we need to be able to use the information we gather in a meaningful way towards management.

- Scientific reviews and literature

- Technical concerns

- Public concerns

- Monitoring and evaluation of efforts

- Compliance

- Effectiveness

- The ultimate goal is to place some wildlife-resource management on the ground, which ensures the longterm survival and health of the wildlife populations.

\section{Gary Beauvais}

- What information is available? What information do we need?

- Information progression

- Presence/absence $\rightarrow$ environmental selection $\rightarrow$ abundance, density $\rightarrow$ reproduction, survival $\rightarrow$.

- In a dialogue between managers and scientists, we need to determine where we are on this information and data-gathering continuum.

- A spatially explicit population viability model parametenzed with local vital rates and highresolution environmental maps is ideal, but currently (2007) this cannot be attained.

- More precise terminology is necessary. There is a tendency to use range, habitat, and distribution interchangeably. For general conversation, this is ok, but the scientists need to know what mangers are asking for when they say they need a habitat or distribution map-one person's weed is another's critical forage.
- There are many lists of species of greatest concern in southwest Wyoming. Existing information includes lists from WYNDD, WYGFD, BLM, USFS, USFWS, Audubon Society, The Nature Conservancy (TNC), and others.

- However, the relative importance of species changes as the area of interest changes.

- To what degree does a given population in a study area contribute to the entire species as a whole?

- Finally, the degree of endemism is an important factor in ranking species.

- What about distribution, conditions, and habitat requirements?

- Existing information is extensive.

- Many distributions and conditions of important environments are mapped.

- Habitat modeling and use summaries have been done.

- However, many of the maps have been prepared based on the mapping agency's own perspective of hotspots.

- So why do we need more information?

- Legitimate information gaps do exist (species, species groups, environments; an example is invertebrate fauna, such as terrestrial insects).

- Data progression: we can always ask the next question and gain more and better data on complex ecological details.

- Existing information is often scattered, unorganized, inaccessible, and not summarized.

- It is important to provide for a data infrastructure that collects, organizes, summarizes, and disseminates existing information.

- Data maintenance is of primary importance. We need to break the cycle of building project specific databases, allowing them to lapse/end, and then rebuilding them.

\section{Doug Keinath}

-What information do we need to guide management?

- Examples of why information is needed:

- Of the species listed as having the highest conservation need by WYGFD, 279 are listed as highest conservation need, with 235 of those lacking 
information (examples of species where information is lacking are sage-grouse, northern goshawk, and the Wyoming pocket gopher).

- As habitat is mitigated for one species, it needs to be understood that many species have competing interests.

- Competing interests include development in relation to species scenarios and species in relation to species scenarios.

- The role of the WLCI is to filter the extensive data and ideas before us and synthesize them into something that informs adaptive management, focusing on specific outcomes.

- These questions will help answer whether the WLCI is doing the right science:

- What do we know and what do we assume?

- What do we know compared to what we need to know for conservation?

- How do we prioritize species, landscapes, and actions?

- How much do we do because we can do it, or because it is easy, rather than because it is the right thing to do?

\section{Audience Questions and Comments}

\section{Existing Information and Information Needs:}

- What examples of synthesis products exist and how do we proceed?

- The USFS Region 2 just finished a state of knowledge assessment on species of concern. They wanted as much information as possible synthesized into one document. These are good documents and do provide a good state of the species. However, it takes time and money to do that, and as soon as those documents are published, they start to become outdated. The USFS is going to try to keep those documents updated by using appendixes. There is also a good assessment on goshawks. For some of the more rare or flamboyant species, more information is starting to come in.

- There is a huge need to organize all of this information. Many reports are contained in individual offices, and all of this information could be combined for common use in its entirety.
- Much has been said about individual species management but not much has been said about ecosystem health. WLCI needs to base a model on what NRCS does: start with a map of southwest Wyoming, collect baseline information about the area, and integrate the data. Mapping "hot" areas is priority, because that mapping will guide mitigation efforts.

- Have habitat evaluation procedures been considered to create a management tool to address the concerns of the previous speaker?

- Known points of occurrence for a species are taken and used to create a GIS map and create a larger model. Taking unprocessed data points of documented sightings and turning them into a predictive information map is a core part of the GAP and re-GAP analysis (processes used to fill in gaps in data) sponsored by the USGS. Also, it is recognized that management needs to occur at a systems level rather than at a species level-but again, precision in terminology is really important here. We cannot just state that, "this is poor rangeland and that is good rangeland" because those judgments are so species specific.

- A good set of models is available but WLCI needs to test, validate, and improve these. It is also important to understand how species respond to the wide variety of habitats that exist. Management pushes us to consider one type of ecosystem based on agriculture or forest needs. Unless some species must be addressed by legal requirements or need, things ought to be mapped on an ecological scale so a broad approach can be taken.

- From a different perspective, there are two visible data gaps. Data come in two categories of questions: where and what. We focus on the where questions. We know we can answer these where questions, although the answers could be more defined. After we answer the "where" questions, however, then come the "what" questions: what do we do? The "what" questions are the key priority questions, the areas where we have the largest gaps. TNC is looking to capture the full range of biodiversity.

- This group does not need to focus on ecosystem function and processes, but instead needs to address immediate concerns. However, process and system needs are key questions. The Western Governors' Association is starting to consider creating a longterm sagebrush station. It is important to focus on two narrow classifications of species: indicator species and 
umbrella species (if we protect indicator and umbrella species, we also protect all species that use a certain habitat or provide coverage).

- What kind of soils data do you have with WYNDD? A connection needs to be made to the belowground ecosystem.

- There are three main programs at WYNDD: zoology, vegetation ecology, and rare-plant botany. WYNDD botanists have identified the lack of good soils information. WYNDD is often forced to rely on vegetation as an indicator of soil quality.

- Is an adequate data vetting or analysis in place?

- That is part of putting together these state-ofknowledge summaries. We take the wealth of data from different areas with different qualities and we have to derive a defensible synthesis in the end. There is no real technique for doing that. Someone has to do the synthesis, and someone has to review it.

\section{Methodology}

- As we start to get into the "what" part of the science, an adequate monitoring inventory needs to be taking place. A lot of inventory and monitoring is being done in different ways. When it comes to trying to evaluate WLCI project success, monitoring and inventorying need to be uniform or brought into sync. What are ways of standardizing terminology and methodology?

- The most pressing need is getting people to standardize monitoring approaches. New approaches are being developed, and there is a need for more.

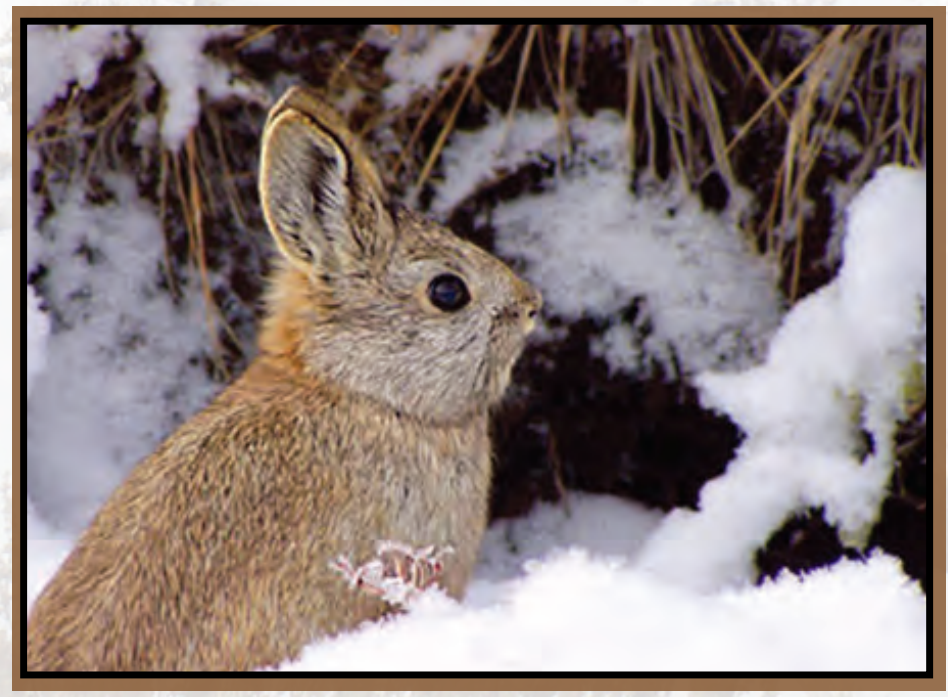

- Standardizing methodology is absolutely necessary, and this standardization needs to be done while a standard regime has been requested and the scientists are willing to follow it.

- More on standardization is needed to produce an outcome that is understandable to the people who are actually on the ground. However, consistency can be the opposite of innovation.

\section{Additional Comments}

- In Montana, a similar effort spent 5 years putting together a species-monitoring program through collaring animals and setting polygons for research areas. But over the last 2 years as protection was being requested, the polygons have been forced to shrink to accommodate energy development. The biggest planning polygon has been moved two times and has continually shrunk. Another polygon's habitat was burned, and coal-bed-methane water ponds are breeding mosquitoes that carry the West Nile Virus, which adds an elevated risk to these areas as well.

- Scientists should not guide the science and the information-managers and the public need to drive the debate and identify needs. Action cannot wait until the science is perfect because the time is just not available.

- At its conception, the WLCI was to do exactly that - take a data set and use the USGS GIS and TNC capabilities to study energy and wildlife resources and identify the areas that are not affected at this time and protect them.

- The focus needs to be on concrete things that can be done to ensure everything discussed happens.

- Most discussion has focused on terrestrial aspects. However, there is also a lot of aquatic habitat. Additionally, the amphibians and the reptiles have not been considered, and there is potential for those critters to disappear from the landscape without recognizing it has happened. Remember the animals that are not as easy to see. 


\section{WLCI, Panel 3: Plenary and Breakout Sessions}

\section{Breakout Session: Identify Conditions and Distribution of Key Wildlife Species, Habitat, and Species Habitat Requirements}

The Panel 3 break-out session began with a general introductory period when participants expressed their concerns and what they were hoping to address in the session or throughout the WLCI process in general. During this period, several critical needs emerged, including the necessity of focusing on immediate needs and placing longer-term research needs in a position of secondary importance; the need to compile existing data and create a baseline; the need to standardize methodologies; the need to assess current management strategies; and finally, the need to identify key indicator and umbrella species. As the discussion progressed, the group began considering the questions given the panel. Short-term needs, long-term needs, current activities that relate to the WLCI, and the most necessary science contributions were identified. To conclude, the group recommended the next steps the WLCI needs to take in this management area.

\section{Objectives:}

1. Frame priority science objectives.

2. Assess current (2007) management situations.

3. Add to science/technological information needs for the WLCI Science Plan.

\section{Questions from Panel 3}

4. What are the highest priority needs to be addressed in this management issue topic?

5. Which needs are short-term and which are long-term?

6. How does this management issue topic relate to others?

7. What current activities are you aware of that would contribute to the knowledge of this management issue?

8. What is the most important science contribution that could be made that would contribute to specific on-the-ground actions of this management issue?

\section{Introductions/Concerns/Brainstorming}

Needs

- Need to focus on immediate needs of the WLCI coordinating team and wildlife habitat.

- Need a comprehensive spatial analysis that gives direction and identifies important wildlife areas.

- Need to identify areas that will not be affected and focus on preserving those. To do this an inventory needs to be put in place on the ground.

- Need to combine all the data that are already out there.

- Reclamation needs to be discussed in the context of working with industry through the USGS to improve reclamation techniques.

- A key task is to develop a current status (although it may be too late for a baseline in the Green River Basin).

- The short-term science needs to be emphasized. The BLM has short-term needs throughout southwest Wyoming that cannot be done because of lack of funding. These short-term needs include soil surveys, forestry inventories, wildlife monitoring, bat inventories, and more. Even the WLCI money that BLM is receiving this year (2007), and next has not been directed toward inventory and monitoring. The BLM is authorizing a lot of things for use on the ground, and they need this information immediately.

- There is still an issue of information relative to effects. Several years ago when the sage-grouse issue began to arise, it became evident that as far as basic history and ecology, there was plenty of knowledge, but only a limited knowledge of the role effects played. Effects need to be a strong focus. 
- We have very limited knowledge for some species, such as on the Wyoming pocket gopher.

- We need to decide what the key wildlife species are.

- We need to remember how difficult reclamation work is.

- We need to remember the issues with drought and other nonenergy driven concerns.

- It is critically important to start to assess the effects of oil and gas development on wildlife, but equally important is to determine what some of the potentially positive changes are (tools for reclamation), and to consider these changes/tools first.

- There is a lack of methods for small mammal surveys (trying to identify a trend of response to oil and gas).

- There is a lack of herpetological surveys and fish surveys on the Blacksfork River, which contains sensitive fish species.

- We need to find out more information about the forbs.

- The data are there, the circles are on the map, and now we need to consider what management strategies and areas will give us the most bang for the buck.

- Colorado is a good model for native seed/vegetation development.

\section{Opportunities for partnership/compilation of existing data}

- The USGS Wyoming Cooperative Fish and Wildlife Unit will be involved in WLCI, providing assistance as needed to do the research on the ground. The Cooperative Unit has hired an academic research professional to focus on the sagebrush biome.

- WYNDD can help provide information about the data process now and later and can offer a lot of monitoring and inventorying expertise.

- The BLM offices could send copies of surveys to the natural history database.

- The BLM already has several treatments on the ground, and these can provide some quick answers from surveys of treatments. Between Kemmerer and Pinedale, there is a large and growing pygmy rabbit data compilation. Wyoming is a stronghold of pygmy rabbit populations as the range collapses- the same holds true for sage-grouse, sage sparrows, and other species that are historically peripheral and now (2007) are neoendemics.
- WYNDD focuses many of their efforts on gathering data about key wildlife species. It is difficult to become proactive (example: a Wyoming pocket gopher listing petition has come up, and there is a lack of information about it).

\section{Concerns}

- There is a lot of mitigation that is required as a result of oil and gas development, and duplicating mitigation efforts needs to be avoided. Instead, we need to take advantage of the situation and focus on helping the overall landscape, rather than reacting to effects alone.

- The key habitats have been identified, which provides a good starting point for focusing efforts. But how is the WLCI effort going to be staffed when onsite work begins? Many WLCI partners are short-staffed.

- There is a concern about species that are in danger elsewhere (Prebles meadow jumping mouse in Colorado)

- There may not be a lot of aquatic habitat in southwest Wyoming, but there are many aquatic issues.

- Native fish are in peril in lowland habitats.

- WLCI needs to be concerned with amphibians and reptiles, especially because there is limited training and time to help crews deal with those species in southwest Wyoming.

- We need to maintain the fauna that the area has, especially with animals like spadefish.

- Also, there are issues with the landmass's network of ephemeral, perennial drainages that are the lifeblood of that system-issues with the quantity and quality of the water. As development proceeds, Wyoming and the WLCI need to ensure the end result is not a dry channel. Because of legal water-use patterns, the Blacksfork goes dry in the Bridger Valley, and that is all that is supporting round-tail chubs.

- In the aquatic realm, there are also invasive species (examples are important sport fish; however, there are also nongame species that are hybridizing with native species).

- The aquatic system is the cohesion that sustains the ecosystem.

- There is concern with the offsite mitigation strategy: what can be done when so many areas are already leased? 
Models

- The USGS can take advantage of what TNC has done, but it must be recognized that the layers need to be improved, and it is only a framework.

- The Strategic Habitat Conservation Initiative (SHCI) has identified WLCI as a target for their program, which will analyze population objectives at a landscape scale, identify limiting factors, and adopt adaptive management to evaluate effectiveness of management. SHCI sees WLCI as a model.

\section{Additional Comments}

- The WLCI process need not be thought of as a linear process. There is an easily achievable goal such as preventing listing that can be prioritized at the same time that mechanisms are being developed. It is a circular, adaptive process.

- People's wish lists are too long. The science team will identify and set priorities, and people need to be aware that this will happen.

- How will the WLCI serve the Healthy Landscapes Initiative in the intermountain west? How does the WLCI's offsite mitigation strategy relate to the concept of conservation credit trading: Are there opportunities to offset effects and will an expert system be used?

\section{USGS Wrap-up}

- Healthy Lands Initiative includes/incorporates seven Western States, but the Secretary of the Interior is putting all of his science effort here in Wyoming because we are developing an approach that includes many stakeholders, and this approach can be exported to other places. We need to engage the local communities if we want to have success.

- The USGS did not start studies in the Green River Basin this year (2007). Stream gaging has been going on for more than a century, and geologic mapping has been ongoing for decades.

- However, although the USGS has been in southwest Wyoming for a long time, the effort has been small. In gearing up for this large initiative, USGS funds have been redirected into the Green River Basin.

- There is an immediate need. The first week in June 2007, USGS representatives were in Washington explaining why the 2008 Healthy Lands Initiative needed to be funded.
- The USGS is less concerned about long-term strategic science and more concerned with immediate needs and requirements. There is a definite need for shortterm science products. Drivers of change do require a longer term perspective, so the USGS needs to be mindful of balancing long-term science goals and issues and short-term tactical goals.

- The USGS wants to work closely with the university cooperative units program, other Federal agencies, the State of Wyoming, and the agricultural community. The USGS role is envisioned as being part of a partnership, including student involvement, not the USGS coming in and telling stakeholders what is to be done.

- Two final key concerns: communication of this effort to those who live in southwest Wyoming and to the outreach community needs to be addressed, as it is critical to communicate this initiative to the outside community. Finally, the WLCI link with industry is important, and one challenge is developing sound links with industry. We need to take advantage of the unpublished science that industry has been doing.

\section{Addressing Breakout Questions}

\section{Review of Key Panel Points, Zack Bowen}

- Collaboration on the WLCI Science Plan is key.

- This is a nonlinear process.

- BLM is redirecting funding

- USGS science effort

- Coming formation of committees to work with WLCI

- Providing a common set of ideas is important.

- The goal is to help create a template for the USGS science plan.

- Even if the initiative does not get funded, things will keep happening, and this document can serve many people.

\section{Highest Priority Needs, Zack Bowen}

- Involving multiple stakeholders

- Considering background work 
- Evaluating effects of mitigation and remediation

- Evaluating stipulations of Best Management Practices

- Mapping

- Anthropogenic features

- Habitat mapping

- Mapping of key wildlife-species

- What are they?

- Where are they?

- What is the identification framework?

- Who are the key players?

- State agencies

- WYNDD

- the U.S. Department of Agriculture

- and others

- Previous ecoregion map: ecoregional assessment for shrublands

- Will serve as foundation for WLCI map

- Does not include riparian areas.

\section{What are the highest priority needs and how are they identified?}

- Compile/Assimilate all existing information and data in the next several months

- Hold a meeting in Rock Springs with those behind existing assessments and the onsite personnel.

- Identify priority areas (put circles on the map)

- Start identifying key indicators

- Create a framework for a plan that will:

- Address knowledge gaps

- Collect baseline information

- Identify what projects are already happening and where

- Identify work that is happening in the private realm.

- Identify key indicators

- Inform management
- Create protocols

- Standardize techniques

- Enhance methods

- Identify causal relations of effects onsite

- Develop management-oriented science (as opposed to research-oriented science)

- Use applied research

- Consider reclamation

- Identify goals of reclamation (cattle? native vegetation?)

- Address priority needs

- Understand affected areas and extent of effect

- Assess and evaluate current management strategies

- For example, one of the management-objective research needs is evaluating sagebrush treatment needs

- Occur within a prioritized timeframe

What are short-term needs and what are long-term needs?

- Short-term

- Compilation of existing data

- Getting circles on the map

- Prioritizing needs

- Embarking on immediate managementoriented projects

- Long-term

- Considering current (2007) techniques

- For example, treating sagebrush

- Evaluating reclamation

- Creating a summary of data assimilation

\section{To what other issues does WLCI relate?}

- National Healthy Landscapes Initiative

- Agency Projects

- Strategic Habitat Conservation Initiative (SHCI) 


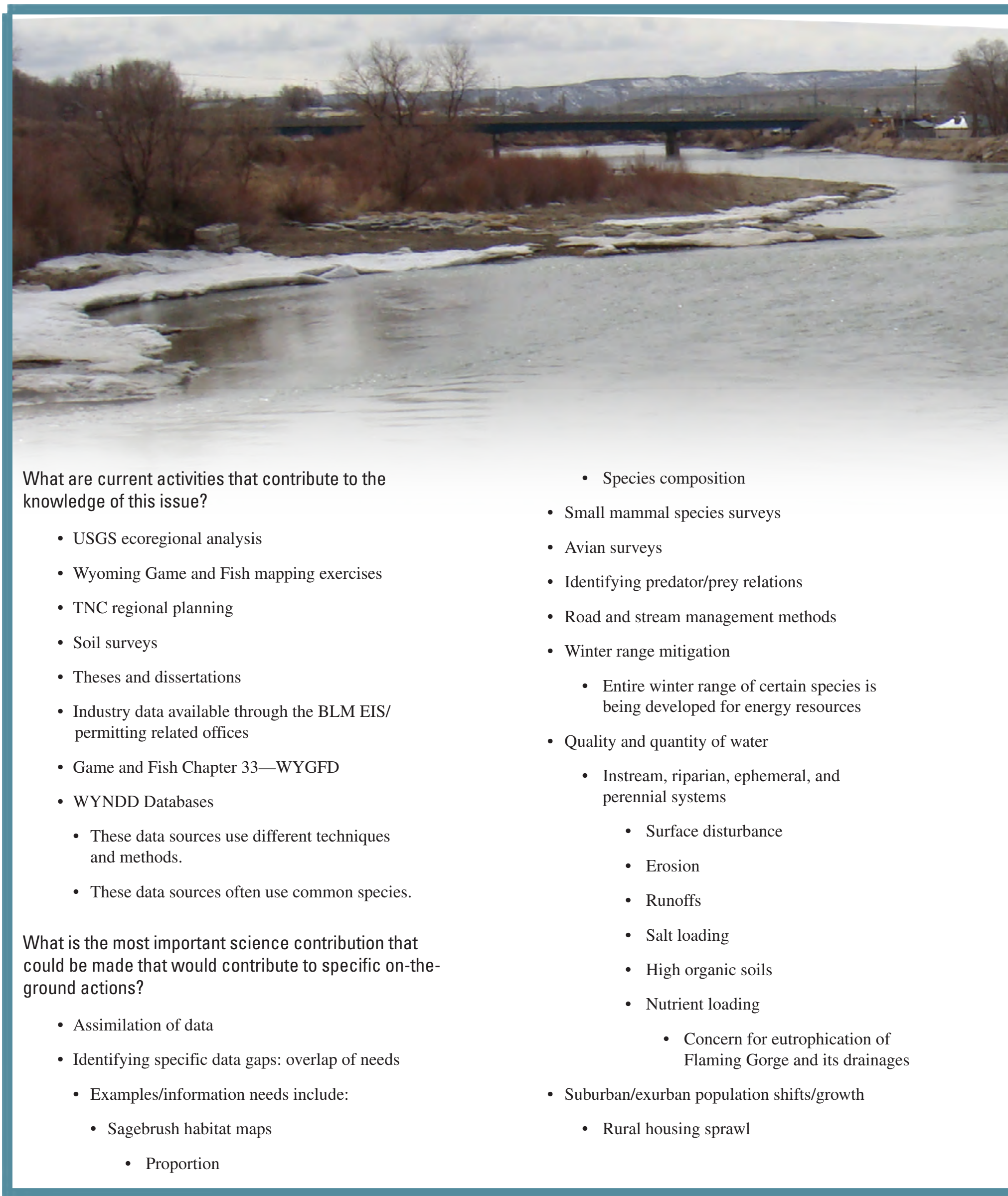




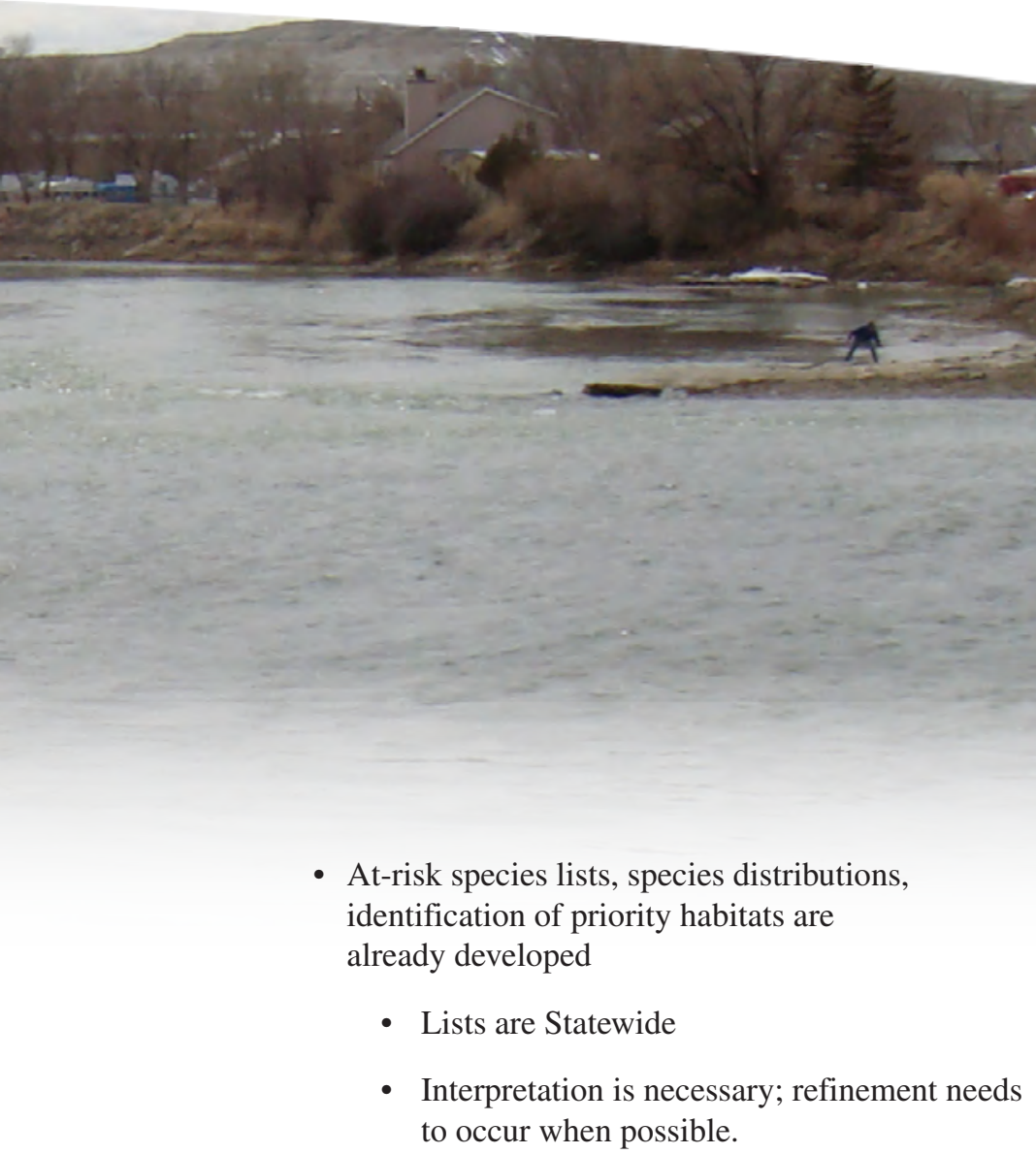

- Informing management

\section{Next Steps}

- Meet with people on the ground.

- Examine the circles that are already on the map:

- USGS ecoregional analysis

- Wyoming Game and Fish maps

- TNC regional planning

- Soil survey maps

- The USGS and TNC have processed the pertinent theses and dissertations, the BLM information, and the soil surveys. There is a need to compile and integrate those main efforts.

- Identify the key wildlife and habitat areas that WLCI wants to prioritize and focus on

- The need to categorize, rather than selecting only animals that are at risk (in order to gain public support).

- Identify knowledge gaps

\section{Final Notes}

- Need to set priorities.

- Need to remember the process of science.

- Everything is run through the executive committee.

- Data need to be assimilated for this process to be successful.

- Habitat assessment and management will occur with or without WLCI, but WLCI needs to help focus projects and provide direction.

- This process is going to take time, but it is time to start.

- Once objectives are identified, follow through is necessary to meet the overall objectives of the plan.

- Need to focus on where the energy information is most needed.

- At some point, a discussion about who is going to implement the selected strategies will be necessary.

- The WLCI is not intended to be a burden but rather a means to facilitate what is already going on and improve it. 


\section{WLCI, Panel 4: Plenary and Breakout Sessions}

\section{Plenary Session: Evaluating Wildlife and Livestock Responses to Development}

\section{Panel Lead}

Matthew Kauffman, U.S. Geological Survey (USGS), Wyoming Cooperative Fish and Wildlife Research Unit

\section{Panelists}

Dean Clause, Wyoming Game and Fish Department (WYGFD)

Pat Deibert, U.S. Fish and Wildlife Service (USFWS)

Niels Hansen, State Grazing Board

Rollie Sparrow, Theodore Roosevelt Conservation Partnership

Kevin Spence, WYGFD

Andy Warren, Bureau of Land Management (BLM)

\section{Panel Introductions}

- Key Wildlife Issues:

- We know very little about how energy development affects sensitive wildlife species (individual nutrition, behavior, demography, population).

- Key Livestock Issues:

- The effects of energy development on livestock and livestock systems need to be quantified (individual nutrition, behavior, management system).

\section{Dean Clause and Kevin Spence}

- Direct effects on wildlife from development include vegetation and habitat loss, water-quality and waterquantity changes resulting in habitat loss, habitat degradation, incidental mortalities (evaporation pits, fences), and fragmentation of habitats and populations.

- Indirect effects on wildlife from development include loss of vegetation and habitat due to avoidance from disturbance (traffic, noise, contaminants), increased stress levels from all types of disturbances, decreased population performance, increased interand intraspecies competition, and human population growth resulting in increased residential development, water-use demands, recreational use, fencing, traffic, noise, vehicle collisions, exploitation, urbanization, and population.
- Planning and land-management decisions:

- It is difficult to assess cumulative effects on wildlife and design mitigation and restoration without knowing where energy development will occur.

- Requires a commitment to long-term management to ensure successful habitat restoration and maintenance.

- Focus needs to be on crucial and irreplaceable habitats to sustain wildlife populations.

- Needs to be an ability to modify development activities to sustain wildlife habitat function as new information becomes available - the adaptive management concept.

- Habitat protection, reclamation, restoration, and enhancement:

- It is difficult to successfully reclaim native vegetation in low precipitation areas and under the threat of exotic plant invasion.

- Need to recognize that vegetation treatments are merely the initial habitat improvement action and that the benefits may not be fully realized by wildlife for several decades.

- Livestock, wildlife, and feral horses may impede implementation and success of reclamation, restoration, and enhancement efforts.

- Habitat condition, fragmentation and competition:

- Lands disturbed by energy development cannot be expected to continue to support the same numbers of livestock and wildlife on less acres of available forage.

- All parties need to be willing to institute temporary reduction in livestock and wildlife for mitigation and restoration efforts to be successful.

- Needs to be a willingness to adopt nontraditional grazing strategies, such as grassbanks, conservation easements, and temporary allotment buyouts.

- Wildlife data:

- More field data are needed to understand the distribution, population, and habitat needs of several 
aquatic and terrestrial wildlife species that inhabit southwest Wyoming.

- Wildlife mortality (illegal and incidental):

- Is the increasing human population associated with the energy boom affecting wildlife through illegal harvest and exploitation? Will increasing demand for recreation on public lands further threaten the condition of key habitats?

- Water quality, watershed function, and contamination:

- What are the cumulative effects of energydevelopment disturbances on watershed health and function?

- Effects of coal-bed-methane produced water on discharge stream system function/stability and aquatic wildlife species.

- Direct loss of flows in system-limited springs, seeps, and desert streams as a result of energydevelopment activities.

- There is increasing human population demand for municipal water equating to the construction of more dams and transbasin diversions. How can aquatic and terrestrial wildlife habitat effects be avoided or mitigated?

- More information is needed on the appropriate culverts for new road crossings on perennial and ephemeral drainages.

- Increasing energy-development activities increases the potential for chemical spills into streams.

\section{U.S. Fish and Wildlife Service}

- Recent research on sage-grouse and mule deer produced a database on those species and helped make inferences to other species with similar life histories and habitat usages.

- However, there are very little experimental data. Many species have been overlooked, including the olivebacked pocket mouse, the Intermountain wandering garter snake, and the California floater.

- There is a need to avoid more listing.

- We need accurate and relevant data-consider the WGFD Comprehensive Wildlife Comprehensive Strategy (July 2005).

- We need conservation agreements and partnerships.
- The challenge is to implement multiple-use management on reduced surface areas when basic life history and reactions of species are unknown.

\section{Rollie Sparrow}

- It is important to make this initiative relevant to the people who care about this area. No one in the public is coming forward to ask for protection of ecosystem functions or pocket gophers. Local stakeholders are interested in their deer herds, air-contamination issues, and viewsheds. We need to be able to tell people why dealing with landscapes and ecosystem function will protect their deer herds. We need to include human and social values.

- We need evidence that offsite mitigation works. There are a lot of management issues that would be addressed well through scientific frameworks. We need to measure, assess, and reevaluate. We could use this type of structured approach to understand offsite mitigation. Many years of sage-grouse and mule deer data have been given to decisionmakers, but the data have not been used.

- Adaptive management is a rigorous process, but making management decisions based on monitoring is not yet happening.

\section{Neils Hansen}

- Wyoming livestock industry issues and concerns:

- Dust and weeds, including concerns with plant health and vigor, poisonous plants, respiratory issues, stress on lambs and calves leading to weaning issues, shortened life expediency, poor vegetation quality, and dust on plants exacerbating tooth wear.

- Indirect costs include the loss of safe zones and critical areas; the poor placement of roads near water sources; an inability to maintain rotation plans and grazing plans from cut fences, open gates, and poorly maintained cattle guards; and the inability of stock to use land in the winter because of impassable snowbanks left by snowplows.

- Direct economic loss includes: loss of Animal Unit Months (AUMs) to roads and locations, costing operators in lost value and cash flow; loss of critical pasture areas to fragmentation, which is no less serious to livestock than to wildlife, causing loss of trailing areas (migration routes), lambing, calving, and wintering groups; death loss and injuries from 
automobile collisions; death and loss from increased trash on roadsides and downwind roads, locations, staging areas and facilities; theft and vandalism of stock, equipment and facilities; and lost sheep when herders change vocation and begin to work oil and gas fields.

- You cannot separate the effects of oil and gas on livestock from the effects of oil and gas on wildlife. Habitat needs to be studied. It does not matter if you are talking about a migration corridor or a critical livestock trail. When the effects on animals are seen (conception rates, medical bills, weaning weights, and dust ammonia) and the same issues do not occur where there is no development, then there is an issue related to development.

- Livestock serve as an indicator species for what is happening to wildlife.

- Increased stress on animals results from activity, such as traffic. These stressors affect wildlife and livestock.

- The main differences between livestock and wildlife issues are mechanical and financial. In a livestock operation, when there are issues with calves, they bear the cost.

- Regarding mechanical issues, livestock owners manipulate everything possible, which means livestock can be used to improve the habitat for the wildlife. An example of where cattle were brought in to improve the range for elk was provided.

Andy Warren

- In the Rawlins area, about 95 percent of riparian areas are not on public land, and 75 percent of crucial winter range is not on public land.

- Reclamation is difficult. How can goals be reached when sources for native seed are not available for our precipitation zone?

- Dust issues need to be better addressed.

- Water is trapped in culverts below roads, which can cause gullification and can affect native species and exotics.

- Regarding exotics, some are almost unusable for sheep, and others are causing other issues.

- Areas north of Baggs are needed to take pressure off the winter ranges. There is a lack of connectivity between summer and winter ranges.
- There is a big need for GIS, and there is room for improvement.

- We want to map sage-grouse nesting habitat along with buffers around leks.

- Wild horses are on 10 to 15 percent of WLCI area, and strategies for maintaining a balance within these areas need to be considered. Within the last 5 years in Adobe Town, 3,000 horses have been documented even though the herd-size objective is 700 . There is a need for evaluating the effects of these horses on other species.

- Riparian effects were the subject of a conference 20 years ago. Today the topic is oil and gas. In 20 years from now will ATVs be the topic? The tip of the iceberg has barely been touched with that topic.

\section{Matt Kauffman}

- We need to quantify effects across a range of taxa and a range of development levels. We need to understand how the gradient of development affects demographics.

- On the livestock side, we need to quantify the effects felt by ranchers. There is also a need to quantify the economic costs when a rancher's allotments are developed for oil and gas.

- We need to integrate the science and management.

- Objectives for the discussion are to identify direct and indirect ways in which development affects wildlife and livestock and to develop a framework to prioritize research aimed at understanding and quantifying these effects.

\section{Audience Questions and Comments}

\section{Involving Multiple Stakeholders}

- Just presenting the data will not guarantee their use. With this science plan, it is critical to get the local stakeholders and the public involved and educated. Remember the selenium issue in Central Valley, California, which drew departmental-level interest as much as WLCI has? A great deal of science went into that, but the public and congressional attention spans were very short. The science continued, and as the clean-up phase was entered, the funding was gone. It is important to get the local stakeholders involved early on. Maybe the public can help collect some of that data. 
- There is a depth of experience on these panels. What advice do you have for successful information and technical transfer from science to management? How do we successfully communicate this and involve the public?

- Do not put this information in the Federal Register and hold a public meeting. With the deep involvement of agriculture and county commissioners, we need to involve agricultural extension.

- The goal is to disseminate the information quickly. Do not hold a meeting like this in Laramie to talk to a rancher in Rock Springs. The need is to go to where the ranchers are.

- We need to ensure that the research information that is produced addresses questions. Managers need to be engaged early and often and be asked what are the questions? This is a repetitive process that ensures data produced are immediately useful and available, not waiting for reports to be published.

\section{Technical Issues}

- A common theme throughout this conference is the effect of habitat fragmentation. There is a lot of work on different species to establish buffer zones around roads. This group could take all of the development out there and attach different buffers for different species to establish a footprint. At what well densities would you expect to lose different species from the landscape? The map shown last night was a really crude dataset. To what extent is there a dataset that shows roads and pipelines?

- A dataset is an important consideration. The inventory and monitoring panel will address that issue in the next session. As far as evaluating the indirect effects, there is probably need for some research on different individual species and taxonomic groups for quantifying those indirect effects.

- We have done multispecies models and have looked at threshold-density effects on species. Assessment of roads occurs is done by individual offices, but there is high inaccuracy in datasets. These are important issues, but they are not cheap and money is needed to acquire the data sources. The USGS is also working on species responses.

- The distance of the flight zone varies greatly by the stage of development. In early days of the drilling process, the effect on animals is greater. But elk near I-80 have had the opportunity to adapt to the disturbance until that disturbance changes in some way.

- The focus has been on strategies to collect species data and then use it on the ground. Is there another dimension of information that needs to be assembled? For example, a description of effective management techniques for reclamation, mitigation, habitat enhancement, and collateral effects on nonselected species?

- There is a project that began this year (2007) to study treatments put in place since the 1950s to evaluate the effects of these treatments on wildlife.

- These studies will be put into the feedback loop of adaptive management, which is why this is a 30 -year project. We need time to evaluate.

- Do not discount the ranch records mentioned as a tool for understanding direct and indirect effects on livestock. There is an abundance of data.

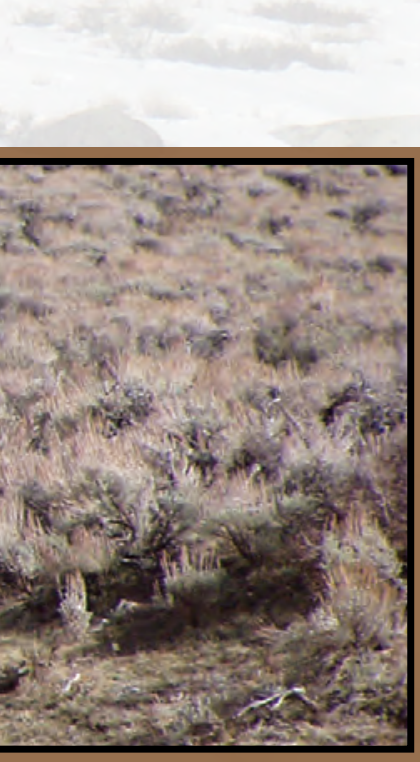




\section{WLCI, Panel 4: Plenary and Breakout Sessions}

\section{Breakout Session: Evaluating Wildlife and Livestock Responses to Development}

The group was asked to consider research priorities that evaluate the responses of wildlife and livestock to development. The group initially spent time discussing data gaps in livestock monitoring that could be put in place to better support the use of livestock as an indicator species for some big-game populations. The group felt that private landowners and ranchers are an untapped resource of information in determining development effects on livestock and wildlife. The group also discussed the direct and indirect effects of development on habitat and wildlife. From this list of effects, the group identified research needs, including some general cross-cutting needs, and a list of criteria to be used to prioritize research projects. The group concluded with a discussion on increasing public involvement in this process.

\section{Objectives}

- To identify indirect and direct ways energy affects wildlife and livestock.

- To develop a framework to prioritize research.

- To address how to access the performance of wildlife and livestock?

- To consider livestock, dust, forage quality, water, and the ability to manage and rotate livestock.

- To consider the disturbance influence on wildlife and livestock.

- The overarching goal is to identify research projects and determine how to quantify viable wildlife species populations because this requires extensive quantitative information.

\section{Concerns}

- Habitat loss associated with direct and indirect effects.

- Traffic and noise, the activity level associated with the areas of concern. Increased stress levels of animals.

- Disruption of migration corridors and dispersal of wildlife.

- Displacement distance.

- Population performance, wildlife and livestock. Reduced survival or individual performance.
- Water quality, timing and quantity, flow regimes.

- Concern about the effect of artificial light and dust.

\section{Needs/Questions}

- A GIS layer that represents trailing areas, lambing grounds, concentration of animals, and sensitive areas for agriculture would be useful. Gather information from all producers and collate seasonal distribution maps. Limit this effort to cattle, sheep, and wild horses. This information and maps would be applicable to rangeland management and water resources. Gather information by meeting with permittees. Radio collaring would be a viable piece of information if money is available.

- Better baseline information on vegetation and better grazing practices. Information is needed about grazing practices and how to shift the landscape back to bunch grass. Research on restoration techniques is needed.

- A study is needed to consider the effects that are present during construction of drilling and during maintenance of wells. At what level and intensity does energy development affect the wildlife?

- Identify of core areas of wildlife populations and how those areas can be connected.

- Determine what the effect of energy development is on migration corridors and what the threshold is.

- There is a data need to identify keystone species in this area, especially for amphibians and reptiles. The Great Basin gopher snake is an example.

- There is a need to investigate small keystone species and the effects of energy development.

- We need to determine what species are thriving, for example invasive species.

- What patterns of predation will result from energy development?

- Integration of information from on the ground managers to administrators is a primary need.

- We need to address the background information on past treatments and information in general before 
proceeding. How are we going to deal with the checkerboard area?

- We need to recognize different energy developments (coal-bed methane, deep wells, and wind farms), and consider the variability of each.

- We need to study not just energy development but also rural development. Water development projects could also affect this area.

- What is the ATV use in the basin? This is a major issue in restoration.

- We need to ensure that control areas are established.

\section{Intersecting Needs}

- Baseline data for livestock and wildlife. Gathering existing background information and fulfilling data gaps.

- Historical migration corridors.

- GIS layering for livestock concentrations.

- Other species distribution and habitat needs.

- Control or conservation areas needed for study, such as spatial and temporal areas of energy development.

\section{Priorities}

- Determining what grazing practices can enhance or improve habitat.

- Identifying how wildlife, livestock, and feral horses respond to the different types, stages, and features of development through time.

- Identifying species like umbrella or keystone species that, if managed, will sustain or enable conservation of other species.

- Determine the different patch-size needs and edge effects that influence the behavior, demography, and population growth of various species, including livestock.

\section{Direct effects}

- Vegetation and habitat loss

- Traffic, noise, and higher activity levels relates to animal stress.

- Fragmentation of migration corridors and species dispersal.
- Population performance

- Water quality, quantity, and flow regimes

- Light

- Dust

- Changes in overland hydrology

\section{Indirect effects}

- Disturbance avoidance

- Reduction in herd size or AUMs

- Animal stress

- Rural development

- Water demand and water development

- Population performance

- Roads and wells

\section{Criteria for setting priorities}

- Keeping in touch with public views and administrator needs.

- Strong, diverse, project partners and matching funds.

- Protecting and enhancing ecosystems. Once important thresholds are reached then proceed to project partners.

- Emphasizing onsite management.

- Build on existing data and information.

- Consideration of effects of study projects to landowners.

- Fill identified data gaps.

- Species urgency and habitat levels.

- Common benefits to all interests, with priority for projects that will benefit more species.

- Projects that have close coordination or multiple objectives and share this information.

\section{Public involvement}

- Going out to the public and reaching them at the local level.

- Education of the local landowner. 


\section{WLCI, Panel 5: Plenary and Breakout Sessions}

\section{Plenary Session: Inventory and Monitoring Strategy}

\section{Panel Leads}

Tom DiNardo, U.S. Geological Survey (USGS)

Pat Anderson, USGS

Myron Brooks, USGS

\section{Panelists}

Jim Cagney, Bureau of Land Management (BLM)

Dusty Perkins, National Park Service (NPS)

Cathy Purves, Trout Unlimited (TU)

Pete Ramirez, U.S. Fish and Wildlife Service (USFWS)

Lisa Reinhart, Wyoming Department of Agriculture (WYDA)

Dan Stroud, Wyoming Game and Fish Department (WYGFD)

Lowell Suring, U.S. Forest Service (USFS)

Dave Zafft, WYGFD

\section{Tom DiNardo}

- Panel objectives

- Inventory WLCI partner monitoring needs and requirements, ongoing efforts to identify data gaps, and inconsistencies and commonalities.

- Explore and articulate technology approaches and alternatives in order to collaboratively build a monitoring knowledge base for management decisionmaking.

- Begin the process to develop integrated monitoring strategies, approaches, protocols, and measures for the WLCI.

\section{Jim Cagney}

- Inventory and monitoring data need to be differentiated. Inventory is a process that samples and describes a population and describes the current status. Monitoring is a process where site-specific information is collected to measure the success of a specific action, measuring change over time.

- Goals and objectives have to go together. Goals are conceptual, and objectives are measurable.

- Characteristics include trend, utilization, actual use, and climate. Phases include design, data collection, and interpretation and analysis.
- It is difficult to differentiate climate effects from grazing-management effects.

- Funding. In the BLM, the most important thing is working with cooperators and having a lot of informal discussions. In the Piceance Basin, Colorado, the agency worked with drillers to plan for road closures when the hole is dry, ensuring that the road will not be there forever. However, the BLM is losing its field presence.

- Without monitoring, adaptive management is an empty promise.

- Projects need to have implemented strategies, and the projects need not be the strategies themselves.

- There is a valid concern that money will be available. Some of the money will be used for research, and the rest will be used for projects on the ground with no overhead. A lot of funding sources are available for projects but we are lacking informal discussions and monitoring. Time for project development is not the limiting factor.

\section{Dan Stroud}

- Aquatic concerns

- A variety of recent surveys in the Green River Watershed on distribution of fishes are available, but reptile and amphibian data are lacking and habitat associations.

- Altered hydrograph, change in water temperature, loss of habitat connectivity.

- Effects on water quality and quantity.

- Expansion of exotics like salt cedar.

- Urbanization, loss of historic floodplain habitats.

- WLCI nongame

- Monitoring occurs on five levels.

- Monitoring techniques need to be directly comparable to landscape-scale monitoring.

- Current (2007) efforts are in place for some Species of Greater Conservation Need (SGCN) in southwest Wyoming. 
- Past and current efforts to collect data could also be used for SGCN species in the future.

- Monitoring programs and techniques need to be based on data that are readily and currently available and are consistent throughout southwest Wyoming.

- WLCI Vegetation

- Prioritization of key species is needed.

- Data collection needs to occur within these habitats.

- There is a need to develop vegetation objectives and goals.

- Monitoring will occur to determine the outcome of these changes.

- Information needs

- Southwest Wyoming does not have a good baseline inventory, which is needed on the ground.

- However, before data collection begins, goals and objectives first need to be set. A complete inventory is not necessarily desirable.

- Specifics we do need include vegetation community types and health of those types.

- Existing data

- There are some good starting points. The Game and Fish Strategic Habitat Plan includes efforts for aquatic and terrestrial areas. The Wyoming Comprehensive Wildlife Conservation Strategy is available, as are land cover scales throughout southwest Wyoming.

- Habitats need to be assessed and improved on the ground. We need to begin with an assimilation of data and plans that are already available.

\section{Dusty Perkins}

- The National Park Service, Northern Colorado River Plateau Inventory and Monitoring Network has protocol established for integrated upland, integrated riparian, exotic plants, land birds, water quality, springs and seeps, aquatic invertebrates, land condition, land cover, land use, human demographics, air quality, and climate. It has designed a three-phase monitoring program.

- Phase I is park scoping and background work identifying key park resources and issues, summarizing existing information, developing an ecological context, and drafting conceptual models for major ecosystems.
- Phase II is identifying what to monitor across the network, which entails updating and expanding phase I work and the initial selection and prioritization of vital signs.

- Phase III is developing a full monitoring plan, including monitoring protocols, sampling designs, and a data-management plan. Finally, at the end of phase III there are 9 months of intensive peer review and then the final plan is implemented.

- Lessons learned: The importance of stakeholder support, getting the right indicators, maintaining communication in the early years of monitoring, and the value of concise informational summaries.

\section{Pete Ramirez}

- The EPA focuses mainly on human health effects of contaminants but USFWS focuses on the effects of contaminants on wildlife and fish health.

- When there is a contaminant issue some people expect to see a lot of dead birds, but with some effects, for example selenium, you do not see quantities of dead birds. Scavengers carry them off, or they survive the exposure and die somewhere else. There might be intergenerational effects, reproductive effects, but not always quantities of dead birds.

- Cumulative Effects:

- Reserve pits is one issue. More operators are using the closed system for drilling fluids now.

- Ground-water and soil contamination also are issues. Consider the geology first. Areas of potential coal-bed methane, some of which are on marine Cretaceous shales, can contain everything from arsenic to zinc to selenium. Commercial wastewater disposal of oil-field-produced water is also a concern because it is sometimes reinjected or is trucked to commercial disposal operations. Initially, it was thought that there was no issue if there was no oil in the ponds, but gas-produced water is more toxic than water produced from oil fields, because it has added chemicals for tracing. As wetlands are lost, birds see these artificial ponds and stop to rest. There are more and more oil spills as the infrastructure gets older (as seen in the Salt Creek field). Truck traffic increases as trucks are used to transport fluids to disposal sites. Pipelines could be used instead, but then there could be leaks and spills, and brine spills are very damaging to the landscape. 
- Air contamination is a big concern. If livestock are getting dust-induced pneumonia, what is happening to wildlife?

- Monitoring programs:

- Biomonitoring of environmental status and trends, fish monitoring, and a contaminant assessment program all might be helpful.

- Learning from past and ongoing programs about what works and what does not work is of primary importance.

- Involvement of local stakeholders and local public is very important. The BP Amoco refinery recovery in Casper used a collaborative process and it worked well.

\section{Cathy Purves}

- Trout Unlimited (TU) offers an NGO perspective. In 2004, the public lands initiative was established mainly because of accelerated mineral development. We had a three-phase plan.

- The first phase was developing a two-prong approach of science in addition to public stakeholder involvement. The best available science, combined with the involvement of hunters and anglers, was used to identify key areas. We identified 12 areas. The two identified areas in Wyoming were the Upper Green and the Wyoming Range.

- The second phase, establishing principles for responsible oil and gas development, was hard to do. We created a visual spatial perspective of Game and Fish needs with social values of stakeholders-it was essentially a sportsmen/energy conservation plan.

- The Third phase was combining with the Conservation Science Index (CSI), with a goal of creating rigorous data layers and models. CSI is a tool for establishing priorities.

- There are gaps and needs.

- We need a good definition of responsible energy development.

- We need data from Federal and State agencies. There are big gaps in aquatic-habitat data, groundwater data, and ground-water and surface-water interactions.

- There is a need for better communication exchange, for an avenue for data exchange, and for opportunities to collaborate, including collaboration with industry.
- We need to consider long-term economic-value reality on the landscape and to consider how energy will affect the traditional economies of Wyoming in 20 or 30 years.

- Decisionmakers need to buy-in because our public addresses issues at a political level (the Coalition for the Wyoming Range is an example of this).

- TU creates opportunities for public users to be heard. It uses a spatial analysis plan to work with energy companies, State agencies, and Federal agencies. If used collectively, information can change regulations.

\section{Lisa Reinhart}

- The Jonah Interagency Office (JIO) is an interagency ground with the BLM, DEQ, WYGFD, and the WYDA. It provides adaptive-management recommendations to the BLM.

- What happens to data after collection? This is where the JIO fits in with the WLCI. A database is needed to analyze all the data being collected. Technology needs to be used to store, analyze, graph, and map all these data.

\section{Tom DiNardo}

- A summarization of the stated management need is development of an integrated inventory and monitoring strategy to evaluate management actions and rehabilitation treatments for adaptive management decisionmaking.

- A strategy is needed and the WLCI is capable of creating a strategy.

- The definition of monitoring is the collection and analysis of repeated observations or measurements to evaluate changes in the condition and progress toward meeting a management objective (Elzinga and others, 1988; Elzinga, C.L., Salzer, D.W., and Willoughby, J.W., 1998: Measuring and Monitoring Plant Populations; BLM/RS/ST-98/005+1730, Bureau of Land Management, Denver, Co). ]

Monitoring is a key part of what has been termed "adaptive management," in which monitoring measures progress toward or succeed at meeting an objective and provides the evidence for management change or continuation. Monitoring is a process that provides scientists, conservation managers, and technologists with feedback on the status of processes, models, populations, conditions, and treatments, which have 
been applied or are projected. Monitoring provides the feedback necessary for adaptive management. Specific individual occurrences, conditions, or items are receiving monitoring consideration by the WLCI.

- Monitoring ground- and surface-water quality and quantity, land treatments, status of species populations and habitat conditions-sage-grouse, sagebrush habitat.

- Monitoring the amount and type of human disturbance-increase of impervious surfaces, change in runoff and sedimentation transport and rates, and nutrients.

- Monitoring the effects of multiple uses on the landscape (wildlife range in relation to grazing in relation to human development).

- Identifying and monitoring unique and priority conservation targets on the WLCI landscape for condition, state-transition changes.

- Monitoring land status, land use, land cover and vegetation changes.

- Monitoring habitat conditions.

- Monitoring air quality.

- Monitoring status of restoration practices.

- Monitoring status and performance of aquatic communities.

- A key difference that the WLCI partnership can bring is to develop and implement a monitoringstrategy approach that combines and integrates individual agency inventory and monitoring efforts to assess the effects of natural processes, human actions, and conservation actions on the southwest Wyoming landscape.

- The integrating agent is technology and its application to this initiative.

- Finally, what future landscape the citizens of Wyoming desire needs to be considered. An objective of the WLCI could be to pursue modeling alternative Wyoming landscape scenarios that study multiple, predicative, land-use landscapes that balance the needs of world-class wildlife, rangeland grazing needs, energy, and other resources and human population development.
- The proposed process to do this is to model the alternatives; determine the management actions required to achieve the alternatives (restoration, reclamation, mitigation); determine the monitoring data requirements, protocols, and methods that are needed to ensure success; monitor the effectiveness of those actions; apply adaptive management to those strategies and adjust; essentially, adopt a 10 to 30 -year process designed to monitor progress toward a well-defined future landscape condition.

- Remote sensing, GIS, and principles from landscape ecology can be combined into a powerful approach for monitoring environmental quality over large regions. This approach supplements but does not replace finer scale monitoring. By using this approach, pattern indicators can be implemented - the real power of the landscape approach is quantifying changes and trends in large-scale patterns through time

- Considerable research remains to refine and test the landscape-monitoring approach. Many potential indicators can be proposed. However, multivariate analysis of available indicators shows that many of these are highly correlated. In addition, it will be necessary to test the sensitivity of indicators to measurement and classification errors before they become reliable measures of change.

\section{Audience Questions and Comments}

\section{Monitoring}

- There is importance in pretreatment monitoring. A lot of money is available for burning sagebrush, and if nesting habitat is limiting a sage-grouse population, there is no need to burn sagebrush. Pretreatment monitoring will help establish objectives to enhance offsite areas.

- Pretreatment monitoring needs to be part of the inventory.

While you are monitoring areas that are being affected, you also need to monitor areas that are not affected. For example, this could help to evaluate the influence of drought. Data need to be rigorous and collected with an eye toward hypothesis testing, even testing more than one hypothesis at once. 


\section{Offsite Mitigation}

- A focus on testing the hypothesis that this initiative is actually enhancing habitat and maintaining populations through offsite mitigation is important. The research can increase from that, but the starting point is measuring the effect of this initiative on this landscape.

- Monitoring takes on a lot of dimensions depending on the question. Cumulative effects have to start with a model of a system that will drive what will be monitored. Another dimension is the evaluation of actions and that is related, but quite different. A specific action will have indicators to evaluate how specific resources are responding to specific actions. Many think that monitoring is easy, but doing it with scientific credibility and reliability so it can withstand the test of time, to give a true evaluation of effects is difficult.

- The JIO has been used as an example of how the WLCI can work, so the office needs to tell us what is needed to improve what it does. Overall, funding is still not visible for positions on the ground to get things done and is instead available for the monitoring aspect. One aspect of the $\mathrm{JIO}$ is offsite mitigation, and it needs to be determined if the JIO had personnel collecting data onsite, would the office come up with more desirable projects?

- Some frustrations have been related to offsite mitigation. There have not been proactive efforts to identify areas on the ground, but progress is being made. The Nature Conservancy is paid to do priorities of areas, taking into account the development scenarios in southwest Wyoming.
The hope is that the JIO takes that information and does assessments in some of those areas. WLCI needs to be doing similar things in areas that are going to be developed. JIO success so far is reclamation criteria and associated monitoring strategy for reclamation criteria.

- There have been a lot of challenges. One is getting consensus on what is a good mitigation project. We need to proceed and start doing projects, followed by monitoring to determine what does work and then larger projects can be done.

- Determining what is needed for offsite mitigation is hard to do. Onsite, data are available from operators. Offsite, it is harder to determine what is going on and hopefully the WLCI can help with this.

\section{Additional Comments}

- Monitoring and other terms need to be defined. A lot of this seems like research (not just monitoring). Defining research and science might seem elementary but is important.

- There are different meanings for different terms.

- There is an applied research element in WLCI; the knowledge needs to be used as a basis for decisionmaking.

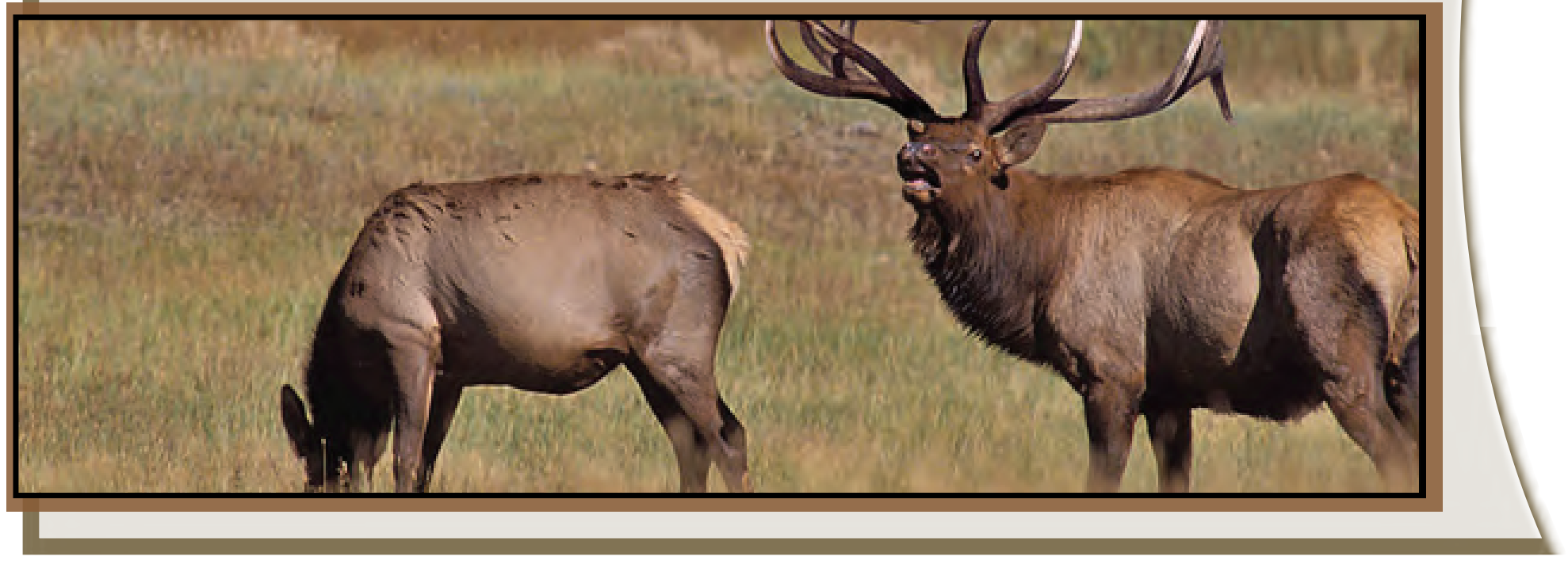




\section{WLCI, Panel 5: Plenary and Breakout Sessions}

\section{Breakout Session: Inventory and Monitoring Strategy}

The Panel 5 breakout session focused on inventory and monitoring. During the session, the conversation was organized around three overarching topic areas: needs and opportunities; strategies for addressing needs; and linkages, such as other initiatives, organizations, and management issue areas that overlap or connect with the WLCI.

\section{Needs and Opportunities}

- There is opportunity and a need to develop partnerships around monitoring.

- Using existing resources and efforts can be valuable for integration.

- Long-term funding sources are needed for monitoring.

- Ambient water-quality monitoring for surface water.

- An inventory needs to be taken to identify what is already known and where knowledge gaps exist.

- Identify baseline information needs for a science plan.

- Gather the necessary baseline information.

- Need to clarify and define "cumulative effects."

- The effectiveness of management needs to be evaluated.

- Develop a better framework for the issue.

- Understand regulations, legal issues, and limiting factors that are specific to this region.

- A joint vision will be necessary for monitoring success.

- Link with the baseline information for site-specific objective development. Information will be needed for the ongoing assessment needs and requirements.

- Prioritize habitats for inventorying and baseline data collection.

- Identify indicator, umbrella, or high-visibility species.

- Need to consider air monitoring.

- Need to consider social system factors.

- Need to inventory and monitor aquatic habitats, banner species, and vegetation condition/habitat condition.
- Need to document responses, actions, and damages to habitat from oil spills or other effects from oil and gas development.

- Need to create a long-term trust fund. In 30 years, the big oil operators/players will be gone, and those people dealing with smaller operators will not have the capital to deal with the clean-up.

- Develop an array of sampling sites to yield statistical information about the effects of development on these resources.

- Determine what conditions and change of human dimension need to be included as part of the process.

\section{Strategies for Addressing Needs}

- Clarify and better define terminology, including measures (metrics).

- Most agencies have old, archaic monitoring. Monitoring needs to be combined into one lexicon, however, all procedures cannot be standardized.

- Clarify objectives.

- Example: "To double the existing sage grouse population."

- Link monitoring activities to the clarified objectives.

- Baseline information collection has not yet taken place, but there is an opportunity to collectively take advantage of existing information and efforts to establish a baseline.

- Data collection needs to be coordinated and part of a strategic effort.

- Focus monitoring on indicator, umbrella, or highvisibility species.

- Avoid collecting unnecessary new information. Use existing data to help identify priority areas, priority species, priority status, and additional monitoring needs.

- Study other examples of regional and need-driven efforts to comprehensively assess and protect other regions. 


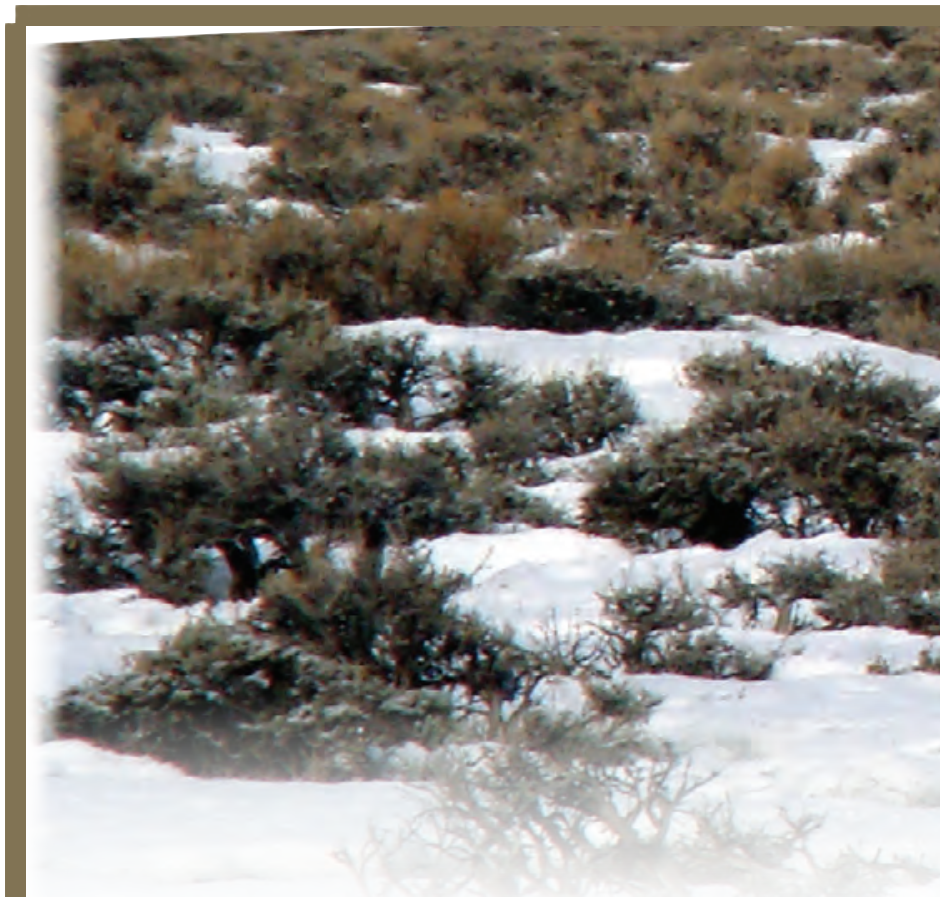

- Focus some monitoring on wildlife species to better understand the effect from disturbance or effects from management activities or both.

- Ensure that existing monitoring efforts add critical data fields that will be used to develop priorities (develop a prototype).

- Identify each agency's regulatory abilities.

- Create a "lessons learned" clearinghouse.

- Manage data on a daily basis.

- Identify who to pay and what to do. Need to ensure there is a staff with the ability to take on the workload.

- Without people on the ground, the projects planned with the WLCI are not going to happen.

- Recognize this is a landscape process, and monitoring needs to be selective-not everything that is monitored is important, or not everything is important enough to be monitored.

- Every agency needs to customize monitoring to address local issues.

- The fundamental strategy is to take preliminary information to make decisions on high-level priorities, and focus on monitoring and coordinating data collection strategically among partners, using the following steps:

- Involve all partners in parts of this.

- Identify partners and resources.
- Clarify terms.

- Define vision, objectives, and goals.

- Indicate what we have and know.

- Identify what is being collected.

- Define priorities.

- Define status of priorities.

- Define needs and gaps.

- Strategize coordination (including guidance to current efforts).

- Strategize how to organize and apply the data that exist and the new data to be input.

- Define protocol requirements, training, staff, and funding.

- Strategize funding and resources for implementation.

- Identify points of communication among managers.

- Focus always on avoidance, reclamation, mitigation, and enhancement.

- Link to on-the-ground actions.

\section{Linkages}

- Need to link with management area A, data management, to make both sets of objectives successful. Management area B needs to design what is engineered by management area $\mathrm{B}$. 


\section{WLCI, Panel 6: Plenary and Breakout Sessions}

\section{Plenary Discussion: Develop a Data Clearinghouse and Information Management Framework}

\section{Panel Lead}

Sky Bristol, U.S. Geological Survey (USGS)

\section{Panelists}

Gary Beauvais, Director, Wyoming Natural Diversity Database (WYNDD)

Dan Blake, U.S. Fish and Wildlife Service (USFWS)

Tom DiNardo, USGS

Jeff Hamerlinck, Director, Wyoming Geographic Information Science Center (WYGISC)

Larry Neasloney, Bureau of Land Management (BLM)

Kirk Nordyke, Wyoming Game and Fish Department

(WYGFD)

Barb Ray, USGS

\section{Jeff Hamerlinck}

- Regarding state-of-the-art geospatial capacity, there are a lot of data but less information and even less knowledge. Good base data layers exist for Wyoming as a whole. Thematic data are less strong because everyone has specific needs. WYGISC can support many different initiatives with GIS, remote sensing and image processing, and analysis and communicating results through visualization. WYGISC has worked collaboratively with many groups.

- Regarding technology, there is a need for more on-theground local capacity. Local planning offices and assessors could be the source of some information. This technology needs to be included. How well does this technology meet the needs of WLCI? There is merit to the academic, baseline approach in addition to the focused, issue-based approach that was discussed in yesterday's cumulative-effects session.

- Building a statewide spatial-data infrastructure includes data development and stewardship. This infrastructure includes framework data, land cover, and support for thematic specialists.

- WYGISC has done a lot of work in land-cover mapping, snow-cover mapping, and collaborative work with WYGFD and the BLM.

- Also heavily involved in decision-support applications, data integration, and access. Decision support goes beyond GIS and involves creating tools for more efficient and better decisionmaking. WYGISC worked with the USGS in the past, including on the Gap Analysis Program (http://www. gap.UIdaho.edu/, accessed April 4, 2008) (GAP) analysis.

- Also interested in working with local governments in helping them develop scenarios in light of energy development in the State.

- The Wyoming Energy Resources Information Clearinghouse (WERIC) represents a good model for multiple agency collaboration.

- The WYGISC data server is a current tool. It was designed for GIS professionals but also provides a nice display tool for non-GIS professionals. Recently, we tried to add some more sophisticated functionality.

- The Wyoming GeoLibrary is a geospatial collaboratory, a collaborative application or distributed system. Maintain stewards for that system. The data reside with and are maintained by the experts familiar with it. This results in shared access. People can find metadata about geospatial information. This is especially important for data that are proprietary or sensitive. People can just see metadata and then communicate directly with the data holder to receive data.

\section{Gary Beauvais}

- WYNDD is a service and research unit of the University of Wyoming that is dedicated to collection, interpretation, and dissemination of information on rare plants, rare animals, and important vegetation types in Wyoming. They do this to provide information to aid decisionmaking, and they do not influence how the information gets used. Products and services include maps of observation of rare species and vegetation types. Increasingly they are converting dot maps and extrapolating models across the region to produce predictive maps of species distributions. They also produce State-oriented abstracts and summaries of rare species. This is a state-of-knowledge product. Data are kept live and up-to-date. This is not difficult to do for rare plants, but it is harder to do for rare animals. 
- WYNDD staff does inventory, monitoring, and educational services, such as field classes. WYNDD data users generate over 120 data requests per year, in addition to over 300 informal data requests. Environmental consultants are the major source of requests. Other users are county governments, State agencies, and more. The organization has a 14-member advisory committee. WYNDD works a lot with WYGISC.

- For WLCI, WYNDD could be a source of data on rare animals, plants, and certain land cover types in the State. WYNDD is also interested in how WLCI data could be entered in the WYNDD database. WYNDD staff has done a lot of work inventorying and monitoring in southwest Wyoming.

- Regarding a natural resource data infrastructure, WYNDD could potentially be a component or member. We need to consider how to maintain a Web portal situation into the future. People want to pay for project-specific data but they do not want to pay for the upkeep and maintenance of databases. How is a system built that is a true infrastructure and that is maintained into the future?

\section{Sky Bristol}

- Sustainability is a huge issue in data management. It will be challenging to convert data from the ranching community into something that can be integrated into the project.

- Several data clearinghouses and individual databases are already in place ready for evaluation and potential use. The first task is to understand what those resources are-they include the WYGISC data server, the USGS National Oil Gas Assessment server, the BLM, oil and gas assessment data, and some landcover and species information. Other data are not readily available to the scientific community and adaptive management processes (species migration routes).

- Standards and frameworks do exist to make disparate systems interoperable.

- The WLCI can provide a focus to create a sustainable resource. A data clearinghouse needs to be simple and durable. We need to avoid re-creating the problem of developing data clearinghouses that are not maintained. What are the most valuable data to seek, and what incentives exist to get cross-agency focus for a single data source? Baseline data need to be iteratively gathered and established. State-ofknowledge summaries are absolutely valuable.
- Challenges and opportunities include using the FACTS filter (funding, accountability, coordination, transparency, and science); using a mix of strategic and tactical, comprehensive and adaptive strategies; using a baseline and a temporal scale; perpetuating a legacy; and using the WLCI as an agent for open sharing.

\section{Audience Questions and Comments}

\section{Data System Users}

- In meetings, U.S. Department of the Interior Secretary Kempthorne asked what exactly the money would produce for him and whether this data system would be useful to him and other decisionmakers. The other important group is the scientists. This is a good way for scientists to exchange data and share information. A third group is the public living in the Basin-making information relevant to them is a large part of the WLCI's goal. There is a lot of high-quality information but it has to make sense to the person on the landscape. The data have to be all things to all people. To be successful, local communities need to be involved.

- Examples of getting public involved with data collection:

- The "Did you feel it?" earthquake project.

- Public participation in identifying locations of invasive species.

- There is a need and a want to analyze existing data in a better way. It is time to start on the adaptive management process. Funding decisions are being made right now (2007) and short-term data and an informed science reaction are necessary, in addition to a longer term plan.

- The public expect data to be available to them digitally, and the public need to be engaged. The broader public is increasingly capable of doing its own data visualization.

- The USGS is taking the position that data needs to be available for multiple audiences. How should it get packaged? For instance, portals can connect the audience to the correct data.

- National Science Foundation (NSF) has created the National Ecology Observatory Network and other programs - these have not yet been considered (2007) as models but probably should be. 
- The expectations of the administrators need to be known. However, the audience could also be a private citizen, and there needs to be planning for that type of audience.

- The audiences are broad, but ultimately the data need to work for the decisionmakers and those data need to be as simple as possible.

- There is also a big education and outreach potential here. Who will deliver that?

- Technological tools need to be used to help select outreach and education for different groups of stakeholders to maximize their interaction.

\section{Data Protection}

- Electronic media can be flawed, as evidenced by the Cobell lawsuit, brownouts, and computer viruses. There is a need to ensure a nonelectronic aspect too, so that the information is still there if there is a problem.

- What kind of filters and protections will be put in place for some of the data that they do not want to get out to certain audiences? For instance, herpetology collectors might use the data to poach snakes for sale.

- It might be best in instances like that to point to metadata rather than produce the actual data. Ultimately, what is important is data ownershipwho owns and decides where the data need to go?

- An advantage of a distributed data system is that the data are maintained by the group of origin. WYNDD asked the legislature for permission to withhold point locations for some sensitive species and that permission was granted. Point locations are

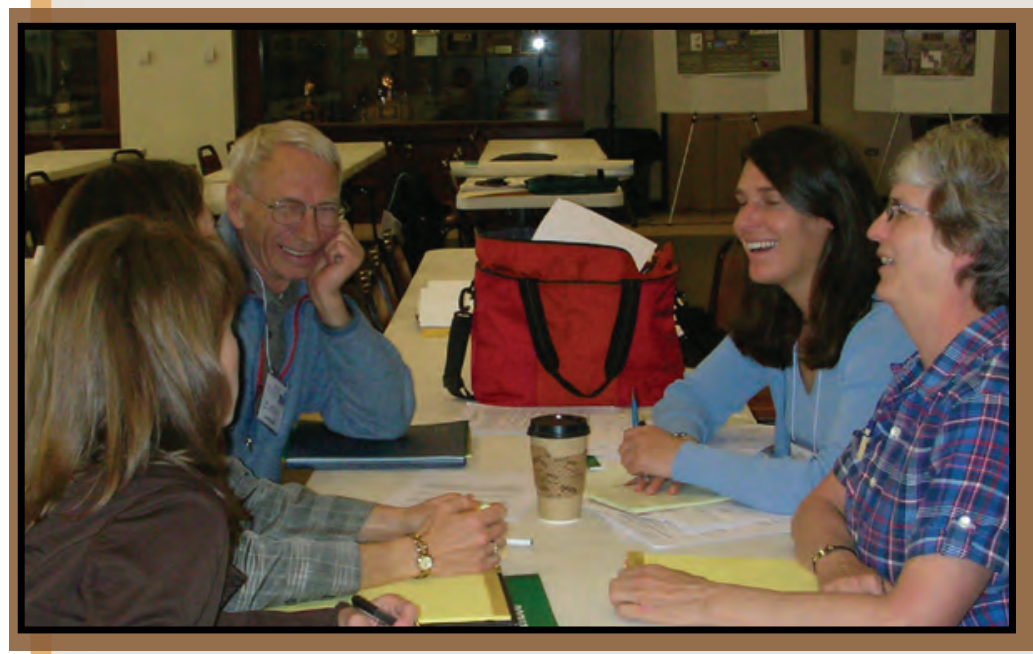

in the database but are only required to produce the township information. It is important to maintain security at the point of origin.

- There will be a need for some real assurances as to how data are going to be protected when they are turned in to the BLM. Our experience is that some data turned in to a Federal agency can be made available through the Freedom of Information Act.

- There are clear guidelines on what information can be protected. One of the strengths WLCI brings is that data collection can be approached from many different perspectives. The plan is to leverage the capabilities and supply resources to existing infrastructures.

\section{Additional Comments}

- Climate change in the national park and the Jonah Infill images are two striking geospatial data displays. These types of things need to be included in our daily work. The connection of WLCI with conditions on the ground needs to be demonstrated. To do this, a map with wells and sage-grouse leks could be created and then overlaid with the effects of a management action resulting from WLCI.

- Trust that people understand a map, because they do. For instance, maps have been a great way to demonstrate changing land uses with regard to open-space loss. Show the maps to the public.

- All the things that have already been done need to be tracked. For instance, human footprint work has already been done relative to sage-grouse habitat. How are we going to find all this information?

- State-of-knowledge summaries are essential for this. There is a lot of information out there. It takes effort to know what is known and what is not known.

- See www.wlci.gov (accessed April 4, 2008). It has a fact sheet and links to earlier work. WLCI really needs the focus that is provided by something like a centralized Web site. 


\section{WLCI, Panel 6: Plenary and Breakout Sessions}

\section{Breakout Session: Develop a Data Clearinghouse and Information Management Framework}

The group began by recognizing a clear theme from the plenary discussions that the public is a major piece of the audience, and that other audiences need to be identified. The main goal is to establish a network of groups and people who can work on this project. Specific types of content were discussed. The group also agreed that key data resources need to be identified and worked to develop concrete next steps to put on the ground as soon as possible so information can be provided to key groups.

\section{Who are we working to serve?}

- WLCI

- Managers and decisionmakers

- Agencies or others who can use or contribute data

- Public

- NGOs

- Industry

- Political representatives

- Additional audiences identified as we proceed

\section{General considerations}

- What information is known, what information is needed, and what will be coming in from monitoring?

- How will the information be maintained, updated, who will have access, how will it be used?

- The public will want information and maps; managers want data to effect decisions. Existing clearinghouses are not so useful for the public. (They can be difficult for nontechnical people.)

- A data resource for public outreach will assist manager goals.

- Management interface needs to be fairly simple, too, and will have similar questions. Some people are comfortable with GIS and some are not.

- We need an architecture that brings together many data sources, with a distributed environment that allows each to own and maintain their data.

- We could have two types of databases-a clearinghouse open to the public and another for managers that is not necessarily open to the public. The two can be part of the same overall structure.

- Only certain people may have the ability to upload information or to change anything, but it needs to be available to everyone.

- WLCI is a coordinated effort. Its partners will want to know where something is being done, why it is being done, how it is linked to other activities, and did it work? Each agency will use the information in its own decision matrix.

- There are two components to the science plan: WLCI as a whole (WLCI science advisory group), and the USGS science plan, and this workshop was originally designed to help the USGS design its plan. Not everything talked about at this workshop applies to the USGS.

- There could be a data management component attached to the science plan or as a separate component.

- We do not want WLCI's database to be one that disappears over time. We want a database for southwest Wyoming that is useful for other statewide efforts and is useful for others.

\section{Based on identified audiences, what are the specific types of content we want to see?}

- Does WLCI need a new database with some specifications for resolution, or does it need a system that uses whatever databases are available?

- A system that is compatible with everything out there is necessary, and a way to keep minimal metadata record for new data when it is acquired.

- State-of-the knowledge summaries were mentioned and best-management guidelines.

- We need baseline information that is consistent no matter what application it goes into.

- Who is the filter? The "who" is a network of best available centers like WYGISC. The USGS has much work to do to bring about this system for its own data. Their Web site will be the place to go to get to the clearinghouse. 
- Data architecture includes a lot of different types of information across spatial, temporal, and topical issues. Also, do we need a desired future condition, so that all actions applied are leading toward something in the future?

- The other panels are coming up with their needs. Will those needs be captured well enough to include in this structure, or will they be a separate link?

- What scale do we need? Different datasets match at certain levels.

- If private land information is important to the decisionmaker, it needs to be available.

- Ranchers have information to contribute but it is sensitive. Those data need not be sought after right away. Increase transparency of the WLCI first and then focus on other audiences.

- Paper sources include field records and ranch records. Not all of these sources will be online and available right away, but their existence needs to be known. There is a perception that the data are not publicized. We need flexibility with basic metadata record and what its use could be.

- Most wildlife datasets are status monitoring, but there is also tracking the results of an action. There is also compliance monitoring.

- A basic need is whether habitat modification is having the desired effect.

- There is a wealth of data on the Jonah Field.

- Protocols need to help answer the questions.

- We need standardized collection techniques.

- The database has to match what is being monitored. How do we report the same things at different levels of a management agency? Base information will be collected, but maybe a little more data could be collected on mule deer for a certain layer, which needs to be available at the appropriate level. The base information has to be usable for folks on the ground and folks looking at it from critical level.

- What about queries?

- What are some frequently asked questions that can be highlighted on the Web site, with some answers?

- A data explorer tool will be one of the products.

- This process is moving fast, so managers may want a model to help choose a project area because the sitelevel data do not exist.
- Some think this is about wildlife habitat, but socioeconomic effects also were mentioned and supporting and sustaining livestock operations. We need to be clear about what the expectations are and what the focus needs to be.

- Roads and subdivisions and all the land uses are part of this process, but not social effects.

- Water quality, reclamation, vegetation monitoring, and air-quality monitoring are all important to wildlife.

- Should the WLCI database track changes in resources that are not being managed? For example, acid deposition in Wind River from air contamination, and the effects on fisheries. The USFS is tracking that. Will WLCI study the direct effects of industry only? Do we include downstream effects?

- If the goal is habitat management, we have to look at the ecosystem. Land, water, and air all have effects on habitat management.

- Most of the Wind River range is out of the WLCI area.

- Acid deposition is important information and is available from USFS. We just need to link to it. We need to identify data gaps.

- We need to identify the status of projects. The WLCI is approving projects today, and money is being allocated. This status identification would help the public know how their dollars are being spent in real time and increase the public buy-in.

- The USFS Web site that tracks fires throughout the year could be a model.

- We can often find the spatial data, but it is harder to find the report that goes with the data.

- The USGS is trying to link data with published reports.

- Resource managers need distilled reports, not 200 pages; they might need a synthesis of two or three reports and other documents.

- The middle layer is important, for example, Wyoming Departmental Environmental Quality (WYDEQ) data that can be used here.

- Combining datasets is a lot of work. Tools are getting better for combining disparate datasets, but the combination still needs critical thinking.

- For the Wyoming Energy Resources Information Clearinghouse (WERIC), a product (permit) is being 
developed and could be posted on the public side. For WLCI, will there be products; who would develop those; what form would they be?

- Keep in mind that databases do not make decisions; they are a resource for decisionmakers.

- Adopt WERIC as a model?

- Yes, potentially, the end result could be multiple WERICs, multiple portals for different needs. We need to start with coordination for decisionmakers, across the different groups.

- The process needs to be designed so it does not require a major change in the way data are collected right now. WLCI needs to obtain the information all the entities are collecting, and make it usable for everyone, including project applicants.

\section{What are the concrete things we can start doing?}

- Professional services are needed. Who will organize this process? Is a separate group needed to focus on this aspect?

- Have an information technology advisory group. Is that where the decisions for professional services would come from?

- Would like to see this advisory group arise from our workshop to do the initial preparations, to get this process started. Any volunteers?

- Do we need a technical representative from each of the partners to develop the strategy? Who will chair the group? The BLM, the USGS, WYGFD, the NRCS, WYGISC, USFWS. Farm Bureau? Wyoming Department of Agriculture (WYDA)? They have data. NRCS could contact other agriculture folks. The Farm Bureau is not a cooperator at this point. NGOs are not included either.

- Managing all these data is a big workload.

- The budget side will become an issue soon: What is affordable? How does it fit? There are a lot of competing priorities for this money.

- It sounds as though the USGS is the agency that is obtaining the money; they need to be the lead.

- The USGS work would produce new databases that would be provided, including hosting data from others or at least creating a metadata record so we know the data are there and can go get them.

- Strategy team needs a sounding board.
- This strategy team would not create data that do not exist, but they would identify what is already available.

- JIO monitoring data are being organized, and we want to be sure their structure meshes with WLCI (next step?)

- Fairly soon, an interested person should be able to go to the Web site, find a map, and a list of data types that would be part of this process.

\section{Actions}

Who?

- Data strategy team: The USGS, BLM, WYGFD, NRCS, USFS, USFWS, WYGISC. To facilitate:

- Data strategy

- Data model(s)

- Data architecture

- New database efforts

- Information-management work plan (tasks, timelines, budgets)

- Community of Practice: Farm Bureau, the NPS, JIO, the USGS, WYDEQ, industry, and landowners

What?

- Data architecture including spatial, temporal, and topical

- Data sets (GIS); Web site data explorer

- Information (reports)

- Tools (models and other derivatives)

- Inventory (feeds into Web site)

- Management-issues evaluation

- Project viewer

When?

- Data strategy team and community of practice idea: present to executive committee

- Information-management work plan

- Data explorer Web site

- Inventory is ongoing

- Management-issues evaluation 


\section{WLCI Plenary-Closing Remarks}

\section{Next steps}

- Need to determine how the big WLCI science plan will be done.

- Workshop information will help develop the draft science plan. WLCI is not the only entity doing science in southwest Wyoming, and this plan will describe only what components and activities the USGS will implement.

\section{Audience Questions and Comments}

- Is this the USGS or the WLCI science plan?

- This will be an integrated science plan. It is what USGS will do.

- The science/technology advisory group will comprise science agencies that work on southwest Wyoming issues. There are issues that the USGS has statutory responsibilities for, such as water monitoring. There is also a subset of issues that the USGS deals with and that also will be put into the report.

- In the southwest Wyoming landscape, it is necessary to bring all of these skills together, in addition to the expertise at this meeting. We are looking to you for leadership.

- What about a diagram that shows all of the science efforts so that science needs can be prioritized without confusion?

- WLCI is to acknowledge the larger set of needs and remember it is still early in the process. There has to be a science and technical advisory group to focus the WLCI.

\section{Outreach}

- The workshop results and report will be put on the WLCI Web site as will the USGS science plan. There is a communications committee for WLCI, and news coverage for this so far has been good. On February 9, 2007, a news conference was held with Wyoming Governor Freudenthal, and many department heads were there. Channels 2, 13, 5 and CST, covered the event. There have also been four open houses held in Rawlins, Kemmerer, Rock
Springs, and Pinedale. They were a big success. This science workshop has been a big success. Channel K2 was here on Thursday, and Channel 13 was here yesterday from Cheyenne. Bob Beck from Wyoming Public Radio was here yesterday. We also had Mary Paxson from Senator Thomas' Office and representatives from Representative Cubin and Senator Enzi's office that were at the open houses. They will continue to be kept in the loop on this initiative.

\section{Closing}

- The WLCI will help us look at terrestrial and aquatic ecosystems in southwest Wyoming.

- One goal is to facilitate energy development and make industry aware of this so they can use Best Management Practices (BMPs) in the field.

- Because there are dramatic changes, it is easy to focus on the negative. But let us focus on the positive being gained from this initiative. The effects are going to occur, and a way to deal with those has to be found so wildlife populations can be maintained. There are still 100,000 pronghorn and mule deer in southwest Wyoming. Granted, these populations are trending downward and the duration of those trends in unknown, but in the meantime, the best possible mitigation needs to occur. WLCI is a positive opportunity to do the best that can be done in southwest Wyoming.

- The next meeting of the executive committee is May 30, 2007 and these results will be presented there.

- The WYDA has been a great partner for us. They have pointed out the importance of the landowner/ranching interests in this issue. They need to be invited.

- In the fall of 2006, the budget initiative for 2008 was started. This early start was ambitious but it was not possible to wait until 2008 to get the money to do this, so funds were redirected to this area to get this going. There is an element of risk.

- The USGS has been in Wyoming a long time and will remain as an active partner in Wyoming. WLCI is breaking ground that will have transfer value to other States-it is a model. 


\section{Appendix 2. Evaluating Cumulative Environmental Effects of Development Activities in Southwest Wyoming: State Trust Wildlife Resources}

Wyoming Game and Fish Department Issues and Concerns

Steve Tessmann, Staff Biologist, Wyoming Game and

Fish Department (WYGFD)

During the breakouts, participants were asked to address three key topics: (1) state of the knowledge; (2) perceived knowledge and data gaps; and (3) how the information will be used to address on-the-ground management actions.
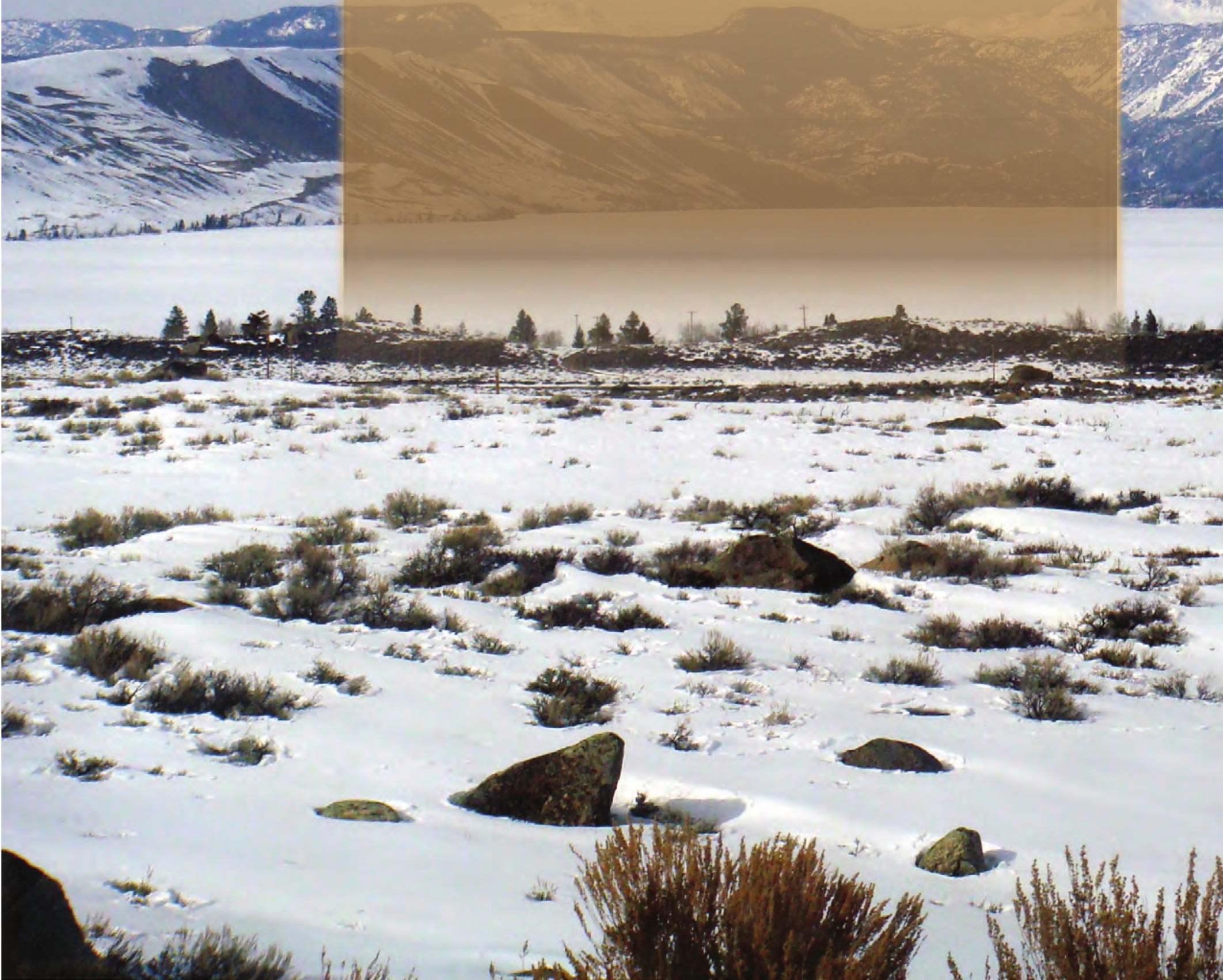


\section{State of the Knowledge}

Cumulative change assessment has been a core concept of the National Environmental Policy Act (NEPA) since the Act's inception in 1969. Agencies have struggled to implement this requirement, especially as it pertains to wildlife resources. About 10 years ago, the Council on Environmental Quality (CEQ) published its review on the effectiveness of cumulative change assessments, finding in general that existing methods were poor at quantifying cumulative effects (Council on Environmental Quality, 1997b, p. 49), and that the absence of data standards has been a substantial issue in developing adequate documentation that supports NEPA analyses. There are many reasons why cumulative-effects analyses have fallen short of NEPA goals:

- Agencies often lack resources and empirical data needed to support such analyses;

- It is not often within an agency's primary mission to collect and maintain such data;

- The timetable for permitting individual actions may not allow the level of scientific rigor needed;

- The scope of analysis for individual project authorizations often is insufficient to address cumulative effects. However, broad planning efforts, such as resource or forest management plans, may lack detail about existing resource conditions and potential future actions.

The Wyoming Landscape Conservation Initiative (WLCI) has the potential to address many of these issues. As envisioned, it will be a well-funded, independent, interdisciplinary effort with access to a wide range of data resources and analytical tools, and hopefully it will have the capability to augment available data through data collection, monitoring, and other means.

\section{Knowledge and Data Gaps}

To address information gaps from an informed perspective, an agreement needs to be made on the scope and content of a cumulative-effects analysis and the type of support information that is needed. The most authoritative guidance is in the CEQ Regulations and the CEQ Handbook (Council on Environmental Quality, 1997b). However, even these provide only conceptual guidance that needs to be interpreted on a project-by-project basis.
NEPA clearly envisioned a landscape or ecosystem approach to cumulative-effects analysis and the Council on Environmental Quality (1997b, p. 20; U.S. Environmental Protection Agency, 1999, p.7). There are three fundamental requirements to conduct a satisfactory cumulative-effects analysis:

- Sufficient baseline data or the means of obtaining it needs to be available;

- Cumulative-effects principles and concepts and the analytical approach to be used, need to be understood and agreed upon; and

- The scope of the analysis needs to be ecologically meaningful and scaled appropriately to the specific resources that are affected.

To address the first item, a better job needs to be done of identifying, accessing, and recording existing data, reports, and other relevant information. There is value in establishing a centralized repository that houses comprehensive data sets and links to relevant outside data sources. Baseline sampling and monitoring programs are also needed to fill critical information voids.

Various criteria have been suggested to analyze cumulative effects and determine their significance: population-based thresholds, ecological thresholds, and social thresholds, to name a few. The most reasonable way to ensure that incremental cumulative effects do not become significant is probably a "quid pro quo" approach. Rather than undertake the difficult task of detecting population-level response, we mitigate incremental disturbances as they take place in important or limiting habitat types. The WYGFD Oil and Gas Recommendations have established several thresholds for developments within key wildlife habitats. As these development thresholds are reached and surpassed, the types and locations of mitigation change and the amount of mitigation increases. However, the major emphasis is to avoid and minimize the effects.

It is also essential to identify the appropriate scope of a cumulative effects analysis. To do this, several basic questions need to be asked and answered:

- What biological or ecological components are of concern to the analysis? The WYGFD has tended to focus on key species and limiting habitat components, such as crucial winter ranges, reproductive habitats, and aquatic systems.

- How will we define appropriate landscape boundaries? The WYGFD delineates landscapes based on populations of key species, watersheds, or wildlife communities. The CEQ Handbook advocates a similar approach in the form of "project impact 
zones" (Council on Environmental Quality, 1997b, p. 12). From a wildlife perspective, such zones or landscapes would comprise the geographic areas in which it is possible to mitigate an effect to a specific habitat function, and they can vary depending on the species and habitats that are affected.

- How broadly would the analysis consider other activities that have already altered the landscape?

The WYGFD believes all past and ongoing developments and land uses need to be factored into the analysis if they contribute incrementally to an overall substantial effect. In addition, preexisting effects often will provide opportunities for future mitigation.

- To what degree will future actions be considered? The WYGFD believes all known and reasonably foreseeable future energy development and land uses need to be considered because the cumulative effect of each proposed action will depend on its relations to other future actions.

\section{How will the information be used to address on-the-ground management actions?}

The WLCI needs to assemble a user-friendly system of continually expanded and updated baseline data, other pertinent information, and state-of-the-art analytical techniques. Land managers, planners, and project administrators would have the ability to access this system in an interactive fashion, to conduct truly comprehensive environmental analyses, and to identify opportunities for effective mitigation. Some specific field applications include:

- Identify and delineate Wyoming landscapes and provide a comprehensive description of their existing and future condition;

- Provide data and analytical tools that would foster better decisions ranging from individual project authorizations to major land-use plans;

- Identify missing or incomplete data and collection methods;

- Identify future risks to ecosystem integrity and strategies that can alleviate those risks;

- Apply landscape principles to locations in which long-term mitigation can be implemented effectively,
- Provide a sound technical basis to design habitat or rangeland management plans, restoration, and enhancement projects; and

- Provide an integrated approach to accommodate a range of resource uses without causing undue changes to one in favor of another (also known as "multiple-use management").

\section{References}

Council on Environmental Quality, 1997a, The National Environmental Policy Act: A study of its effectiveness after twenty-five years: Executive Office of the President, Washington, D.C., 51 p.

Council on Environmental Quality, 1997b, Considering cumulative effects under the National Environmental Policy Act: Executive Office of the President, Washington, D.C., 64 p. plus appendixes.

U.S. Environmental Protection Agency, 1999, Consideration of cumulative impacts in EPA review of NEPA documents: EPA 315-R-99002/May 1999, 22 p.

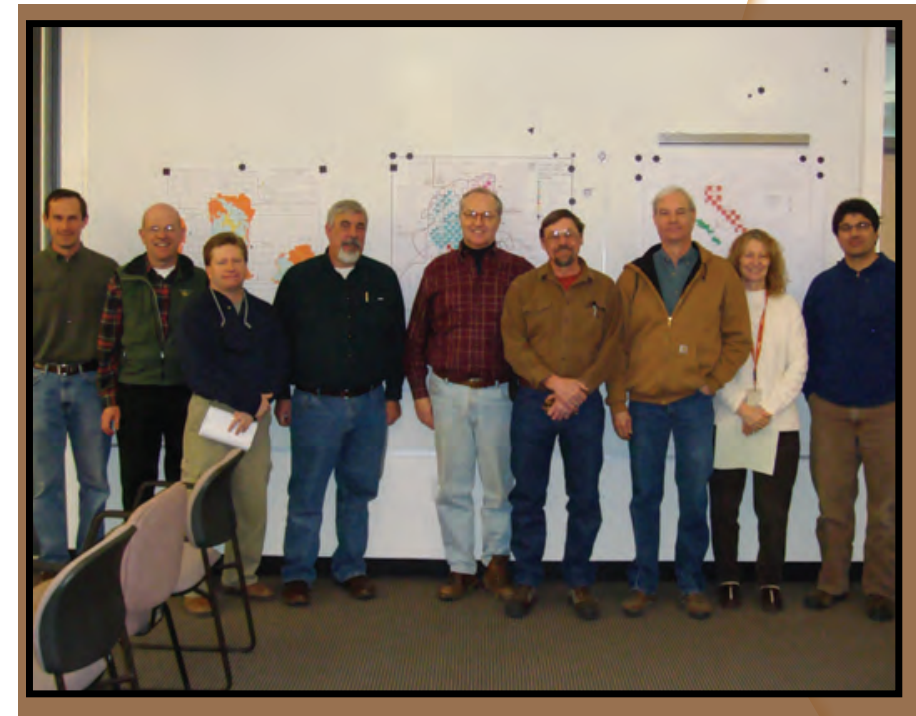




\section{Appendix 3. Existing Major Studies/Data Resources}

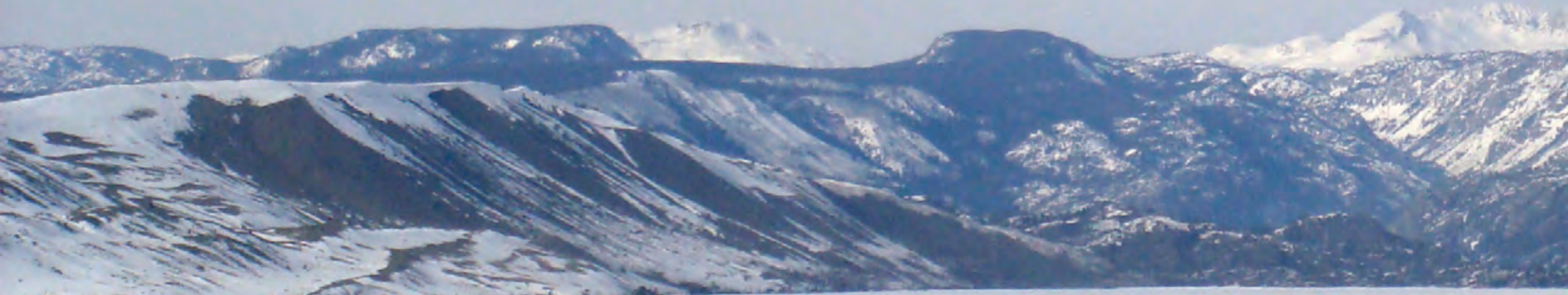

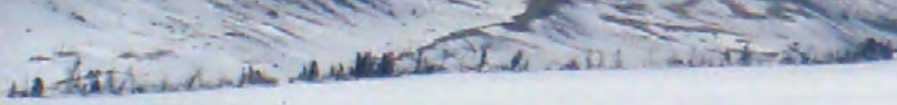




\section{Studies and data resources identified by the key drivers of change breakout group}

- Critical winter range inventories in southwest Wyoming

- Southwest Wyoming Resource Assessment

- Cumulative Impacts Task Force (CITF), which became the Green River Basin Advisory Group and then a Federal Advisory Committee Act (FACA) report with recommendations

- Resource Management Plans (RMPs)

- Wyoming Game and Fish Department (WYGFD) herd assessments

- Natural Resources Conservation Service (NRCS) soil inventory (Pinedale, Wyoming)

- U.S. Geological Survey (USGS) data on mule deer winter range

- Environmental Protection Agency (EPA) E-map has been implemented to national coverage

- Geologic maps and ground-water maps

- Bureau of Land Management (BLM) maps, land-use plans, range program allotment assessments, Environmental Impact Statements (EIS), and oil and gas potential plans

- U.S. Fish and Wildlife Service wildlife surveys, habitat maps, and restoration techniques

- WYGFD mapping

- Wyoming Oil and Gas Conservation information

- The Nature Conservancy (TNC) Regional Planning

- Industry data available through the BLM

- Related theses and dissertations

- Ecoregional Assessment for Shrublands

- Strategic Habitat Conservation Initiative

- USGS Ecoregional Analysis

- Wyoming Natural Diversity Database

- The Utah big-game range-trend studies monitoring

- Soil sampling for Sublette County, Wyoming

- Ecology description of the Saratoga Atlantic Rim done by a Carbon County team

- Operator's precipitation information

- Voluntary monitoring from the Upper Green River

- Monitoring done by the National Park Service (NPS) Fire Effects Crew in prescribed burn areas

- NPS inventory and monitoring at Fossil Buttes

- Wyoming Department of Environmental Quality (WYDEQ) mine-lands inventory on Abandoned Mine Lands (AMLs)

- Private landowner data (can be linked to through conservation districts) 


\section{Appendix 4. Identify Conditions and Distribution of Key Wildlife Species, Habitat and Species Habitat Requirements}

\section{Wyoming Game and Fish Department Issues and Concerns}

Southwest Wyoming supports diverse species assemblages and complex habitats, ranging from tundra vegetation communities atop 13,000 -foot mountain peaks to high desert salt shrub communities at just over $\mathbf{6 , 0 0 0}$ feet. The zones in between include mountain shrub and aspen communities in the foothills, which transition to high desert sagebrush-steppe in the basins. These vegetation communities mix and overlap with changes in elevation across the region. Interspersed through these vegetative ecotypes is a complex network of drainages and aquatic habitats. These complex habitats support a diverse range of vertebrate and invertebrate species. The vertebrate community, including aquatic and terrestrial species (resident and migratory), includes nearly $\mathbf{5 0 0}$ species. All species share one common requirement to survive in southwest Wyoming: healthy habitats and functioning ecosystems.
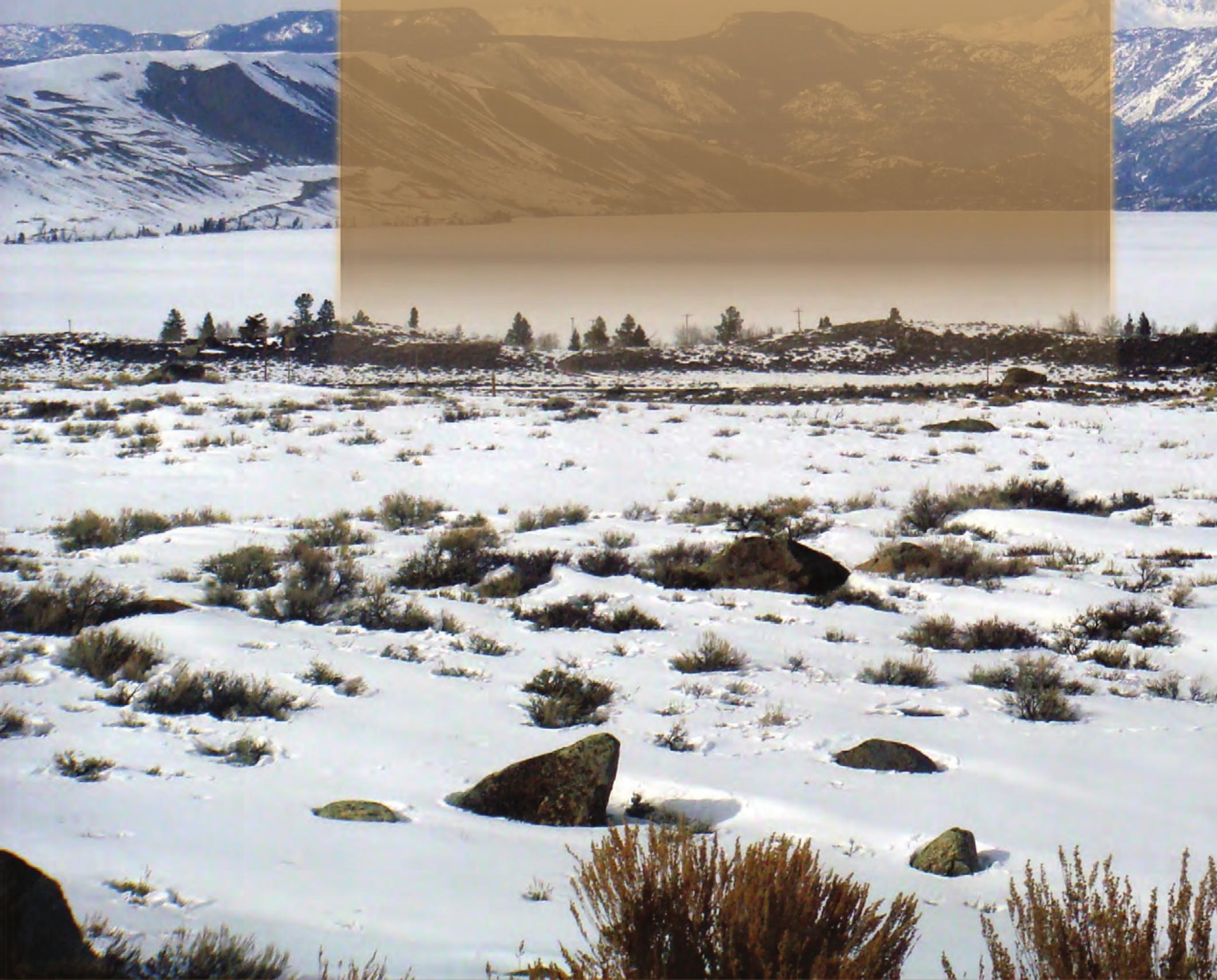


\section{Aquatic and Herpetological Wildlife}

- All activities that alter the landscape influence the aquatic systems. Ultimately, these activities influence the flora and fauna that depend upon these systems. Affected habitats include, but are not limited to, perennial rivers and streams, lakes and reservoirs, and ephemeral drainages and playas. Although influences from external activities can be positive or negative, development or habitat enhancements that alter intact landscapes, vegetative communities, and hydrologic processes likely will have negative effects on the adjacent aquatic ecosystems. For example, spring enhancements that provide water for livestock and wildlife may reduce adjacent upland habitat and diminish riparian areas associated with the spring.

- Effects from development include changing rates of erosion and sedimentation, water infiltration, surface runoff, nutrient transport, and eutrophication of receiving waters. In addition, riparian and wetland vegetation may be lost, aquatic habitats may be dewatered, and toxic substances may enter surface- and ground-water resources.

- Southwest Wyoming encompasses the headwaters for three major drainages of the continental United States. These drainages have unique assemblages of aquatic and herpetological species.

- The major drainages of the region support a combined native fish assemblage of 17 species. The Wyoming Comprehensive Wildlife Conservation Strategy (CWCS) identifies 12 of these as species of greatest conservation need (SGCN). In addition to the federally endangered Kendall Warm Springs dace, the WYGFD designates flannelmouth suckers, bluehead suckers, leatherside chub, and roundtail chub as status 1 species. Status 1 indicates that species are rare and their habitats are declining or vulnerable. Habitat alterations and the introduction of nonnative species are believed to be primary threats to these SGCN. The current (2007) distribution of many of these species is known, but there is little knowledge concerning their population status, life history, or habitat requirements.

- Southwest Wyoming also supports regionally and nationally important sport-fisheries for native species like cutthroat trout and introduced species including numerous trout, Kokanee salmon, smallmouth bass, and channel catfish. The Flaming Gorge Reservoir provided an estimated 107,800 angler days in 2003. At a minimum, the estimated value of the Flaming Gorge Reservoir to the region (Wyoming and Utah) was $\$ 10,200,000$. Fisheries managers in Wyoming are concerned that the valuable sport-fishery resources in the area will be degraded as human population and water use increases and the landscape is altered by current (2007) and future human activities.
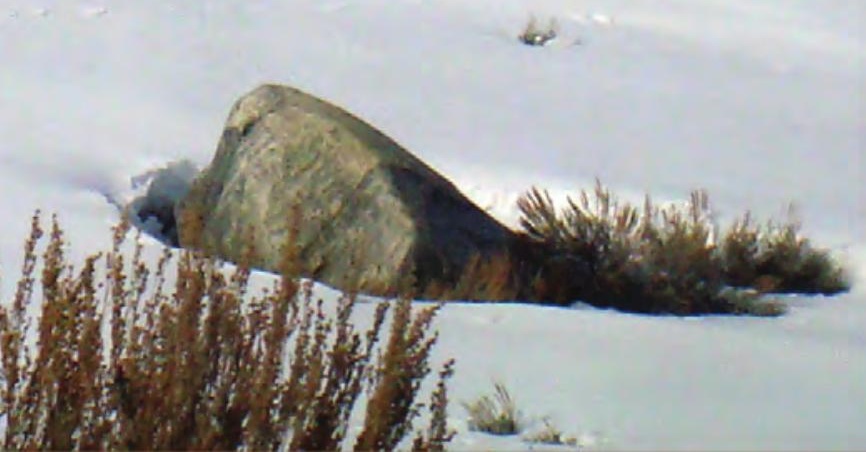
- Known distributions of 10 reptile and 6 amphibian species occur either completely or partially within southwest Wyoming. The CWCS identifies all the reptiles and amphibians as SGCN. Population status, distribution, and habitat data are lacking for most of these species. Habitat changes and other factors may be adversely affecting these species. For example, specific species that could be changed by oil and gas development and the associated infrastructure is the greater short-horned lizard. This lizard occupies habitat that overlaps many of the current (2007) and proposed areas of oil and gas development. Another example of an affected species is the Great Basin spadefoot that occupies a tenuous niche with stringent habitat requirements in low elevation sagebrush habitat. Three different types of habitat are required for species survival: overwintering burrow sites, temporary breeding ponds (such as playas), and foraging areas. The toads require safe passage between these areas.

- The development of natural resources in Wyoming has resulted in a massive network of roadways and infrastructure that hinders movements of these animals between required habitats and increases direct mortality because animals_especially snakes-are hit by vehicles. Development also compacts soils, making burrowing difficult or impossible. Temporary ponds and associated aquatic microhabitats may be altered by anthropogenic activities. Although habitat changes and other factors may be adversely affecting this species, the lack of data precludes identification of specific issues and development of management recommendations.

\section{Terrestrial Wildlife}

- At least 329 species of birds and 111 species of mammals have been documented in southwest Wyoming. Of these, at least 40 avian and 24 mammalian SGCN use a variety of the region's habitats to support viable breeding populations.

- The most significant breeding populations of several species occur in southwest Wyoming. Avian species with substantial breeding populations in southwest Wyoming include the trumpeter swan, sage-grouse, sandhill crane, long-billed curlew, black tern, Forster's tern, and five species of juniper-dependent avian SGCN. Mammal species include the pygmy rabbit,
Wyoming pocket gopher, Great Basin pocket mouse, Canada lynx, and three juniper-dependent mammalian SGCN.

- Southwest Wyoming also provides highly significant habitats for numerous migratory birds, especially those species dependent on riparian and wetland habitats during migration.

- Populations of SGCN use highly significant geographic and habitat locations in southwest Wyoming, such as the Upper Green River, New Fork potholes, Daniel/ Merna native pastures, Seedskadee National Wildlife Refuge (NWR), Cokeville Meadows NWR, and the Wyoming Range.

- Science-based management of southwest Wyoming's sagebrush habitats has some of the greatest potential in the nation to contribute significantly to recovery efforts of endangered species like the black-footed ferret and to prevent the listing of species like the greater sagegrouse, pygmy rabbit, white-tailed prairie dog, and the Wyoming pocket gopher.

- Southwest Wyoming contains 12 Terrestrial Priority Areas delineated by the WYGFD. These include:

- Muddy Creek/Little Snake River

- Black's Fork/Smith's Fork

- Cedar Mountain

- Bear River Divide

- Rock Creek Ridge/Dempsey Ridge

- Raymond Mountain/Upper Smith's Fork

- Slate Creek Ridge/Miller Mountain/Fort Hill

- Green River Corridor

- Little Sandy/Steamboat Mountain

- Northern Wyoming Range

- Mesa South of Pinedale

- Salt Wells/Little Bitter Creek

- Currently (2007), the greatest observed habitat changes are occurring in mid and lower elevation shrub-steppe habitats that tend to serve as transition and winter range for ungulates, and year-round habitats for many species considered sagebrush obligates. 
- Southwest Wyoming is home to four species of big game: moose, pronghorn, elk, and mule deer. A few white-tailed deer also occur in this area but are restricted in distribution and number. These species produced more than 230,000 total recreation days for hunters in 2006 and are economically significant at the local and State level. Currently, 4 moose, 7 pronghorn, 7 mule deer, and 11 elk populations occupy the region. Southwest Wyoming contributes the following percentages of total statewide population for these species: moose 70 percent, pronghorn 20 percent, elk 25 percent, and mule deer 20 percent. Total population estimates for southwest Wyoming are: 7,000 moose, 107,000 pronghorn, 27,000 elk, and 106,000 mule deer.

- Two trophy game species can be found in southwest Wyoming (black bears and mountain lions). The region is also home to five species of upland game birds (ruffed grouse, dusky grouse, Columbian sharptailed grouse, greater sage-grouse, and chukars), and two small game species (desert cottontails and red squirrels). Numerous species classified as furbearers (mink, muskrat, beaver, bobcats, and martens) or predatory animals (coyotes, red fox) are found in this part of the State as well. An extensive list of waterfowl species use wetland habitats throughout southwest Wyoming.

- As with aquatic systems, any activity that alters the landscape influences terrestrial systems to a greater or lesser degree, depending on the type and scale of disturbance. Some habitat alterations result in a positive seasonal response from some game species (for example, type conversion of native habitats to alfalfa fields may have a positive influence on mule deer and pronghorn fawn production and recruitment) yet may be detrimental to others (for example, conversion of properly functioning riparian meadow habitats to pasture or croplands may reduce grouse chick survival).

- Current (2007) changes to terrestrial systems are numerous. These range from obvious effects, such as type conversion of native habitats (for example, conversion to croplands or energy developments) or increased human-related disturbance during critical time periods (for example, winter or reproductive seasons), to more subtle changes brought about by competition with nonnative plant and animal species, loss of habitat connectivity, changes in hydrologic function, and provision of certain structural features that allow for the expansion of species into previously unoccupied or little used habitats.
- Southwest Wyoming has long been known as one of the highest density sage-grouse areas in the world. Like mule deer and many other species that are dependent upon sagebrush habitats, greater sage-grouse have declined dramatically (the decrease in population is estimated to be about 60 percent) throughout the West and in Wyoming.

\section{Research/Management Needs}

- The escalation and rapidity of changes resulting from energy development to terrestrial and aquatic systems in the region indicate that research needs to focus on providing practical applications that can be used to avoid or mitigate effects.

- Field data are needed to understand the distribution, wildlife movement and barriers, habitat selection, basic life history, responses to disturbance, population status, and life stage and seasonal habitat needs of many native species (fish, amphibian, reptile, passerine birds, raptors, small and large mammals) in southwest Wyoming. For example, much of the data on amphibians and reptiles are sparse and out of date. For a majority of terrestrial and aquatic species, system complexity continues to act as a barrier to the understanding of system function and system response to alteration.

- More in-depth understanding is needed of species in terrestrial and aquatic taxa that are sagebrush obligates. This understanding includes gaining knowledge regarding species distribution and seasonal habitat needs.

- Adequate information relative to distribution of SGCN and predictive habitat models based on solid field data are essential first steps in developing habitat-improvement projects or monitoring programs. Such information and tools are fully developed for some SGCN, but are incomplete for other SGCN in southwest Wyoming. 
- Knowledge of the existing condition of wildlife distribution and abundance needs to be improved through increased survey efforts and the development of better estimation techniques. Additionally, knowledge of existing vegetative community distributions and conditions needs to be refined and improved through remote sensing and field checking.

- Aquatic ecosystems and the species dependent upon them need water.

- A better understanding of how anthropogenic activities (especially oil and gas development) are altering sediment and nutrient transport across the landscape and into aquatic habitats needs to be developed. A determination of how these processes are increasing the eutrophication of the receiving waters (for example, Fontenelle Reservoir, Green River, Flaming Gorge Reservoir) also needs to be done.

- There is a need to monitor and evaluate road crossings of ephemeral and perennial drainages. Monitoring information would be used to design better systems for passing traffic across drainages while maintaining fish passage (if applicable) and hydrologic function at the crossing. Drainage crossings need to be designed to accommodate infrequent but substantial precipitation. Currently (2007), major precipitation events tend to blow out culverts and roads, resulting in large volumes of sediment entering adjacent aquatic systems.
- Disease is a big concern with amphibians. An understanding of prevalent diseases (chytrid, ATV, red leg), and their presence or absence and distribution in southwest Wyoming populations needs to be developed.

- Research needs to define the direct effects of development, such as increased noise (interfering with frog and toad calls), road mortality (all species), and disposal of wastewater (amphibians).

- Additional data are needed to understand overwintering sites and den sites for snakes. Road mortality is a major issue, and it needs to be quantified in relation to the population at large through research.

- Finalization needs to be made for the Wyoming Basins Ecoregional Assessment and the unprocessed data need to be made readily available for additional evaluations to facilitate progress.

- Development of effective reclamation techniques and increasing monitoring efforts in each of the habitats that are being changed by development needs to be done.

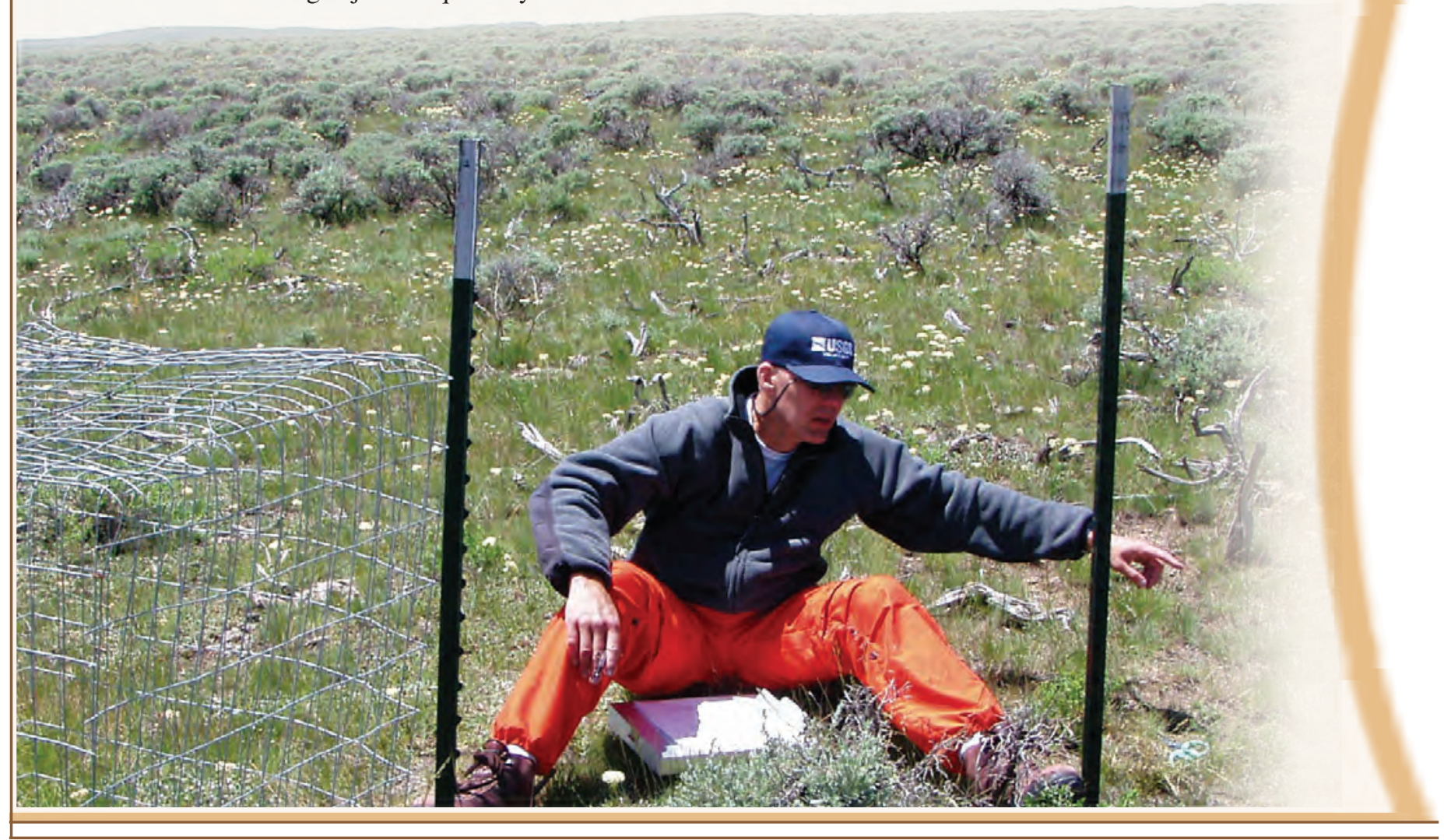




\section{Appendix 5. High Priority Short-term and Long-term Science Needs}

\section{Short-term Needs}

- Compiling existing critical data

- Developing boundaries for critical habitat areas

- Prioritizing needs

- Determining what grazing practices can enhance or improve habitat

- Identifying how wildlife, livestock, and feral horses respond to the different types, stages, and features of energy development through time

- Identifying species like umbrella or keystone species that, if managed, will sustain or help conservation of other species

- Determining the different patch size needs and edge effects that influence the behavior, the demography, and population growth on various species, including livestock

- Data architecture, including spatial, temporal, and topical

- Data sets (geographic information system [GIS]); Web site data explorer

- Information (reports)

- Tools (models and other derivatives)

- Inventory (feeds into Web site)

- Creating protected control or conservation areas for study, spatial and temporal areas of energy development

\section{Long-term Needs}

- Summarizing data assimilation

- Examining current reclamation techniques

- Considering current management techniques (Example: examine sagebrush treating techniques)

- Creating a GIS layering system that represents trailing areas, lambing grounds, concentration of animals, and sensitive areas for agriculture

\section{Ongoing Science Needs}

- Baseline studies concerning surface and groundwater

- Baseline air data

- Baseline monitoring for climate change

- Baseline for geochemistry of soils

- Baseline for historic land use and land cover

- Baseline information on historical migration corridors of wildlife

- Baseline information for native vegetation

- Determine the threshold of energy effects on migration corridors

- Data for keystone species of amphibians and reptiles

- Aquatic habitat data

- Management issues evaluation

- Project viewer 


\title{
Appendix 6. Evaluating Wildlife and Livestock Response to Development
}

\author{
Wyoming Game and Fish Department Issues and Concerns
}

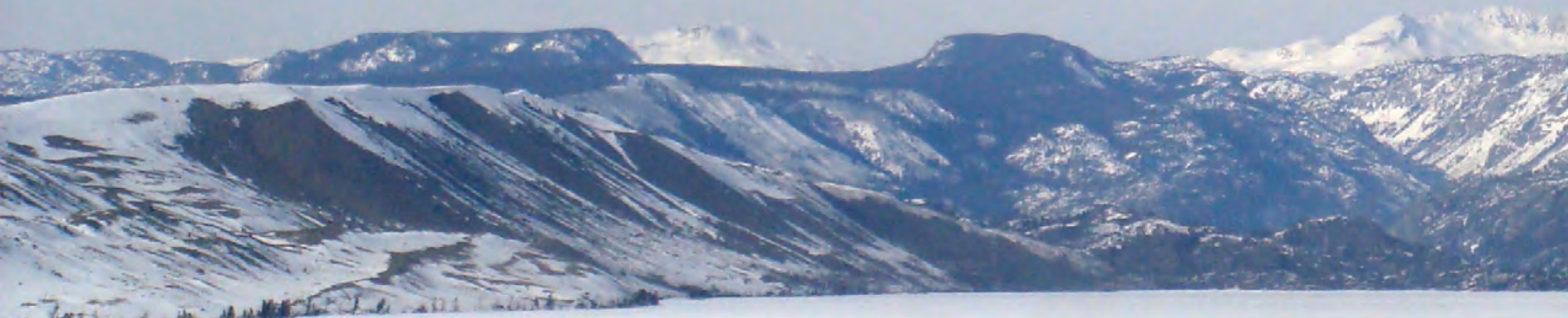

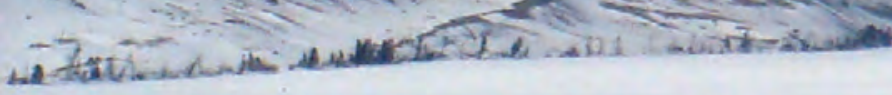

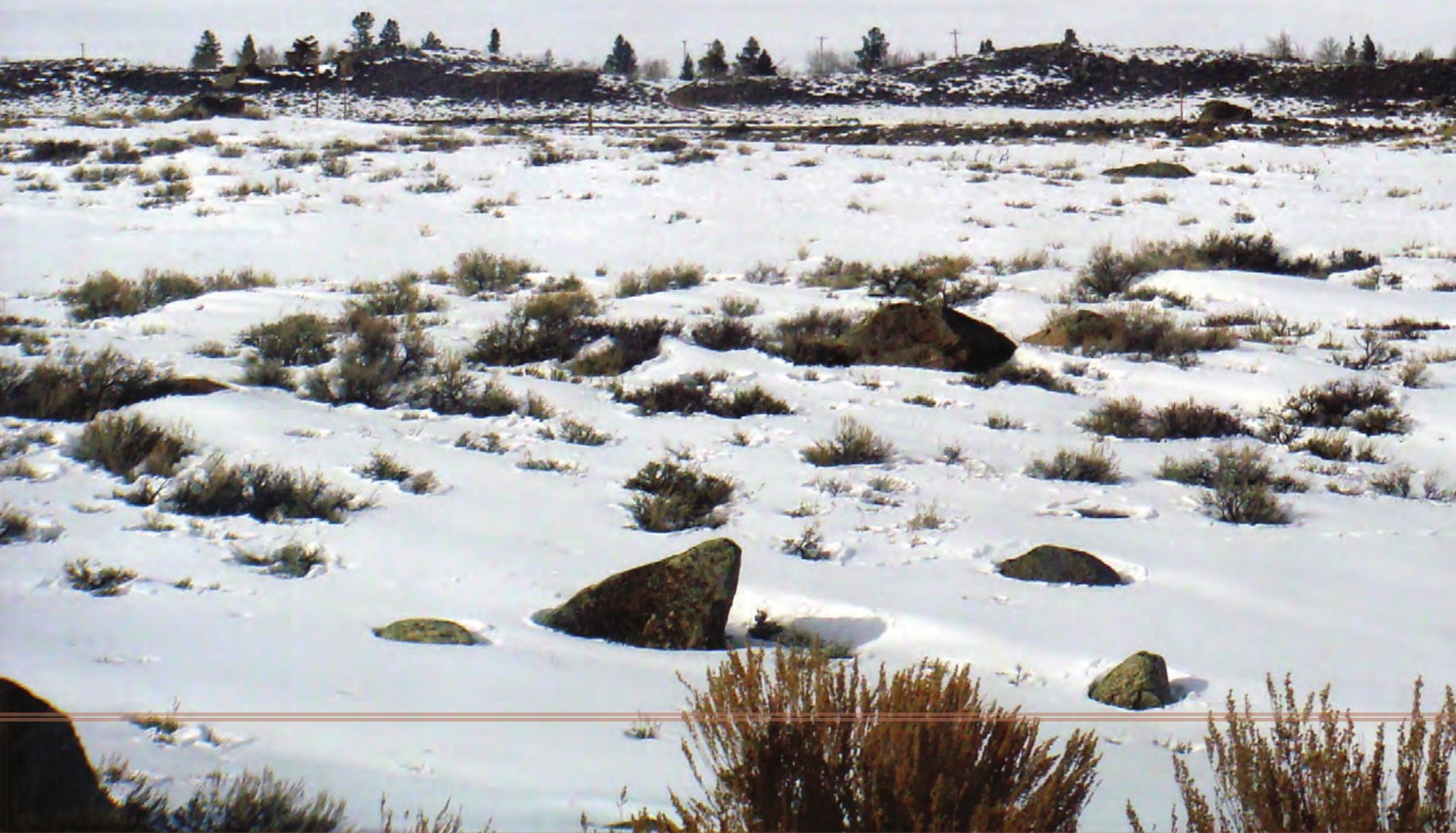




\section{Some Direct Effects to Wildlife from Development}

- Vegetation/habitat loss

- Water quality and quantity/habitat loss

- Habitat degradation

- Vehicle wildlife collisions, poaching

- Incidental mortalities (evaporation pits, fences)

- Fragmentation of habitats and populations

\section{Some Indirect Effects to Wildlife from Development}

- Loss of vegetation/habitat because of avoidance from disturbance (traffic, noise, contaminants)

- Increased stress levels from all types of disturbances

- Decreased population performance (survival and reproduction)

- Increased inter- and intraspecies competition

- Human population growth resulting in increased residential development, water-use demands, recreational use, fencing, traffic, noise, vehicle collisions, exploitation, urbanization, and contamination

\section{Issues Affecting Terrestrial and Aquatic Wildlife and Their Habitats}

\section{Planning and land-management decisions}

Planning efforts, directions, and decisions resulting in approved land-management activities related to energy development are critical to minimize effects and sustain wildlife species and their habitats. Most energydevelopment planning documents (for example, NEPA) lack details in regards to long-term effects to wildlife resources. An evaluation at a landscape or basin scale is needed to identify ongoing and potential development activities as they relate to wildlife.

- It is extremely difficult to assess development-related cumulative effects on wildlife populations in southwest Wyoming without knowing the location and scale of energy development that is anticipated/planned for the next 40 years.

- Sound, consistent, and committed long-term landmanagement strategies are the key to successful wildlife habitat restoration and maintenance. Efforts are also needed to sustain those wildlife populations that essentially are irreplaceable.

- Predevelopment planning to identify known wildlife habitats and other potential conflicts will help managers and decisionmakers assess potential effects and minimize them. 
- The concept of "Adaptive Management," or making modifications as new information or unanticipated changes arise, has great merit. Not all effects can be assessed adequately because of unforeseen wildlife population response to development or a paucity of data. Specific wildlife and habitat thresholds that cause changes in development activities need to be identified.

- Energy development likely will occur on the landscape more quickly than science-based research can be produced. Researchers will be challenged to identify in a timely manner the short- and long-term effects of energy development on many wildlife species for mitigation measures to be useful.

\section{Habitat protection, reclamation, restoration, and enhancement}

Restoring or replacing destroyed and disturbed habitats is essential to minimize effects to wildlife. Protection of important or crucial habitats is the most desirable objective. The following are some concerns/ recommendations:

- Ongoing concern with inconsistent successes and failures in reclaiming native vegetation on lands disturbed by energy-development activities in low precipitation (6-9 inches) areas. Soils and other environmental conditions in these areas make restoring native vegetation difficult. This situation encourages establishment of invasive plant species. Plant species availability, seeding rates, selection of desirable and adapted species, and planting methods are all important factors to be considered in reclamation and are not well understood.

- In reality, the treatment is merely the initial habitat-improvement action, the benefits of which may not be fully realized by wildlife for several decades. Evaluation of past treatments and management on those treatments typically has been poorly documented. Better evaluation standards and monitoring efforts on treatments are needed to document and demonstrate benefits and to help identify desirable efforts on future projects.

- Understanding how best to enhance reclamation without diminishing existing grazing opportunities will be a challenge because development disturbs and eliminates from use a great percentage of the landscapes in question. Research is needed to evaluate the interaction between restoration success and cattle use of reclaimed areas (timing, intensity, spatial extent), and creative options need to be explored to mediate such effects.

- Treatments designed to enhance vegetation and mitigate wildlife-habitat effects from development are often difficult to implement because of the inability to rest treatments from livestock grazing. Obtaining long-term followup grazing management on treatments could also be problematic in many instances.

- There are situations in southwest Wyoming where grazing and browsing by feral horses and wildlife impede successful treatment of vegetation, and affect the long-term health and maintenance of vegetative communities.

- Research data are available. These habitat protection measures need to be reevaluated where credible data exist.

\section{Habitat condition, fragmentation, and competition}

Direct and indirect loss of habitat from energydevelopment activities results in fragmentation of habitats and, in some instances, wildlife populations. Displacement and avoidance of wildlife from areas with energy development and urbanization increases competition on surrounding habitats, resulting in degraded conditions and less wildlife.

- Lands disturbed by intensive energy development cannot be expected to continue to support the same number of livestock and wildlife on less acres of available forage. This will continue to increase intra- and interspecies competition among wildlife and livestock, resulting in compromised wildlife and/or livestock levels because of deterioration and loss of habitats.

- To successfully mitigate wildlife-habitat effects from development in southwest Wyoming, managers, landowners, and the public could be willing to institute temporary reductions in livestock, feral horse, and big game numbers in development areas and nondevelopment restoration areas.

- Producers may require incentives to temporarily reduce livestock numbers while maintaining viable ranching operations. 
- Hunters and anglers may experience short-term loss of hunting, angling, and wildlifeviewing opportunities.

- The public also would experience short-term losses of feral horse-viewing opportunities.

- Agencies, livestock producers, and other interested public likely will need to adopt nontraditional grazing management strategies, such as grassbanking, conservation easements, and temporary grazing allotment buyouts to ensure success in long-term landscape scaled habitat enhancement and restoration.

- Road networks resulting from energy development can create habitat fragmentation issues for herptiles, especially for snakes. Are increasing road densities creating impediments that are preventing access between life stage habitats and negatively affecting herptile populations?

\section{Wildlife data}

Very little is known about demographics for most of the wildlife species in Wyoming. The general lack of knowledge and understanding of habitats and distribution for many wildlife species makes assessing effects from development activities difficult.

- More field data are needed to understand the distribution, population status, and life stage and seasonal habitat needs of many species (native fish, amphibian, reptile, passerine birds, raptors, small and large mammals) in southwest Wyoming. This information is needed to evaluate whether or not energy development is affecting these species. To date (2007), limited wildlife data have existed prior to development, making it difficult to quantify effects to wildlife.

- We need to deepen our understanding of species that are sagebrush obligates, including terrestrial and aquatic taxa. This includes gaining knowledge regarding the distribution of such species and their seasonal habitat needs. Great Basin spadefoot are an example of a species for which limited data exist, but that might suffer from development. A particular need is to understand habitat relations for species that depend on riparian habitat within the sagebrush steppe ecosystem.

\section{Wildlife mortality (illegal and incidental)}

Additional wildlife effects and mortalities are expected through increased illegal take, fencing, and possibly recreational use.

- Is the increasing human population, as a result of the energy boom in southwest Wyoming, affecting terrestrial and aquatic game species through increased illegal harvests and/or exploitation? Will increased demand for recreational opportunities further threaten the condition of key riparian habitats on public lands?

\section{Water quality, watershed function, and contamination}

Although impacts are anticipated from energydevelopment activities to hydrologic and watershed function and water quality, little has been quantified. Activities that alter hydrologic function have the greatest potential to affect the largest array of wildlife inside and outside the developed area.

- Discharges of sediment-hungry coal-bed methane (CBM) water (low sediment load relative to ambient conditions) within ephemeral and perennial drainages may modify streamchannel geomorphology by eroding channels,

floodplain evulsions, and vertical or lateral channel movements. Additionally, increases in the conductivity and sodium absorption ratio may occur as discharged water interacts with channel sediments or floodplain soils within ephemeral tributaries. Temperature of discharged CBM water may also have deleterious effects to native aquatic wildlife. More information is needed to understand how these changes could impede movement and disrupt aquatic wildlife species life-stage needs.

- What are the cumulative effects of energy-development disturbances on watershed health and function? How are well pads, drilling activities, and pipelines and roads affecting infiltration rates, overland flow, and sediment movement? Subsequently, how is this development affecting riparian habitat stability and aquatic wildlife? 
- Is energy development affecting the quantity and quality of water in southwest Wyoming? Is drilling and use of local water sources for field production affecting flow and water quality in springs, seeps, and lower elevation desert streams? Are wetland types being converted across the landscape where riparian springs, seeps, and streams are being drained or lost, and pit and diked reservoirs are increasing with development activity?

- Will human population increase locally and in other Western States such that increased demand for municipal water could result in transbasin diversions and more dams being constructed in the Green River watershed? How will these water-use developments affect aquatic wildlife in southwest Wyoming, and how can these effects be avoided or mitigated?

- More information is needed to evaluate the most effective size and structure of culvert systems that are constructed where new roads cross perennial streams and ephemeral drainages.

- Increasing levels of energy development increases the potential for contamination in and near developed areas. Information is needed to enable an evaluation of this risk to sensitive species and to promote response plans.

\section{Air quality}

Energy development ultimately will increase contaminants and add to degraded air quality.

Many unknowns exist regarding the effects that air contaminants have on wildlife. Poor air quality has the potential to affect wildlife and habitats ranging great distances outside of areas being developed for energy resources.

- The creation and movement of dust is likely to have negative effects on stream systems; however, little is known about the level of development at which these changes occur or the precise nature of the effects. An increase in sedimentation rates in stream systems is likely occurring in developed areas, although the degree to which this is changing stream hydrological and ecological processes is unknown. Limited knowledge exists regarding the effects of dust on terrestrial wildlife and vegetation. Dust may cause respiratory complications, such as pneumonia in bighorn sheep. What are the effects on other wildlife species? How might dust affect transpiration and photosynthesis in plants?

- As with humans, air contaminants may cause some respiratory complications in wildlife. Particles of air contaminants carried down from precipitation to streams and lakes have the potential to increase acid levels (acidification).

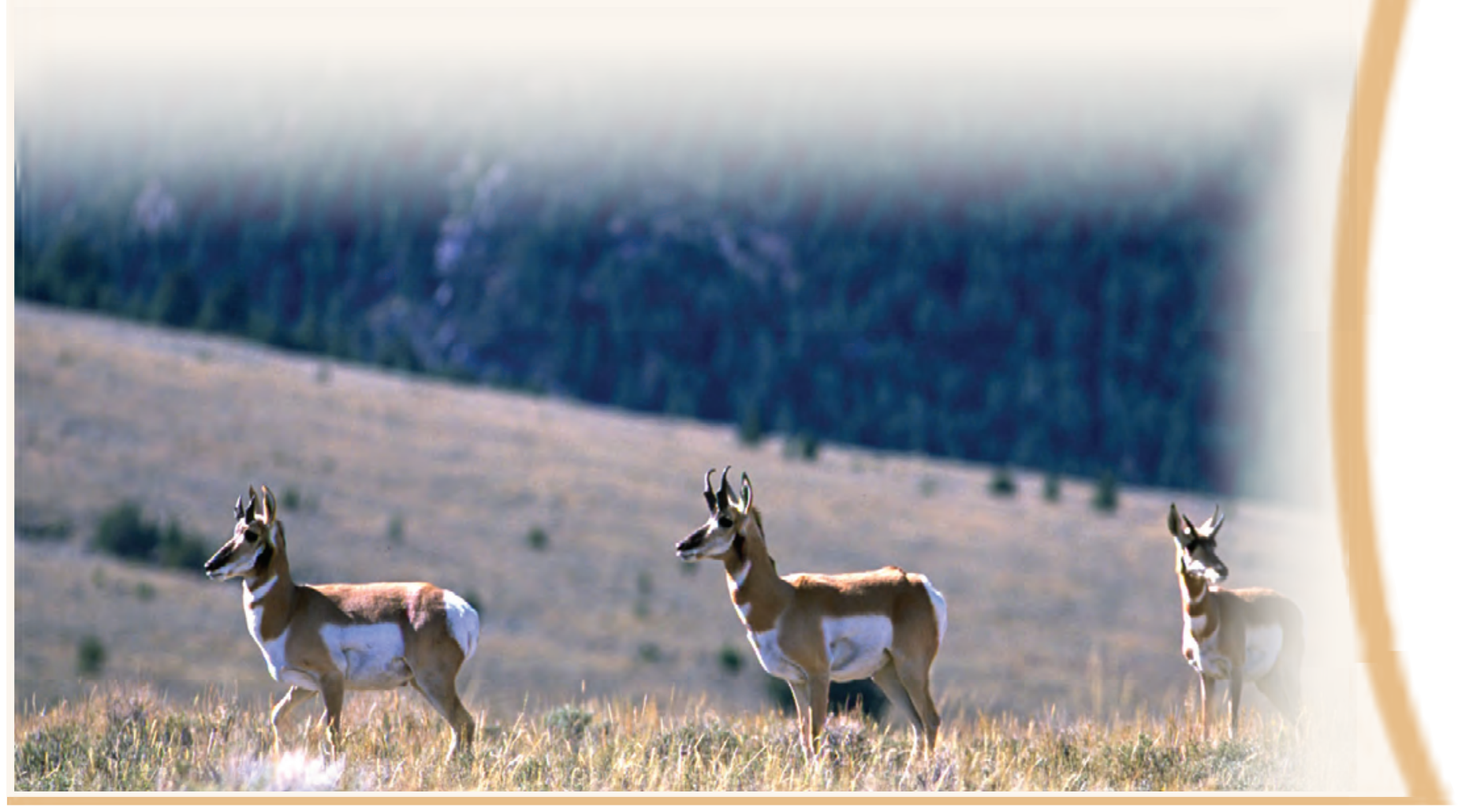




\section{Appendix 7. Development of an Integrated Inventory and Monitoring Strategy}

\section{Wyoming Game and Fish Department Issues and Concerns}

\section{Fish, Reptiles, and Amphibians}

\section{- State of the knowledge}

The distribution of sport fishes is well known in the WLCI study area. Sport-fish populations have been monitored at standard locations in southwest Wyoming for many years. Population monitoring is an important component of cutthroat trout management, including Colorado River cutthroat recovery efforts in the Little Snake River headwaters and in Wyoming Range tributaries (for example, LaBarge Creek). The life history requirements and habitat associations of sport fishes are well documented.

The WYGFD has been gathering baseline information on the distribution and abundance of nongame fishes in southwest Wyoming. Recent surveys in the Green River watershed provided valuable information regarding the distribution and abundance of nongame fishes throughout the watershed. Population monitoring has not yet taken place, and life history requirements and habitat associations are not well understood.

With the exception of populations in the Wyoming Range tributaries to the Green River, knowledge about reptiles and amphibians is limited largely to a general understanding of the distribution of the most common species.

Stream channels and riparian and upland habitats have been altered drastically in many watersheds. Stream channels have been changed by mining, logging, and road construction. Streams are fragmented by reservoirs, diversion structures, road crossings, and dewatered reaches. Fire and flood, once common to the landscape, are controlled. Aspen and mountain-shrub communities are threatened, beaver have been eliminated from many areas, flow regimes have been altered, and exotic plant species have invaded many watersheds.

\section{- Data gaps}

Data gaps include natural population fluctuations; life history requirements; habitat associations of most nongame fishes; quantification of fish loss to irrigation diversions and of the effects of irrigation diversion structures and irrigation practices to fishes; assessment of the loss of riparian and floodplain habitat and effects to fishes and water quality; responses of fishes and habitat to modified grazing practices; and accurate information on the distribution, abundance, and habitat associations of amphibians and reptiles.
- How will information be used?

Information can be used to set priorities for conservation efforts; to determine whether or not population fluctuations are "normal" or are the result of development; to develop grazing strategies and oil/ gas development practices that are least likely to affect wildlife; to reduce fish loss to canals (for example, screening of headgates) in priority areas; to modify irrigation diversions to allow fish passage whenever possible; to pursue minimum streamflows so as to maintain fishes and aquatic wildlife in streams heavily affected by water diversions; to acquire conservation easements and protect riparian corridors in priority areas; to mitigate effects to water quality; and to facilitate the use of limited funding for management activities in priority areas.

\section{Wildlife}

- State of the knowledge

The Comprehensive Wildlife Conservation Strategy (CWCS) for Wyoming identifies Species of Greatest Conservation Need (SGCN). The CWCS with SGCN distribution maps and recommended conservation actions are available from the Wyoming Game and Fish Department (WYGFD) public web site (http://gf.state. wy.us, accessed April 4, 2008). Tables included with the plan present a list of SGCN bird and mammal species. Species that occur within development fields (current [2007] and future) need to be considered during inventory and monitoring efforts. The plan identifies species in need of special management attention because of their statewide population status or trends. The plan also identifies species that require additional information. Finally, the SGCN list for Wyoming also includes some wildlife classified as trophy or big game that are not included in tables 1 and 2 of the CWCS because they currently (2007) receive considerable attention from Regional WYGFD personnel. The CWCS does not address amphibians, reptiles, and fish that are listed as SGCN but needs to be expanded to include these species in the future. Many SGCN have been identified with aquatic objectives. Recommendations for inventory and monitoring of greater sage-grouse have been provided previously and are not addressed in this document. 


\section{- Data gaps}

We recommend that general objectives for inventory and monitoring include the following to address associated data gaps:

1. A comprehensive inventory of the biological and physical components likely to be affected by any proposed development.

2. Information that may allow modification of development plans to minimize potential effects.

3. A monitoring plan that would enable managers to assess effects on a continuum and to detect unforeseen conditions.

4. Collecting data in a manner compatible with larger landscape-level monitoring efforts and work in priority areas.

5. Ensuring that monitoring efforts are not resulting in added disturbance or stresses to wildlife.

6. Monitoring associated with mitigation projects is essential and needs to assess whether mitigation objectives are attained through pre- and posttreatment studies and ongoing monitoring of control sites. This objective is beyond the scope of this document. 
- How will information be used?

Information will be used to (1) prioritize conservation efforts, (2) determine whether or not population fluctuations are "normal" or the result of development, (3) develop grazing strategies and oil/gas development practices least likely to affect wildlife, and (4) to identify areas of importance for the various species of concern and manage those areas to maintain or enhance existing populations of nongame species.

\section{Vegetation and Habitat}

- State of the knowledge

Vegetation information in southwest Wyoming currently (2007) is lacking in quality for adequate identification of current conditions and potential. Whereas various levels of information are available, they are either too coarse for the intended use or are limited in their scope. Adequate on-theground and aerial inventory efforts need to be systematic across the landscape, driven by the objective of determining ecological condition and potential. Inventory and monitoring efforts have been derived in other areas by various methods, including the USDA Natural Resources Conservation Service, NRCS Ecological Site Descriptions and the Utah Big Game Range Trend Studies. Currently (2007), the NRCS is working on a soil survey in Sublette County and modifying their Ecological Site Descriptions to better define successional stages and historical (potential) plant communities. Prioritization of key areas for wildlife species of emphasis (or wildlife guilds) could be used to aid in the initial intensive data collection using some of these methods.

\section{- Data gaps}

Adequate information is not fine-tuned enough for its use across southwest Wyoming or has not been systematically collected or both. This is perhaps one of the most important attributes needed to ensure the success of the WLCI mission regarding the improvement of habitats for wildlife. Good information is needed for this effort, and currently (2007) it does not exist at the scale needed to plan for habitat improvements or to adequately address current conditions.

- How will information be used?

Useful vegetation information will be employed to assess current conditions, determine potential needs, and identify on-the-ground needs for enhancements or projects. If vegetation information is of adequate quality for our purposes, it can be used to assess needs for all species of wildlife and is one of the most important components in any habitat-suitability assessment. 


\section{Appendix 8. Workshop Agenda}

\section{Wyoming Landscape Conservation Initiative Science Workshop}

Rochelle Athletics Center

University of Wyoming

Laramie, Wyoming

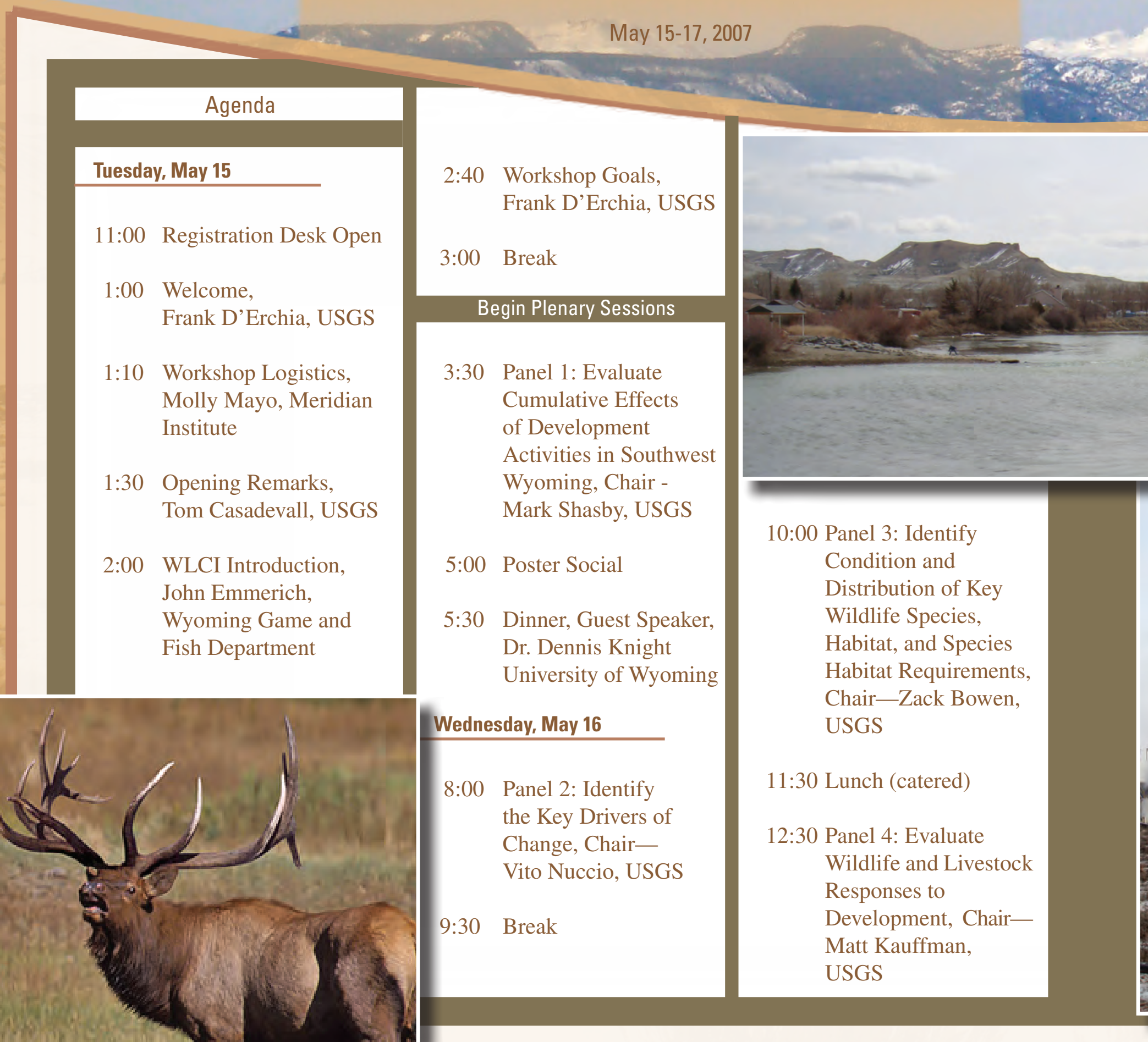




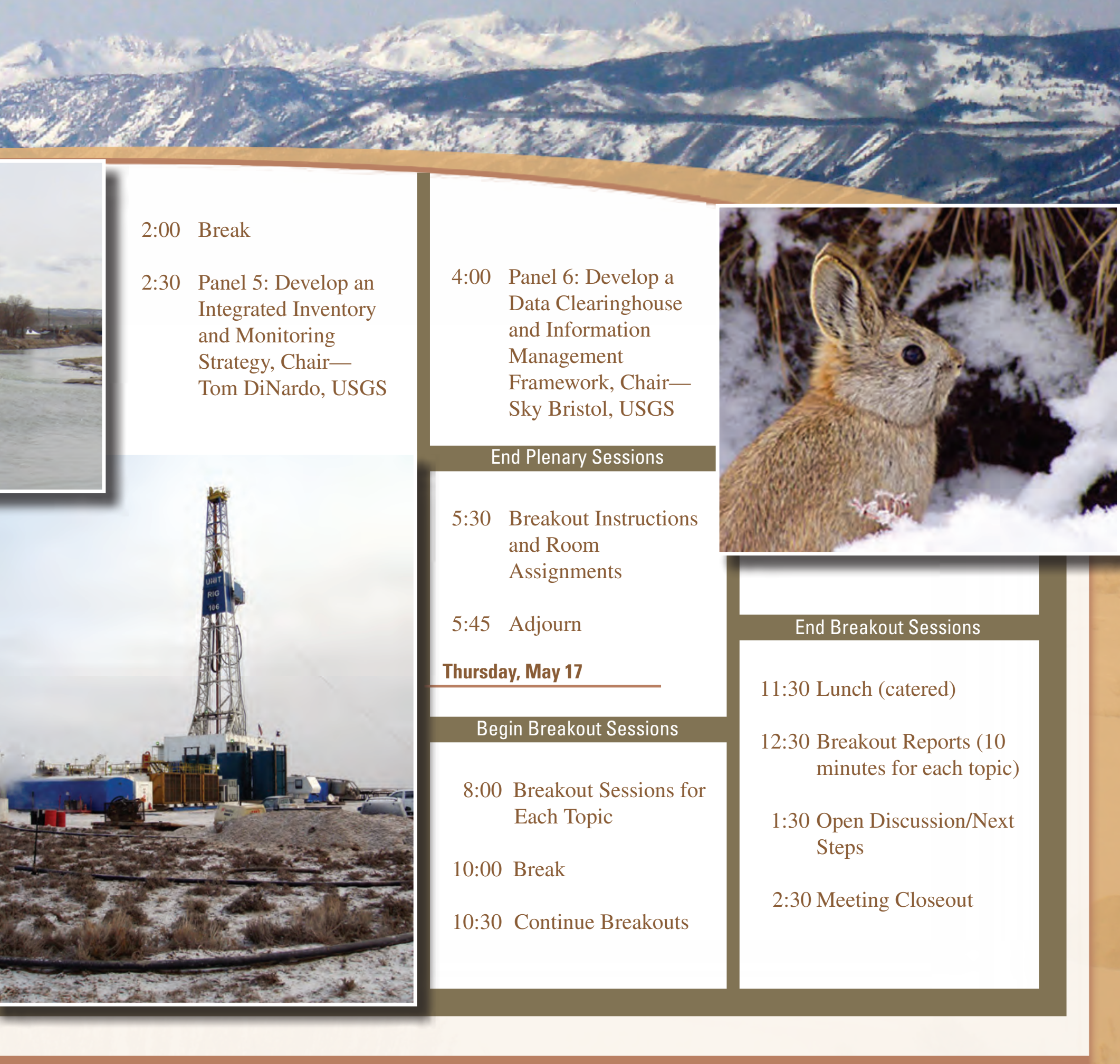




\section{Appendix 9. Plant and Animal Species Discussed at the Wyoming Landscape Conservation Initiative Science Workshop, May 15-17, 1997}

[Scientific nomenclature is according to the Integrated Tax
listing is alphabetical by common name]
Mammals
Beaver (Castor canadensis)
Bighorn sheep (Ovis canadensis)
Black bear (Ursus americanus)
Black-footed ferret (Mustela nigripes)
Bobcat (Lynx rufus)
Canada lynx (Lynx canadensis)
Coyote (Canis latrans)
Desert cottontail (Sylvilagus audubonii)
Elk (Cervus elaphus)
Great Basin pocket mouse (Perognathus parvus)
Horse (feral) (Equus sp.)
Marten (Martes americana)
Mink (Mustela vison)
Moose (Alces alces)
Mountain lion (Puma concolor)
Mule deer (Odocoileus hemionus)
Muskrat (Ondatra zibethicus)
Olive-backed pocket mouse (Perognathus fasciatus)
Prebles meadow jumping mouse (Zapus hudsonius
preblei)
Pronghorn (Antilocapra americana)
Pygmy rabbit (Brachylagus idahoensis)
Red fox (Vulpes vulpes)
Red squirrel (Tamiasciurus hudsonicus)
White-tailed deer (Odocoileus virginianus)
White-tailed prairie dog (Cynomys leucurus)
Wolf (Canis lupus)
Wyoming pocket gopher (Thomomys clusius)

\section{Mammals}

Beaver (Castor canadensis)

Bighorn sheep (Ovis canadensis)

Black bear (Ursus americanus)

Black-footed ferret (Mustela nigripes)

Bobcat (Lynx rufus)

Canada lynx (Lynx canadensis)

Coyote (Canis latrans)

Elk (Cervus elaphus)

Great Basin pocket mouse (Perognathus parvus)

Horse (feral) (Equus sp.)

Marten (Martes americana)

Moose (Alces alces)

Wyoming pocket gopher (Thomomys clusius)

[Scientific nomenclature is according to the Integrated Taxonomic Information System (www.itis.gov);

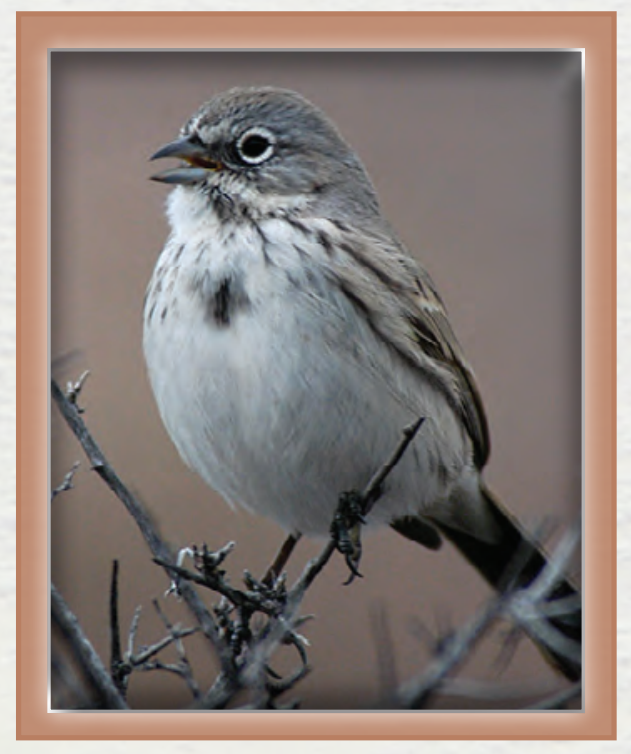

\section{Birds}

Chukar (Alectoris chukar)

Columbian sharp-tailed grouse (Tympanuchus phasianellus)

Dusky grouse (Dendragapus obscurus)

Forster's tern (Sterna forsteri)

Greater sage-grouse (Centrocercus urophasianus)

Northern goshawk (Accipiter gentilis)

Sage-grouse (Centrocercus sp.)

Sage sparrow (Amphispiza belli)

Sandhill crane (Grus canadensis)

Trumpeter swan (Cygnus buccinator) 


\section{Reptiles and amphibians}

Intermountain wandering garter snake (Thamnophis elegans vagrans) Great Basin gopher snake (Pituophis catenifer deserticola)

Great Basin spadefoot (Scaphiopus intermontanus)

Greater short-horned lizard (Phrynosoma hernandesi)

\section{Fish and other aquatic species}

Bluehead sucker (Catostomus discobolus)

California floater (Anodonta californiensis)

Channel catfish (Ictalurus punctatus)

Cutthroat trout (Oncorhynchus clarkii)

Flannelmouth sucker (Catostomus latipinnis)

Kendall Warm Springs dace (Rhinichthys osculus thermalis)

Kokanee salmon (Oncorhynchus nerka)

Leatherside chub (Snyderichthys copei)

Roundtail chub (Gila robusta)

Smallmouth bass (Micropterus dolomieu)

Spadefish (Chaetodipterus sp.)

\section{Insects}

Pine beetle (Dendroctonus sp.)

\section{Plants}

Aspen (Populus sp.)

Sagebrush (Artemisia sp.)

Salt cedar (Tamarix ramosissima)

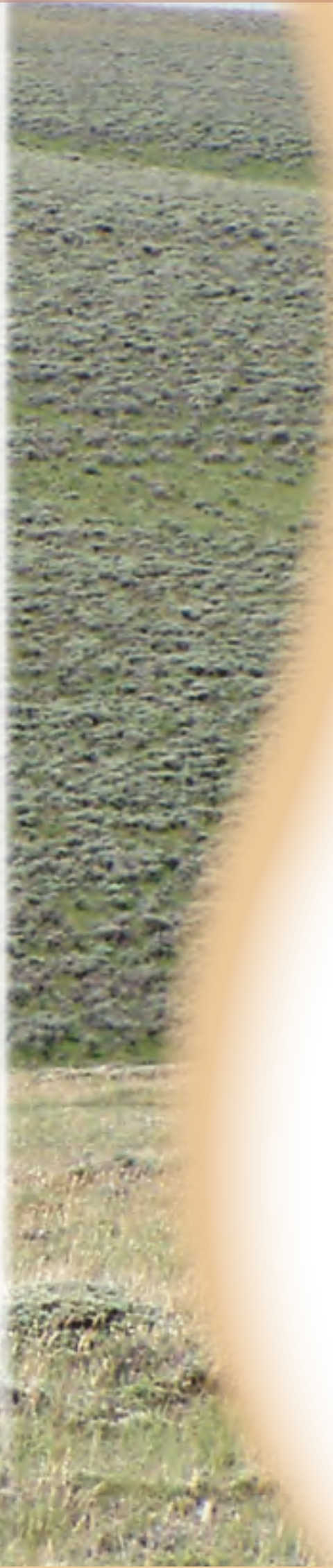




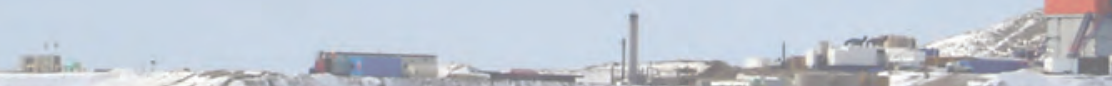
. पर 
